\title{
Genetic dissection of familial combined hyperlipidemia : gene expression in adipose tissue and candidate gene analysis
}

Citation for published version (APA):

Eurlings, P. M. H. (2003). Genetic dissection of familial combined hyperlipidemia : gene expression in adipose tissue and candidate gene analysis. [Doctoral Thesis, Maastricht University]. Universitaire Pers Maastricht. https://doi.org/10.26481/dis.20030605pe

Document status and date:

Published: 01/01/2003

DOI:

10.26481/dis.20030605pe

Document Version:

Publisher's PDF, also known as Version of record

Please check the document version of this publication:

- A submitted manuscript is the version of the article upon submission and before peer-review. There can be important differences between the submitted version and the official published version of record.

People interested in the research are advised to contact the author for the final version of the publication, or visit the DOI to the publisher's website.

- The final author version and the galley proof are versions of the publication after peer review.

- The final published version features the final layout of the paper including the volume, issue and page numbers.

Link to publication

\footnotetext{
General rights rights.

- You may freely distribute the URL identifying the publication in the public portal. please follow below link for the End User Agreement:

www.umlib.nl/taverne-license

Take down policy

If you believe that this document breaches copyright please contact us at:

repository@maastrichtuniversity.nl

providing details and we will investigate your claim.
}

Copyright and moral rights for the publications made accessible in the public portal are retained by the authors and/or other copyright owners and it is a condition of accessing publications that users recognise and abide by the legal requirements associated with these

- Users may download and print one copy of any publication from the public portal for the purpose of private study or research.

- You may not further distribute the material or use it for any profit-making activity or commercial gain

If the publication is distributed under the terms of Article $25 \mathrm{fa}$ of the Dutch Copyright Act, indicated by the "Taverne" license above, 


\section{Genetic Dissection of}

\section{Familial Combined Hyperlipidemia}

Gene expression in adipose tissue and candidate gene analysis 
(c) Petra M.H. Eurlings, Maastricht 2003

ISBN 9052783713

Universitaire Pers Maastricht, Datawyse

Financial support by the Academic Hospital Maastricht, Maastricht University, and Cardiovascular Research Institute Maastricht (CARIM).

Printing of this thesis was financially supported by AstraZeneca, Glaxo Wellcome B.V., Pfizer bv, and Roche Nederland BV. 


\title{
Genetic Dissection of
}

\section{Familial Combined Hyperlipidemia}

\section{Gene expression in adipose tissue and candidate gene analysis}

\author{
PROEFSCHRIFT \\ ter verkrijging van de graad van doctor aan \\ de Universiteit Maastricht, \\ op gezag van de Rector Magnificus, \\ Prof. Dr. A.C. Nieuwenhuijzen Kruseman, \\ volgens het besluit van het College van Decanen, \\ in het openbaar te verdedigen \\ op donderdag 5 juni 2003 om 12.00 uur
} door

Petra Maria Helena Eurlings geboren op 25 februari 1975 te Schinnen

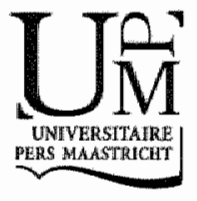


Promotor

Prof.dr. T.W.A. de Bruin

\section{Co-promator}

Dr. C.d.H. van der Kallen

\section{Beoordelingscommissie}

Prof.dr. P.W. de LeeuW (voorzitter)

Prof.dr. M.J.A.P. Daemen

Prof.dr. L.M. Havekes (Leids Universitair Medisch Centrum)

Prof.dr. M.H. Hofker

Prof.dr. R. Vlietinck 


\section{Contents}

Abbreviations

Chapter 1 General introduction

Genetic dissection of Familial Combined Hyperlipidemia and

aims of the thesis 11

Molecular Genetics and Metabolism 2001, 74: 98-104

Chapter 2 Identification of differentially expressed genes in subcutaneous adipose tissue from subjects with Famillal Combined Hyperlipidemia 39 Journal of Lipid Research 2002, 43: 930-935

Chapter 3 New candidate genes for adipose tissue dysfunction in Familial Combined Hyperlipidemia 55

(submitted for publication)

Chapter 4 Variants in the PPARG gene affect fatty acid and gllycerol metabolism in Familial Combined Hyperlipidemia 79 (submitted for publication)

Chapter 5 Identification of the PPARA locus on chromosome 22q13.3 as a modifier gene in Familial Combined Hyperlipidemia 93

Molecular Genetics and Metabolism 2002, 77: 274-281

Chapter 6 General discussion 111

Chapter 7 Summary/Samenvatting 127

Curriculum vitae 137

List of publications 141

Dankwoord 145 


\section{Abbreviations}

ACTB

apo

ASP

BAT3

BMI

C3

CAD

CAP

CAPN2

CCDN1

CCDN2

CCT7

CDKN1A

CETP

CIP29

CNOT8

CYP7A1

DHPLC

DM2

DNA

EGR1

ERBB3

EST

FABP4

FACL2 cytoplasmatic beta-actin

apolipoprotein

acylation stimulating protein

HLA-B associated transcript 3

body mass index

complement component 3

coronary artery disease

CBL-associated protein

calpain 2

G1/S-specific cyclin D1

G1/S-specific cyclin D2

chaperonin containing TCP1 subunit 7 eta

cyclin-dependent kinase inhibitor $1 \mathrm{~A}$

cholesteryl ester transfer protein

cytokine induced protein $29 \mathrm{kDa}$

CCR4-NOT transcript complex unit 8

cholesterol 7 a-hydroxylase

denaturing high-performance liquid chromotography

type 2 diabetes mellitus

deaxyribo nucleic acid

early growth response protein 1

epidermal growth factor receptor $v$-erb-b2 erythroblastic

leukemia viral oncogen homolog 3

expressed sequence tag

fatty acid binding protein 4

fatty-acid-Coenzyme A ligase 
FATP

FCHL

FFA

$\mathrm{FH}$

GADD45

GAPDH

HADHA

HDL

$\mathrm{HL}$

HPRT

HSL

IFNGR2

IGF1

IGF1R

IL-6

IMT

INFy

INSR

|QCAP1

IR

IRS

KRBH

LDL

LOD

LPL

MMP7

PAI1 fatty acid transport protein

familial combined hyperlipidemia

free fatty acids

familial hypercholesterolemia

DNA damage-inducible transcript 1

liver glyceraldehydes 3-phosphate dehydrogenase

hydroxyacyl-Coenzyme A dehydrogenase/3-ketoacyl-Coenzyme A thiolase/enoyl-Coenzyme A hydratase alpha

high-density lipoprotein

hepatic lipase

hypoxanthine phosphoribosyltransferase

hormone sensitive lipase

interferony receptor 2

insulin-like growth factor 1

insulin-like growth factor 1 receptor

interleukin 6

intima media thickness

interferon gamma

insulin receptor

IQ motif containing GTPase activating protein 1

insulin resistance

insulin resistance syndrome

krebs-ringer bicarbonate HEPES

low-density lipoprotein

$\log$ of odds

lipoprotein lipase

matrix metalloproteinase 7

plasminogen activator inhibitor- 1 
PCR

PGR3

PLTP

PPARA

PPARE

PPARG

PPD

PSMB4

PTGER3

RFLP

RNA

RXR

S100A13

S100B

$\mathrm{SD}$

SERBP

SNP

SSH

$\mathrm{TC}$

TDT

TG

TGF $\beta$

TNFa

Txnip

WDUP1

VLDL

VNTR

WHR polymerase chain reaction

$p-53$ responsive gene 3

phospholipid transfer protein

peroxisome proliferator-activated receptor alpha

peroxisome proliferator-activated receptor delta

peroxisome proliferator-activated receptor gamma

peak particle diameter

proteasome prosome macropain subunit beta type 4

prostaglandin E receptor 3

restriction fragment length polymarphism

ribo nucleic acid

retinoid receptor

$\$ 100$ calcium binding protein $\mathrm{A} 13$

$\mathrm{S} 100$ calcium binding protein $\mathrm{B}$

standard deviation

sterol regulatory element-binding protein

single nucleotide polymorphism

suppression subtractive hybridization

total cholesterol

transmission disequilibrium test

triglycerides

transforming growth factor beta

tumor necrosis factor alpha

thioredoxin interacting protein

vitamin D3 regulated gene 1

very low-density lipoprotein

variable tandem repeat

waist to hip ratio 



\section{Chapter 1}

\section{General introduction}

\section{Genetic dissection of Familial Combined}

\section{Hyperlipidemia and aims of the thesis}

PMH Eurlings, CJH van der Kallen, JMW Geurts, MMJ van Greevenbroek, TWA de Bruin.

Based on:

Genetic Dissection of Familial Combined Hyperlipidemia Molecular Genetics and Metabolism. 2001, 74: 98-104 
1. Introduction

2. (Patho)physiology of FCHL

2.1 Diagnosis of FCHL

2.2 Lipid metabolism

23 Adpose tissue and insulin resistance

3. Genetic dissection of complex diseases

3.1 Animal models

3.2 Genetic studies: linkage and association

3.3 FCHL genome scains

3.4 FCHL candidate gene studies

4. Differentiall gene expression studies

5. Conclusion

6. Aim of the thesis 


\section{Introduction}

Familial Combined Hyperlipidemia (FCHL; MIM144250) is the most common genetic hyperlipidemia in man. FCHL is characterized by familial occurrence of multiple type hyperlipidemia, and is associated with clinical manifestations of premature coronary artery disease (CAD), i.e before the age of 60. FCHL may present itself in a family with elevated very low-density lipoprotein (VLDL, type IV hyperlipidemia) cholesterol, elevated low-density lipoprotein (LDL, partly resembling type lla hyperlipidemia) cholesterol, or both (type Ilb hyperlipidemia). "The pattern of hyperlipidemia within one individual may vary over time. The seriously increased risk of fatal and non-fatal CAD in relatives of FCHL probands has been reported to be 1.7 and 5.1 respectively $y^{2,3}$, studied against populations with a different background risk of CAD, i.e. high risk ${ }^{2}$ and low risk. ${ }^{3}$ Despite the seriously elevated risk of CAD, lipid levels are moderately elevated in FCHL, with typical total cholesteroll (TC) levels between 6.0 and $9.0 \mathrm{mmol} / \mathrm{L}$ and fasting triglyceride (TG) concentrations between 2.0 and $6.0 \mathrm{mmol} / \mathrm{L}$. CAD should be considered the unfortunate long term biological sequel of being affected with FCHL.

Although FCHL was delineated about 30 years ago', the complex FCHL phenotype is not fully understood at present. Initially the familial aggregation of traits (i.e high plasma TG and TC levels), the hyperlipidemia affecting half of the children, and bimodal distribution of plasma TG levels were taken as evidence of a dominant mode of inheritance. "However, it is now clear that the genetics of FCHL is complex ${ }^{4-}$ ${ }^{9}$, and it has been suggested that FCHL is heterogeneous. ${ }^{10}$ It is possible that the complex FCHL phenotype results from a defect in multiple genes or "alternatively, that the disorder results from one or more major genes. In both alternatives, geneenvironment interactions remain important.

In this chapter an outline will be given of the current understanding of the pathophysiology of FCHL, and more specifically, the role of adipose tissue and insulin resistance will be reviewed. Furthermore, genetic strategies that can be used to dissect the genetic background of FCHL in both humans and animal models will be discussed. Finally, the aim of research and the outline of this thesis will be given. 


\section{2. (Patho)physiology of FCHL}

\subsection{Diagnosis of FCHL}

As no unique biochemical or genetic marker for $\mathrm{FCHL}$ is available yet, family studies are required to establish the diagnosis of FCHL in a single patient. "This may be considered a disadvantage in terms of easy diagnosis and accessibility of patients for study. This disadvantage is encountered at the level of the clinic, but not as much in scientific studies once the FCHL families have been identified. On the other hand, this circumstance motivates the field to find consensus on diagnosis, and move forward towards (new) diagnostic criteria. ${ }^{12}$

To establish the diagnosis of FCHL in a family, each of the following criteria are met: first, a proband with a primary hyperlipidemia with varying phenotypic expression including fasting plasma $T C>6.5 \mathrm{mmol} / \mathrm{L}(250 \mathrm{mg} / \mathrm{dL})$ and/or fasting plasma TG $>2.3 \mathrm{mmol} / \mathrm{L}(180 \mathrm{mg} / \mathrm{dL})$; second, two first-degree relatives with a different hyperlipidemic phenotype (Fredrickson Classification Ila, IIb, or IV) from the

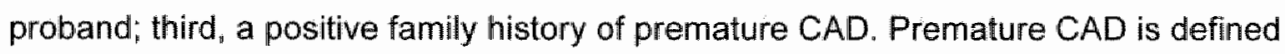
as the occurrence of a myocardial infarction or cerebrovascular incidence before the age of 60 years in at least one first-degree relative of the proband, or the proband him-/herself. To avoid admixture of the study population with phenocopies, secondary causes of hyperlipidemia (renal or hepatic insufficiency and hypothyroidism), presence of the apo E2/E2 genotype (thus, familial dysbetalipoproteinemia), and subjects with tendon xanthomas or a diagnosis of familial hypercholesterolemia are excluded. Obesity (body mass index (BMl) $>30$ $\mathrm{kg} / \mathrm{m}^{2}$ ) and type 2 diabetes mellitus (DM2) are also exclusion criteria for the ascertainment of a proband. Untreated fasting plasma lipid values are obtained from each subject in order to diagnose a subject as either hyperlipidemic ( TC $>6.5 \mathrm{mmo} / \mathrm{L}$ and/or $\mathrm{TG}>2.3 \mathrm{mmol} / \mathrm{L}$ ) or as normolipidemic. 


\subsection{Lipid metabolism}

Hypercholesterolemia, hypertriglyceridemia, elevated apolipoprotein (apo) B (apoB), and apoCIII concentrations and elevated postprandial free fatty acids (FFA) have been reported in FCHL families. Several studies have shown abnormalities in lipoprotein metabolism, including hepatic hypersecretion of apoB containing lipoproteins (VLDL; the large VLDL1 and small VLDL2) combined with a delayed clearance of atherogenic triglyceride-rich lipoprotein remnants, such as VLDL remnants (intermediate density lipoproteins) and chylomicrons remnants (reviewed in ${ }^{13,14}$ ). Increased hepatic VLDL secretion contributes to elevated plasma TG, apoB, and TC concentrations (Figure 1.1). ${ }^{13,15}$ It has been suggested recently that both VLDL1 and VLDL2 are over-secreted in FCHL and that an increased VLDL1 residence time in the circulation contributes to the hypertriglyceridemia. ${ }^{15}$ In addition to abnormalities in hepatic lipid metabolism, insulin resistance (IR) of adipose tissue and muscle has been documented in FCHL as well. ${ }^{16,17}$ Adipose tissue is one of the major contributors of FFA in the circulation. Postprandially high levels of FFA in the circulation can contribute to both a decrease in insulin-stimulated glucose uptake in skeletal muscle and an increase in hepatic lipoprotein synthesis, both characteristics of FCHL. ${ }^{18,19}$ Therefore, liver, adipose tissue and muscle are interesting target tissues for functional and differential gene expression studies in FCHL.

\subsection{Adipose tissue insulin resistance}

Glucose intolerance and/or $\| R$ frequently coexist with alterations in lipid metabolism, and therefore, the existence of IR in FCHL may be an important factor modulating FCHL phenotypes. Indeed, FCHL patients are characterized by impaired insulin-mediated glucose uptake and impaired insulin-mediated removal of plasma FFA. ${ }^{16,17.20,21}$ Moreover, normolipidemic non-affected subjects of FCHL families have been shown to be insulin resistant ${ }^{21}$, indicating a possible role of $I R$ in the development of FCHL.

Visceral obesity is an important determinant of IR in FCHL subjects. ${ }^{18,22} \mathrm{FCHL}$ subjects show higher waist to hip ratio (WHR) and waist circumference for their BMI. Although a $B M \|>30 \mathrm{~kg} / \mathrm{m}^{2}$ represents an exclusion criteria for $\mathrm{FCHL}$ probands in our 


\section{Genes implicated in FCHL}

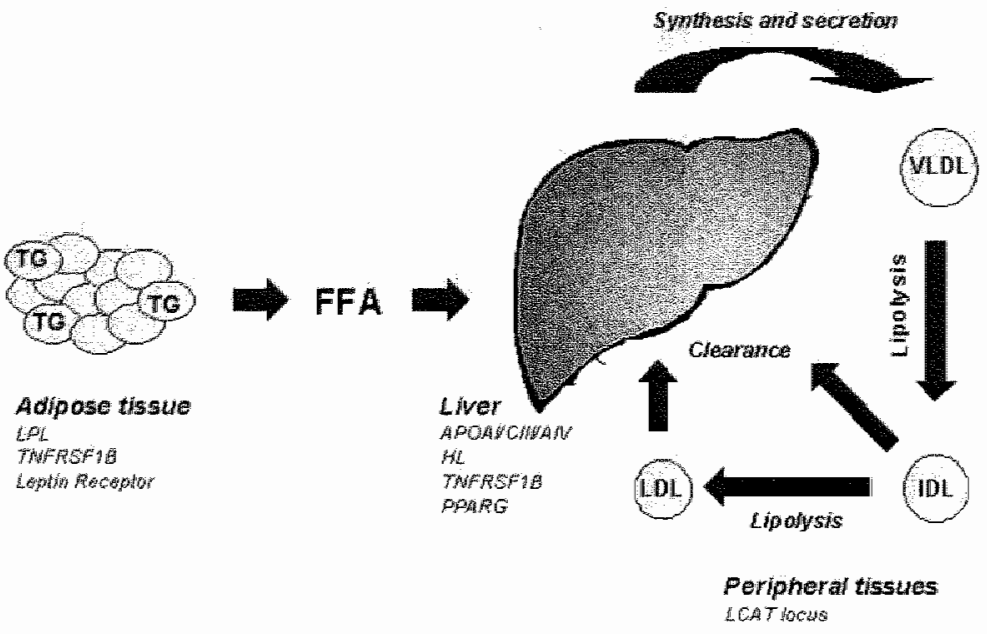

-Figure 1.1 Model for Familial Combined Hyperlipidemia.

Increased hepatic VLDL production in FCHL resulls in an increased flux of atherogenic IDL and LDL particles, and higher concentrations of $T C, T G$, apoB and apoCIII. In addition, insulin resistance of adipose tissue results in an increased FFA flux towards the liver, potentially contributing to hepatic VLDL production. The genegene and gene-environment interactions contributing to the FCHL phenotype remain to be elucidated.

llaboratory, as a secondary cause of hyperlipidemia, the increased WHR and waistcircumference (for the BMI<30) indicate increased amounts of adipose tissue. Evidence exists that adiposity in FCHL is genetically determined. ${ }^{23}$ Adipose tissue is the body"s major site for storage and mobilization of FFA, which in turn are key substrates in the synthesis of TG in the liver. FFA are continulously liberated by lipoprotein lipase (LPL) mediated hydrolysis of TG in VLDL and chylomicrons and, at least in part, stored in adipocytes by intracellular esterification to TG. FCHL patients show an abnormal FFA metabolism that can result in reduced clearance of FFA from 
the circulation in the postprandial state. ${ }^{24}$ The increased FFA concentrations in the postprandial state therefore appear to be generated by the adipose tissue.

Multiple mechanisms can contribute to the increased FFA flux in FCHL subjects; the mechanisms that have been studied until now will be discussed below. LPL represents a good candidate gene responsible for adipose tissue dysfunction in $\mathrm{FCHL}$, but there are conflicting data whether LPL activity is affected in FCHL. ${ }^{25-27}$ LPL hydrolyses TG from VLDL and chylomicrons into FFA and diacylglycerol, before uptake of FFA by the adipocyte. The liberated FFA are, under normal physiological circumstances, stored by adipocytes by intracellular re-esterification to $T G$, a process mediated by the action of the acylation stimulating protein (ASP). ${ }^{28}$ Adipocytes as well as fibroblasts from FCHL patients exhibit an impaired response to the activity of ASP in peripheral tissues. ${ }^{29}$ On the other hand, the release of FFA from visceral adipocytes is mediated by the enzyme hormone sensitive lipase (HSL). Insulin is a very potent inhibitor of lipolysis thus IR may, therefore, result in the reverse: an excessive postprandial release of FFA caused by failed suppression of $\mathrm{HSL}$ activity in FCHL. ${ }^{26}$ Reduced HSL activity has been reported in FCHL subjects, which seems to indicate that lipolysis is down-regulated in the basal state, as our laboratory recently showed. ${ }^{7,30,31}$ Additionally, in vitro studies have shown that $\mathrm{FCHL}$ adipocytes have impaired intracellular FFA utilization upon insullin stimulation, due to impaired FFA re-esterification. ${ }^{17}$

Thus, defects in extracellular TG hydrolysis, intracellular FFA re-esterification and TG lipolysis, or a combination of these defects, can contribute to increased plasma FFA levels as is seen in FCHL. Increased FFA flux from visceral fat depots can lead to a decrease in insulin-stimulated glucose uptake in skeletal muscle, as well as an increase in hepatic lipoprotein synthesis ${ }^{18,19}$, both characteristics of FCHL. However, visceral obesity and IR do not account solely for the observed hyperlipidemia in FCHL. ${ }^{19}$ In the past it has been hypothesized that FCHL is a part of the insulin resistance syndrome (IRS). At present, however, it is believed to be more likely that $\mathrm{IR}$ is one of multiple metabolic pathways contributing to the pathogenesis of FCHL. 


\section{Genetic dissection of complex diseases}

Several approaches can be taken to identify genes which contribute to disease phenotypes in complex genetic disorders, like FCHL, either by studying the disease in the human situation or using animal models. First of all, genome wide screens can be used to identify chromosomal regions potentially containing genes that contribute to the expression of the complex phenotype. Second, candidate gene studies can be used to identify genes either by linkage or association. Finally, in tissues from affected subjects compared to tissue from appropriate controls, differential gene expression studies can be used to yield results that can be translated to chromosomal regions identified by the first two approaches. The advantage of this strategy is that it can be used in humans as well as animal models. Recent reports have shown that this strategy can be useful in the genetic dissection of complex diseases such as $I R$, which has resulted in the identification of the human resistin gene. ${ }^{32.33}$ in general, these research efforts are hampered because genetic complex diseases in man such as hypertension, obesity " and DM2, are incompletely characterized at the molecular and biochemical level. In our view, genetics may also contribute to increased insight in molecular and biochemical mechanisms.

\subsection{Animall models}

Animal models represent an elegant tool for genetic and metabolic studies in order to gain more insight in human diseases. Two types of animal models exist, first the genetically manipulated animals, and, secondly animals that spontaneously express the phenotype of interest. In manipulated models, a gene is either introduced or knocked-out, and this gene has been chosen based on biological evidence in the human disease situation. Therefore, this kind of madel will primarily give new insights in the function of the selected gene(s), and is very useful to study gene function and in vivo metabolism. Spontaneous models are more likely to reveal novel (candidate) genes involved in the disease under study, but can also be very useful in metabolic studies. There are several advantages of using an animal model instead of human individuals. First of all. they allow detailed examination of the 
physiological basis of the disease, and, secondly, they offer a frontlune testing system for studying the efficacy of novel treatments before conducting clinical trails on human subjects.

Al present, two spontaneous animal models are available to assist in the genetic dissection of FCHL. First of all, the St. Thomas mixed hyperlipidemic rabbit which is characterized by increased plasma levels of $\mathrm{TC}_{\mathrm{i}} \mathrm{TG}$, and hepatic overproduction of apoB containing lipoproteins, such as VLDL ${ }^{34}$ "thereby resembling the FCHL phenotype. Secondly, the HcB 19 mice model, which is also characterized by a combination of hypertriglyceridemia, hypercholesterolemia, and elevated plasma apoB levels. ${ }^{35}$ Like FCHL patients, the hyperlipidemia in HcB19 mice is progressive with increasing age ${ }^{35}$ In addition, one genetically manipulated animal model is available for studying $\mathrm{FCHL}$, the apoE-deficient mice model overexpressing human apoAll. This mouse model is characterized by a dose-dependent increase in hepatic VLDL production, resulting in increased plasma TG concentrations, making it an ideal model to study VLDL overproduction. ${ }^{36}$

The HaB19 mouse model is, at present, by far the most used animal model to study FCHL, and will therefore be discussed in more detail. In HCB19 mice, a novel gene, Hyplip1, has been mapped to a portion of the mouse genome that is orthologous to human chromosome $1 \mathrm{q} 21-\mathrm{q} 23^{5,37}$, and this region has been shown to be associated with FCHL. ${ }^{35}$ Recently, Hyplip1 has been identified as the thioredoxin interacting protein (Txnip) gene. ${ }^{36}$ Txnip mRNA levels were found to be substantially decreased in HcB19 mice and a nonsense mutation in the coding region, that is absent in the parental mouse strain, has been identified. ${ }^{38}$ Txnip encodes a cytoplasmic protein that binds and inhibits thioredoxin, a major regulator of cellular redox state. The mutant mice showed a decreased flux of fatty acids through the citric-acid cycle, resulting in increased availability for ketogenesis and TG synthesis. $^{38}$ These data reveal a new pathway involved in altered lipoprotein metabolism causing combined hyperlipidemia in HcB19 mice, but a contribution of this pathway to FCHL in humans still remains to be shown.

Mapping of genetic loci that contribute to the specific phenotype in rodent animal models is considered a more feasible undertaking than in humans. The genetic background is more homogeneous in animals and, therefore, identification of specific genes is within reach. For this reason several investigators advocate the combined animal-human approach to elucidate a complex human disease. ${ }^{32,33,37,39}$ Therefore 
the HCB19 mouse, as well as the St. Thomas rabbit, may continue to prove to be of great value in elucidating the genetic background of $\mathrm{FCHL}$. It would be helpful to the field when other animal models will be identified.

\subsection{Genetic studies: finkage and association}

Today, most of the Mendelian, or so-called monogenetic, diseases have been mapped and the causal genes have been identified. The new challenge is to reveal the genetic determinants of nonmendelian diseases, or so-called complex traits, mainly because these diseases, among which are FCHL, CAD and DM2, are becoming leading healthcare issues. Complex traits are caused by i) the simultaneous (additive) action of several genes (polygenic), sometimes in combination with environment (so-called multifactorial inheritance), or ii) the interaction of genes (epistasis), whether or not in combination with environment (gene-environment interaction). Unraveling the complex genetics of these disorders will provide insight at the molecular level in the pathogenesis, and will enable the development of pharmacological tools to treat these diseases, but will also suggest new means of prevention. Such preventive measures will be, most likely, at the level of lifestyle intervention. There are several approaches that can be used for mapping complex genetic disorders and these will be discussed subsequently. Additionally an overview will be given about the results obtained using these genetic strategies in the genetic dissection of FCHL.

In linkage studies the tendency to being inherited together of genes or other DNA sequence variations at specific loci, as a consequence of their physical proximity on a single chromosome, is studied. More simply said, linkage tracks the co-segregation of a disease/trait and genetic markers within a family. The result of linkage is expressed as a $\log$ of odds (LOD) score " a measure of the likelihood that there is genetic linkage between loci. In general, for complex traits a LOD $=3.3$ to 4.0 , depending on the study design, is evidence for significant linkage, with a $5 \%$ chance of error $(P<0.05){ }^{40} A$ LOD less than zero is considered as evidence against linkage. Most linkage studies study more than two loci simultaneously, and this kind of analyses is called the multilocus or multipoint linkage approach. ${ }^{41}$ Ideally, the whole genome can be screened for linkage (genome-wide scan), and the data will be used 
to calculate the likelihood of linkage at each location in the genome. A major advantage of multipoint linkage is the fact that the influence of genetic markers of limited informativeness is reduced. ${ }^{42}$ Four types of genetic markers can be used for linkage studies; 1) restriction fragment length polymorphisms (RFLPs), which are polymorphisms that create or abolish a restriction site, 2) minisatiellite variable tandem repeat (VNTR) markers, 3) microsatellites; mostly (CA $A_{i n}$ ) repeats, and 4) single nucleotide polymorphisms (SNPS), which include RFLPs but also polymorphisms who do not create or abolish a restriction site. A series of these marker alleles found to be linked on a single chromosome is called a haplotype. ${ }^{42}$

Linkage can be either analyzed according to a pre-concerted genetic model, i.e. parametric linkage analysis, or as a model-free approach, i.e. nonparametric linkage analysis. ${ }^{41}$ Standard linkage analysis, such as done in monogenetic disorders, is parametric because it requires knowledge about the mode of inheritance, disease and marker allele frequencies, and the penetrance of each genotype. Specification of a genetic model is usually a problem in complex/nonmendelian disorders. ${ }^{42}$ Diagnostic criteria are not always clear-cut and different features with different rates of penetrance may exist within families. Therefore parametric linkage analyses can only be used for complex disorders when segregation of the disease is near mendelian. If this does not (fully) apply, nonparametric linkage analysis is the alternative. ${ }^{44}$ This approach ignores unaffected subjects and searches for alleles and chromosiomal regions that are shared between affected subjects. Sib pair analysis is a nonparametric form of linkage anallysis in which markers are tested for linkage to a disease or phenotypic trait by measuring the extent to which affected sib pairs share marker haplotypes. ${ }^{42}$ One drawback is that candidate gene regions defined by sib pair analyses are large. This makes fine mapping necessary, in order to subsequently locate the disease gene. Important to note is the fact that linkage results always need to be interpreted with care because it is vulnerable to errors and over enthusiasm. ${ }^{42}$

Association, in contrast to linkage, is a statistical statement about the cooccurrence of alleles or phenotypes in affected subjects. ${ }^{\star 2}$ Linkage shows a specific genetic relation between a trait/disease and a locus or loci, and not alleles or phenotypes. Although association and linkage are in principle two distinct things, linkage and association merge where the family and the population merge. ${ }^{42}$ For example, when two unrelated people with disease $D$ have inherited the disease from 
a common ancestor, they will share ancestral alleles at loci that are in linkage to disease D. The case-control study has been the mosi widely applied strategy for adequate association studies to characterize the genetic contributors to disease in more delail. A major advantage of this approach is the fact that cases en controls can be easily obtained. ${ }^{42}$.4is Case-control association studies can be very powerful compared to lirkage analyses in finding genetic contributions in complex disease ${ }^{43}$, but a good study design is crucial. Association studies need to have a sufficient sample size, correction for multiple testing is essential, cases and controls have to be well matched, and population stratification has to be circumvented. ${ }^{44}$ In addition, replication of association in a different study population increases the value of the study. All these guidelines will reduce the chance of false positive results. In general, one has to be cautious to declare a gene the candidate gene in a region when the region has not been thoroughly studied yet. ${ }^{44}$ Several methods have been developed to circumvent population stratification in association studies, and the transmission disequilibrium test (TDT) is the most popular method. This method uses parental couples with at least one affected offspring. In this analysis, it is irrelevant whether either parent is affected or not. ${ }^{42}$ The optimal TDT test is probably a function of the question at hand, since many protocols are available.

The genetic structure of a complex trait is not always apparent. In other words, how well does a human phenotype predict its genotype? Segregation analysis is the main statistical tool used to analyze the inheritance of nonmendelian disease. It can provide evidence of a major susceptibility locus and, at least, in part define its properties. Thus, by suggesting whether a complex disease is determined by a small number of genes (oligogenic) or a large number of genes (polygenic), segregation analysis can indicate whether it is worthwhile to implement linkage or association studies to identify these disease-causing genes. ${ }^{45}$

In summary, linkage and association are both effective tools to gain insight into the genetics of complex diseases. Linkage is used to study disease genetics on familly level, whereas association studies the disease on population level. 


\subsection{FCHL genome scans}

Goldstein et al. ${ }^{1}$ (in 1973) were the first to report on the genetic structure of FCHL. Using graphicall and maximum-likelihood methods the distribution of TC and $T G$ levels was analyzed. TG were shown to be bimodally distributed in first-degree relatives. They also noted that offspring of normolipidemic subjects were unaffected and that on average fewer than half of the offspring of affected subjects were hyperlipidemic. These observations led to the conclusion that FCHL is caused by the variable expression in each family of a single autosomal dominant gene with its primary action on TG and a secondary action on TC levels. This conclusion has since been questioned, but has been more or less confirmed (in 1994) by Cullen et al. ${ }^{4}$ On the other hand there was growing evidence in the field that the genetics of FCHL was more complex. ${ }^{24,46,47}$ The first genetic evidence for this view came from segregation analyses that examined the familial clustering of elevated apoB levels

Table 1.1 Major results from FCHL linkage studies presented as LOD scores.

\begin{tabular}{|c|c|c|c|c|c|c|c|c|c|c|}
\hline \multirow[t]{2}{*}{ Chromosome } & \multirow[t]{2}{*}{ Marker } & \multicolumn{8}{|l|}{ Traits } & \multirow[t]{2}{*}{ Ref. } \\
\hline & & FCHL & TG & TC & HDL.C & PPD & apo日 & Loptin & SBP & \\
\hline \multirow[t]{5}{*}{1} & Dis104 to D1S1677 & 59 & 3.3 & & & & & & & 5 \\
\hline & D1S104 to DiS1677 & 3.3 & 1.9 & & & & & & & 51 \\
\hline & D1S1679 & & 1.8 & & & & *o & & & a \\
\hline & D1S194 & 2.6 & & & & & & & & ba \\
\hline & D154665 & & & & & & 47 & 3.4 & & 623 \\
\hline 2 & 0251391 & & 2.3 & & & & & & & 3 \\
\hline 8 & D8S1132 & & & & 4.7 & & & & & $\$ 2$ \\
\hline 4 & D452369 & & & & & & & & 4.6 & :4 \\
\hline \multirow[t]{2}{*}{10} & D $10 \$ 1220$ & & 3.2 & & & & & & & : \\
\hline & Dros169 & & 3.3 & 27 & & & & & & 3 \\
\hline \multirow[t]{2}{*}{11} & D11S1985 to D11S1324 & 2.6 & & & & & & & & 3 \\
\hline & D 1154127 & 3.1 & & & & & & & & $\Leftrightarrow$ \\
\hline 13 & D135659 & & & & 2.2 & 1.2 & & & & 54 \\
\hline 16 & 01653091 & & & & 2.2 & & & & & $s: 2$ \\
\hline 20 & 0205471 & & & & 1.9 & & & & & 52 \\
\hline 21 & 02151437 & & & & & & 2.2 & & & B \\
\hline
\end{tabular}

Table shows highest LOD scores yielded in the dlifferent, studies.

SBP, systolic blood pressure. 
(in 1997) ${ }^{46}$. This study showed that the aggregation of elevated apoB levels in FCHL kindred was best explained by a major gene effect. Thus, instead of only one major gene effect on TG, there was now statistical evidence for another major gene effect, on plasma apoB concentrations. ${ }^{4,48,49}$ Based on growing genetic and metabolic /physiologic evidence. FCHL is considered a complex genetic disorder from this time point on.

At present, several genome scans of FCHL families have been published and the results of new genome screens are awaited. 5,6,8,23,50,51 The genome-wide screens showed linkage of the affected FCHL status to several loci, not only confirming but also illustrating the genetically complex nature of $\mathrm{FCHL}$. The most prominent results, in terms of a LOD score, were chromosomal region 1q21-23 (LOD 5.93), in a Finnish population $^{5}$, and chromosomal region $11 p$ with a LOD score of 2.6 , in a Dutch

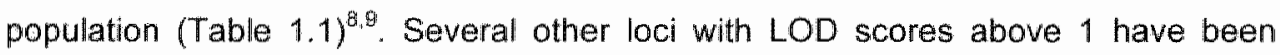
reported (Table 1.1). ${ }^{9.50-52}$

The analysis in Finnish FCHL famillies yielded a LOD of 5.93 on chromosome $1 \mathrm{q} 21-23$, according to a parametric model that used the affected-only strategy. This model favors the detection of dominant genes and elegantly avoids the problem of reduced penetrance..$^{5}$ The diagnosis of FCHL in the Finnish population was according to the 90th population percentiles for plasma TC and TG. Obesity and DM2 were not specifically excluded ${ }^{5}$. Initial analyses in Dutch FCHL families used non-parametric linkage methods (not favoring a dominant or recessive model of inheritance) and followed 'identity-by-descent' principles of mathematical genetic analyses. Such an approach may also reveal recessive genes. ${ }^{53} \mathrm{FCHL}$ was analyzed either as a qualitative or quantitative trait. ${ }^{53}$ The inclusion criteria for FCHL in the Dutch study required a proband with a cholesterol $>6.5 \mathrm{mmol} / \mathrm{L}$ and/or $\mathrm{TG}>$ $2.3 \mathrm{mmol} / \mathrm{L}$, whereas probands with a BMI $>30$ " DM2, other genetic lipid disorders like familial hypercholesterolemia and familial dysbetalipoproteinemia, and hypothyroidism, renal insufficiency, or hepatic disease were excluded. In addition, individuals on lipid lowering medication or glucocorticoid treatment were excluded from analysis ${ }^{8}$. There was no linkage between $\mathrm{FCHL}$ and chromosome 1 but there was significant linkage of FCHL to a locus on chromosome $11 \mathrm{p}$ in Dutch FCHL families. However, a chromosomal locus harboring a gene contributing to adiposity and leptin levels was identified on chromosome 1p31 (D1S1665, LOD 3.4), harboring the leptin receptor. ${ }^{23}$ In a second follow-up study, the genome wide linkage 
data in Dutch families were re-analyzed following the Finnish trait parameters and statistical analyses. ${ }^{9}$ This approach resulted in highly significant evidence of linkage with elevated apoB levels on chromosome 1 p31 (D151665, LOD 4.7) using multipoint analysis. However ${ }_{\text {in }}$ there was no evidence of association between the leptin receptor ( $\mathrm{see}^{23}$ ) and apoB levels, suggesting that two different genes, affecting two different traits (leptin and apoB), reside in this chromosomal region. ${ }^{9}$

The National Heart Lung and Blood Institute Family Heart Study group published replication of linkage of $\mathrm{FCHL}$ to chromosome $1 \mathrm{q} 21$ (marker D1S104), with an additional heterogeneous effect of the apo Al-CIII-AIV gene cluster on chromosome 11 (Table 1.1). ${ }^{51}$ The same dominant model was used as in the Finnish study (affected only approach) and FCHL was defined according to percentiles. Subjects with DM2, obesity, and the use of lipid lowering drugs, were not used as exclusion criterion. A combined German-Chinese study also confirmed linkage of FCHL to region 1q21-q23 (LOD 2.6) (Table 1.1). ${ }^{50}$ This study followed the same selection criteria for FCHL subjects as the Finnish studly, while they excluded individuals with type 1 or 2 diabetes, renal disease, or thyroid disorders. In this study "linkage was found with marker D1S194 that is closely situated to marker D1S104. Marker D1S194 is adjacent to the gene for the retinoid receptor (RXR), and that was suggested as an attractive candidate gene for $\mathrm{FCHL}{ }^{50}$

Recently, the region on chromosome 1q (the Finnish locus) has been narrowed down to 1q21 by fine-mapping the Hyplip1 locus in the mouse and defining the borders of the region of conserved synteny between human and mouse. ${ }^{37}$ This region lies approximately within 5-10 Mb of the peak marker (D1S104) for linkage to FCHL. Recent data suggest that in addition to Hyplip 1 other interesting candidate genes exist in this region.

The fact that linkage of region $1 \mathrm{q} 21-\mathrm{q} 23$ to $\mathrm{FCHL}$ has been reconfirmed $\mathrm{d}^{50.51}$ provides strong evidence that it harbors a strong candidate gene for FCHL. Therefore it is surprising that this result was not obtained in the initial Dutch study. ${ }^{B}$ As mentioned above, differences in genetic analytical methodology and subject selection criteria between the Dutch study and the studies supporting linkage to chromosome $1 q$ could explain this difference. In collaboration with the laboratories from Drs. Peltonen, Lusis, and Rotter (UCLA, Los Angeles, CA), reanalysis of the Dutch families applying the same criteria for affected status and use of the affectedonly analytical mode $\left.\right|^{5}$ yielded a LOD of 1.8 with TG and a LOD of 1.0 with apoB 
(marker D1S1679, $5 \mathrm{cM}$ proximal from the Finnish marker), providing some evidence for this line of reasoning.

Apart from linkage to chromosome 1q21-q23, linkage evidence has been obtained for low high-density lipoprotein cholesterol (HDL-C) loci on chromosomes $8 \mathrm{q} 23$ (D8S1132, LOD 4.7), 16q24.1-24.2 (D16S3091, LOD 2.2) and 20q13.11 (D20S1714, LOD 1.9). ${ }^{52}$ These data imply that are multiple genes negatively affecting HDL-C levels in FCHL subjects. A drawback of this study ${ }^{52}$ is the fact that the families used in this linkage approach are not onlly FCHL familles, but also families solely characterized by low HDL-C levels. Therefore, interpretation of these results in relation to FCHL has to be done with great care until these results have been reproduced in other FCHL populations.

In FCHL evidence for linkage, using quantitative sib-pair analysis, has been found with LDL particle size, HDL-C and TG levels in relation to the hepatic lipase (HL) gene locus. ${ }^{54}$ This study revealed genome-wide linkage of peak particle diameter (PPD; LOD 2.2) and HDL-C levels (LOD 1.2) to the HL gene locus as well. 54

Negative linkage results have also been obtained. Linkage analyses in Finnish FCHL families failed to show significant linkage with the APOAI-CII-AIV gene cluster. $^{55}$ However, TC and apoB levels were found to be assaciated with an intragenic polymorphism ${ }^{55}$, suggesting gene-environment interaction at this locus. In line of these results, Wijsman et al. found evidence against linkage (LOD -8.95) of this gene cluster with $\mathrm{FCHL}^{56}$, and $\mathrm{Xu}$ et al ${ }^{57}$ also could not find a FCHL specific genetic contribution of the APOAI-CIII-AIV gene cluster. The role of the APOAI-CIIAIV gene cluster in FCHL has also been extensively studied using genetic association studies and that will be discussed in the next section. In Finnish FCHL families negative evidence for linkage was obtained for the lipolytic enzymes LPL (LOD -14.6), HL (LOD, -9.4), and HSL (LOD -15.3). However, involvement of these genes in FCHL has been shown using association studies, suggesting that they may function as modifier genes on specific phenotypes, and this will be discussed in next the paragraph. 


\subsection{FCHL Candidate gene studies}

Linkage methods may have limited power to detect genes with a minor genetic contribution to the complex disease phenotype, whereas association studies have more power and can be more suitable for this purpose. ${ }^{58}$ According to this view, association studies are useful to confirm conceptual and positional candidate genes that have been chosen for further elucidation, based on their biological function, or results from linkage approaches. Of the $\mathrm{FCHL}$ candidate genes studied up to this time, the APOAI-CIII-AIV gene cluster, the $L P L$ gene and the $H L$ gene have been studied most extensively.

Although no evidence for linkage between the APOAl-CIII-AIV gene cluster and FCHL has been found, evidence of association of this gene cluster with FCHL was found in several association studies and will be discussed. Hayden and colleagues were the first to report association of the APOAl-CIII-AIV gene cluster with FCHL. ${ }^{59}$ They showed that the rare alleles of the $X \mathrm{mn}$ l polymorphism, $5^{\prime}$ of the APOAl gene, and Sstl polymorphism, 3 ' of exon 4 of the APOCIII gene, were significantly more frequent in $\mathrm{FCHL}$ subjects compared to controls and subjects with other genetic hyperlipidemias. ${ }^{59}$ Dallinga-Thie and colleagues ${ }^{60}$, studied, in addition to the two above mentioned polymorphisms, the Mspl polymorphism located 5 ' of the APOAI gene, and showed that FCHL was associated with a higher frequency of minor alleles compared to spouse controls. Elevated plasma TC, TG, LDL-C, apoB and apoCIII concentrations were associated with higher frequencies of minor alleles in this gene cluster. ${ }^{60}$ Haplotype analysis of the $\mathrm{Xmnl}, \mathrm{Mspl}$ " and Sstl polymorphisms revealed that specific haplotype combinations were significantly more frequent in hyperlipidemic FCHL subjects compared to normolipidemic relatives and spouses. ${ }^{61}$ These haplotypes were associated with elevated plasma TC, TG and apoCill levels.

Groenendijk et al. showed that the allele frequency of the novel intragenic variants; $\mathrm{C}_{317} \mathrm{~T}$, in intron 2 of the APOA/ gene, and $\mathrm{C}_{1100-} \mathrm{T}$, in exon 3 of the APOCIII gene, were significantly different in probands and spouses. ${ }^{62}$ Elevated plasma $T G$ and apoCIII concentrations were found to be associated with the minor alleles.

Analysis of the APOAN gene using two polymorphisms, $A_{347} T$ and [CTGT] $]_{3-4}$, in exon 3 , revealed that the minor allele frequency of $A_{347} T$ was less in probands compared to spouses, whereas no difference in frequency was found for [CTGT] $]_{3-4}$. 
Recently, a novel gene situated adjacent to the APOAl-CII-AIV gene cluster was identified, the APOAV gene. Although its function is largely unclear at present, APOAV is believed to be involved in TG metabolism. ${ }^{54}$ A polymorphism in this gene was shown to be associated with higher plasma TG, higher VLDL-TG, and higher intermediate-density lipoptotein-TG $\mathrm{G}^{\mathrm{At}}$ in hyperlipidemic FCHL subjects. Moreover, the variant was significantly more frequent among $\mathrm{FCHL}$ subjects than in unaffected relatives. These results warrant further genetic studies of the involvement of the APOAV gene in FCHL.

Overall, the data on the APOAl-CIII-AIV-AV gene cluster illustrate the complexity of FCHL, and illustrate a modifying role for this gene cluster, possibly in combination with environmental factors. However, based on the inconclusive linkage results this cluster will not have a major contribution to FCHL. The fact that a gene is a modifier gene or has a minor contribution to the complex phenotype does not necessarily imply that such a gene is without serious biological and medical consequences for the subjects involved. For instance " minor variations in the APOAI-CIII-AIV-AV gene cluster have a major impact on the risk on $\mathrm{CAD}$ in $\mathrm{FCHL}^{65}$

The first genetic studies on the association between the LPL gene and FCHL came from $Y$ ang and colleagues. ${ }^{66}$ They identified a $T_{39} \mathrm{C}$ variant in the promotor of the LPL gene. Only one out of twenty FCHL patients studied had reduced postheparin plasma LPL activity, and this patient was heterozygous for the promotor mutation. ${ }^{66}$ More evidence for a direct relation between variants in the LPL gene and FCHL came from a follow-up study in which two promotor variants $\left(T_{39} \mathrm{C}\right.$ and $\left.T_{-93} G\right)$, that were shown to profoundly reduce the promotor function, were identified in FCHL subjects with low LPL activity, but not in FCHL subjects with normal LPL levels, $C A D$ patients and controls, confirming the suggestion that partial LPL deficiency may be caused by promoter mutations in a subset of $\mathrm{FCHL}$ patients. ${ }^{67}$ The frequently occurring Asn291Ser variant has been shown to be more frequent in $\mathrm{FCHL}^{68}$ and the minor allele was found to be significantly associated with decreased HDL-C, VLDL-C levels and increased TG and VLDL-TG levels. ${ }^{68,69}$ Two other LPL polymorphisms, D9N and N291S, were not directly associated with $\mathrm{FCHL}$, but had a modifying effect on plasma traits such as HDL-C, diastolic blood pressure and apoB levels. ${ }^{70.71}$

Evidence for a role of the HL gene in FCHL came from studies in which the relationship between the $G_{250}$ A promotor polymorphism in relation to insulinstimulated glucose uptake was studied ${ }^{72}$ Presence of the minor allele was found to 
be associated with low rates of insulin-mediated whole body glucose oxidation and high levels of LDL-TG in FCHL subjects. ${ }^{72}$ Moreover, a different variant in the $\mathrm{HL}$ gene, V73M, was found to affect $T C$ and apoB levels, further illustrating that variability in the $F C H L$ phenotype is affected through the $H L$ gene. ${ }^{73}$

Apart from the APOAl-CII-AN-AV gene cluster ${ }^{60.61}$, the $L P L^{66,67.69,70}$, and the $H L$ gene ${ }^{53,54}$, the peroxisome proliferator-activated receptor gamma (PPARG) ${ }^{74}$, the tumor necrosis factor receptor superfamily member $1 B(\text { TNFRSF } 1 B)^{75}$; the $\alpha$ adducin $(A D D 1)^{76}$, the HSL gene $e^{77}$ and the lecithin:cholesterol acyltransferase (LCAT) locus ${ }^{53}$ have been shown to contribute to the expression of the FCHL phenotype. On the other hand, obvious and less obvious candidate genes have been excluded such as the manganese superoxide dismutase $\left(S O D_{2}\right)$, VLDL-receptor $(V L D L R)$, low density lipoprotein receptor $(L D L-R)$, and $A P O B$ gene. ${ }^{53}$

Overall, these results show that candidate gene studies have been very useful in identifying FCHL modifier genes. However, the discussed genes are not likely to be the primary cause of $\mathrm{FCHL}$, but rather represent modifier genes. This interpretation has been based on the fact that linkage approaches have not unequivocally identified these genes in all populations. In summary, the data that have been obtained in different FCHL populations, using linkage and association approaches all support the concept that $\mathrm{FCHL}$ is a complex and heterogeneous genetic disease.

It is of interest to note that many conceptual and positional candidate genes require further study to assess their involvement in the genetic pathophysiology of FCHL. For example, the peroxisome proliferator-activated receptor alpha (PPARA) gene, the resistin gene, the adiponectin gene, and the vitamin D3 upregulated gene 1 (VDUP1). PPAR $\alpha$ is a nuclear transcription factor of genes involved in fatty acid and lipoprotein metabolism. ${ }^{78}$ PPARo activators, such as fibrates, decrease plasma triglyceride concentrations, decrease apocill concentrations, increase HDLcholesterol, and improve insulin sensitivity. ${ }^{78}$ Fibrate treatment has been shown to be effective in the management of $F \mathrm{FHL}^{80.81}$ suggesting a role for PPARA in FCHL. Resistin is a hormone secreted by mature adipocytes and high plasma concentrations of resistin have been related to (increased) insulin resistance. ${ }^{33}$ Based on the fact that FCHL subjects are insulin resistant to a similar degree as subjects with $D M 2^{17}$, resistin is an interesting candidate gene for insulin resistance in FCHL. Adiponectin, is an adipose tissue specific plasma protein, and has been 
related to increased insulin sensitivity with anti-inflammatory properties. ${ }^{82}$ Therefore, adiponectin is also an interesting candidate gene for insulin resistance in FCHL. VDUP1 encodes a cytoplasmatic protein involved in the regulation of the cellular redox state ${ }^{33}$, which is linked to cellular TG synthesis. VDUP1 is the homologue of Txnip (Hyplip 1), which represents the genetic defect in the FCHL mouse model $\mathrm{HCB} 19^{38}$; and therefore requires further exploration. Moreover, it will be worthwhile to analyze candidate genes in Dutch FCHL families that have been implicated of excluded in other FCHL populations, such as PPARG.

In the current thesis the role of both PPARA and PPARG in the genetic pathophysiology of FCHL has been assessed in Dutch FCHL subjects using a casecontrol association study design.

\section{Differential gene expression studies}

Differential gene expression studies present a powerful tool to identify genes involved in genetically complex diseases such as FCHL. Prompted by completion of the human genome project, rapid progress has been made in the identification of genes involved in complex metabolic and cardiovascular diseases. A good example is the identification of the hormone resistin, which functions as a bridge-molecule between obesity and DM2. ${ }^{33}$

In our laboratory, we use two, complementary, strategies to idlentify adipose tissue genes specifically up- or down-regulated in FCHL. As outlined in the paragraph handling about adipose tissue and insulin resistance, adipose tissue is believed to contribute to the FCHL phenotype. The first strategy is the suppression subtractive hybridization ( $\mathrm{SSH}$ ) technique, which is used to isolate differentially expressed sequences from FCHL adipose tissue samples. ${ }^{83} \mathrm{SSH}$ is based on a suppression PCR effect in which long inverted terminal repeats on target DNA result in the repression of undesirable sequences during PCR. SSH enables the generation of a differential CDNA library using only $50 \mathrm{ng}$ of total RNA, which makes it possible to analyze RNA levels from small amounts of human tissue samples. ${ }^{83}$ Arrays containing SSH genes and commercially obtained conceptual FCHL candidate 
genes are generated and screened in parallel to characterize known and unkmown genes in the pathogenesis of this disorder.

As a second approach, commercially available cDNA expression filters (Atlas Human cDNA expression array, Clontech. Palo Alto, CA) have been used to study the differences in adipose tissue gene expression between FCHL patients and controls. This array consists of 588 genes involved in several cellular processes that can be classified as (a) oncogenes, tumor suppressor genes and cell cycle regulators, (b) ion channels, transporters, modulators, effectors, intracellular transducers, and stress response, (c) apoptosis, DNA synthesis, repair and recombination, (d) transcription factors and DNA binding proteins, (e) receptors, cell surface antigens and cell adhesion proteins and (f) growth factors, cytokines, chemokines, interleukins, interferons, and hormones. The major advantage of these arrays is that they are ready to use and require only $2 \mu \mathrm{g}$ of total RNA for a good hybridization signal, based upon the fact that a gene-specific oligo-dT primer mix is used for labeling. It is important to note that a limited number of genes can be studied by this system, and therefore interesting genes can be missed.

At present, as mentioned above, we are using adipose tissue for differential gene expression studies. In order to identify genes specifically differentially expressed in $\mathrm{FCHL}$ and not genes differentially expressed due to secondary causes of hyperlipidemia, such as obesity, it is important to use well characterized age, gender and BMI matched FCHL and control subjects. When differential gene expression data are obtained from the array experiments it is essential to reconfirm this in a larger subset of matched FCHL subjects and controls, using other techniques such as Northernblot analysis or (semi)quantitative Real-Time PCR.

If consistent gene expression patterns can be identified in FCHL adipose tissue, DNA microarray technology will be the next step in the identification of novel genes in FCHL. This technology is ideal for the analyses of large amounts of genetic data, i.e. thousands of genes, in a single experiment and will therefore be especially suited to perform large-scale "expression profiling" and "comparative genomics." This distinguishes microarray analyses from macroarray analyses in which no more than a thousand genes are studied simultaneously. Besides human DNA micro-arrays, mouse micro-arrays can be constructed for genetic profilling experiments. It is of interest to note that the HCB19 mice provide interesting target tissues, such as liver and muscle, for differential gene expression studies. Moreover, functional 
experiments can be performed with genes of interest, that are identified in the above mentioned lines of research, to gain more insight into their effect on FCHL pathogenesis and particularly on adipocytes. Proteomics, which is the study of protein expression, will be the next step to study the identified genes in more detail. Both 2-D protein electrophoresis, a suitable tool to visualize differential gene expression on protein level and antibody arrays, are elegant proteomics tools to gain more insight in the biological relevance of differentially expressed genes at the MRNA level. Array experiments, both on mRNA and protein level, are of great value in combination with genome scan data. At present the first genome wide screens using gene expression levels as quantitative traits are being implemented and will prove to be a powerful approach in genetic dissection of complex traits such as FCHL.

\section{Conclusion}

At present the genetics of the complex FCHL phenotype are still a scientific challenge. The near future will show whether (a) major gene(s) in combination with a number of minor genes and environmental factors generate the $\mathrm{FCHL}$ phenotype, or multiple gene-gene and gene-environment interactions. Until now a strong candidate region for FCHL, situated on chromosome $1 \mathrm{q} 21-23$, has been identified using linkage approaches in five different populations. Another conceptually very strong candidate region is chromosome $1 \mathrm{p} 31_{\text {" whe both increased apoB }}$ concentrations as well as measures for adiposity have been shown to be in linkage in Dutch FCHL familles. In addition important candidate genes have been shown to be involved, including the LPL gene, HL gene, the APOA/-CII-AIV-AV gene cluster and the LCAT locus, whereas obvious candidates such as the APOB, VLDLR and LDLR genes have been excluded. Differential gene expression studies will prove to be of additional value to dissect the genetic background of FCHL, because in combination with genome scan data the relevance of identified pathways can be established. The presently described genetic strategy has been shown to be successful in other complex diseases and is expected to yield more insight in the genetics of FCHL in the near future. 


\section{Aim of the thesis}

In the literature the progress made with regard to our insight in the genetic background of FCHL is clearly visible, but no unique genetic marker for FCHL has been identified yet. Genetic linkage studies as well as association studies have identified genes contributing to $\mathrm{FCHL}$, but there are still important positional and conceptual candidate genes that require further study. On the other hand, only a limited number of functional studies have been implemented to reveal the pathophysiological mechanisms in hepatic "adipose, and muscle tissue contributing to FCHL. This hampers rapid progress in the field. The revolution of functional genomics has provided science with powerful tools to gain more insight in complex diseases. It is therefore essential that genomics tools such as a combination of genome wide screens and differential gene expression studies will be implemented in the genetic dissection of FCHL.

Therefore, the overall objective of this thesis is:

A to identify genes involved in the insulin resistance mediated dysfunction of FCHL adipose tissue and ${ }_{n}$ to identify novel modifier genes involved in the pathophysiology of FCHL.

This approach involved the following investigations:

1) to study the presence of differentially expressed genes in subcutaneous adipose tissue from subjects with FCHL using commercially available macroarrays.

2) to study the presence of differentially expressed genes in subcutaneous adipose tissue from subjects with FCHL using custom made macroarrays which contain conceptual cardiovascular candidate genes and adipose tissue specific differentially expressed cDNAs, isolated using suppression subtractive hybridization.

3) to study the association between complex FCHL traits and the peroxisome proliferator-activated receptor gamma (PPARG) gene.

4) to study the association between complex FCHL traits and the peroxisome proliferator-activated receptor alpha (PPARA) gene. 


\section{References}

1. Goldsiein JL, Schrott HG. Hazzard WR, Biernan EL, Motulsky AG. Hyperlipidemia in coronary heart disease. II. Genetic analysis of lipid levels in 176 families and delineation of a new inherited disorder, combined hyperlipidemia. J.Chin Invest. 1973;52:1544-1568.

2. Austin MA, MoKnight B, Edwards. KL, Bradley CM, McNeely MJ, Psaty BM, Brunzell JD, Motulsky AG. Cardiovascular disease mortality in familial forms of hypertriglyceridemia: A 20year prospective study. Circulation. 2000,101:2777-2782.

3. Voors-Pette $\mathrm{C}$, de Bruin TWA. Excess coronary heart disease in Familial Combined Hyperlipidemia, in relation to genetic factors and central obesity. Atherosclerosis: $2001: 157: 481-489$.

4. Cullen P. Farren $B$, Scott J, Farrall M. Complex segregation analysis provides evidience for a major gene acting on serum triglyceride levels in 55 British families with familial combined hyperlipidemia. Arteriosicler. Thromb. Vasc.Biol. 1994;14:1233-1249.

5. Pajukanta $\mathrm{P}$, Nuotio I, Tenwilliger JD, Porkka $\mathrm{KV}$, Ylitalo $\mathrm{K}$, Pihlajamaki $J$, Suomalainen AJ, Sywanen AC, Lehtimaki $T$, Vikari JS, Laakso M, Taskinen MR, Ehntholm $C_{8}$ Peltonen L. Linkage of familial combined hyperlipidaemia to chromosome 1q21-q23. Nat. Genet. 1998;18:369-373

6. Pajukanta $P$. Terwilliger JD, Perolla $M$, Hiekkalinna $T$, Nuotio 1 , Ellonen $P$, Parkkonen $M$, Hartiala J, Ylitalo K, Pihlajamaki J, Porkka K. Laakso M, Vikari J, Ehnholm C, Taskinen MR, Peltonen L. Genomewide scan for familial combined hyperlipidemia genes in finnish families, suggesting multiple susceptibility loci influencing triglyceride, cholesterol, and apolipoprotein B levels. Am. J Hum Genet. 1999;64:1453-1463.

7. Williams WR, Lalouel JM. Complex segregation analysis of hyperlipidemia in a Seattle sample. Hum. Hered. 1982;32:24-36.

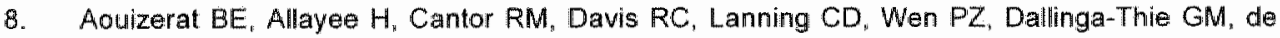
Bruin TWA, Rotter Jl, Lusis A.J. A genome scan for familial combined hyperlipidemia reveals evidence of linkage with a locus on chromosome 11. Am.J. Mum. Genet. 1999;65:397-4 12.

9. Allayee $H$, Krass KL, Pajukanta $P$, Cantor RM, van der Kallen $\mathrm{CJH}$, Mar R, Rotter Jil, de Bruin TWA, Peltonen L. Lusis A.J. Locus for elevated apolipoprotein B levels on chromosome 1 p 31 in families with familial combined hyperlipidemia. Circ. Res, 2002;90:926-931.

10. Aouizerat BE, Allayee H, Bodnar J, Krass KL, Peltonen L. de Bruin TWA, Rotter Jl, Lusis Ad. Novel genes for familial combined hyperlipidemia. Cum. Opin Lipidal. 1999;10:113-122.

11. Grundy SM, Chait A, Brunzell JD. Familial combined hyperlipidemia workshop. Atherosclerosis. 1987;7:203-207.

12. Sniderman $A D$, Castro-Cabezas M., Ribalta J, Carmena $R$, de Bruin TWA de Graaf $J$, Erkelens DW, Mumphies SE, Masana L. Real JT, Talmud PJ, Taskinen MR. A proposal to redefine faimilial combined hyperlipidaemia -- third workshop on FCHL held in Barcelona from 3 to 5 May 2001. during the scientific sessions of the European Sociely for Clinical Investigation. Ew.J.Clin. Invest. 2002;32:71-73

13. de Graaf $J_{\|}$Stalenhoef AF. Defects of lipoprotein metabolism in familial combined hyperlipidaemia. Curr: Opin.Lipidol. 1998:9:189-196.

14. Castra-Cabezas M. de Bruin TWA, Jansen H, Kock LA, Kortlandt W. Erkelens DW. Impaired chylomicron remnant clearance in familial combined hyperlipidemila. Arterioscler. Thromb. Vasc. Biol. 1993;13:804-814.

15. Taskinen MR, Caslake M.J. Packard CJ. Lipoprotein metabolism in FCHL. Eur.J.Clin./nvest. 2001:31 Suppl 1:4 4.

16. Aitman TJ, Godsland IF, Farren B, Crook D, Wong HJ, Scolt J. Defects of insulin action on fatty acid and carbohydrate metabolism in familial combined hyperlipidemia. Arterioscler. Thromb. Vasc. Biol. 1997:17:748-754.

17. van der Kallen CJH, Voors-Pette $C$, Bouwman FG, Keizer HA, Lu JY, van de Hulst RRWJ, Bianchi R, Janssen M-J, Keulen ETP. Boeckx WD. Rotter JI, de Bruin TWA. Evidence of Insulin Resistant Lipid Metabolism of Adipose Tissue in Familial Combined Hyperipidemia, but not in type 2 Diabetes. Atherosclerosis. 2002;164:337-346. 
18. Purnell JQ, Kahn SE, Schwartz RS, Brunzell JD. Relationship of Insulin Sensitivity and ApoB levels to Intra-abdominal Fat in Subjects with Familial Combined Hyperlipidemia: Arterioscter. Thromb. Vasc. Biol. 2001;21:567-572.

19. Lewis GF, Steiner G. Acute effects of insulin in the control of VLDL production in humans: Implications for the insulin-resistant state. Diabetes Care. 1996;19:390-393.

20. Bredie SJ, Tack CJ. Smits $P$, Stalenhoef AF. Nonobese patients with familial combined hyperlipidemia are insulin resistant compared with their nonaffected relatives: Arterioscler. Thromb. Vasc. Biol. 1997:17:1465-1471.

21. Kanjalainen L, Pihlajamaki J, Karhapaa P. Laakso M. Impaired insulin-stimulated glucose oxidation and free fatty acid suppression in patients with familiall combined hyperlipidemia: a precursor defect for dyslipidemia? Arterioscler. Thromb. Vasc. Biol. 1998:18:1548-1553.

22. Keulen ETP, Voors-Pette $C$, de Bruin TWA. Familial dyslipidemic hypertension syndrome: familial combined hyperlipidemia, and the role of abdominal fat mass. Am.J Hyperters. 2001:14:357-363.

23. van der Kallen $C . J H$, Cantor RM, van Greevenbroek MMJ, Geurts JMW, Bouwmain FG, Aouizerat BE, Allayee $H_{2}$ Buurman WA, Lusis AJ, Rotter Ill, de Bruin TWA. Genome scan fior adiposity in Dutch dyslipidemic families reveals novel quantitive trait loci for leptin, body mass index and soluble tumor necrosis factor receptor superfamily $1 \mathrm{~A}$. Int J Obes. Relat.Metab. Disord. 2000;24:1381-1391.

24. Castro-Cabezas $M$., de Bruin TWA, de Valk HW, Shoulders CC, Jansen $H$, Erkelens DW. Impaired fatty acid metabolism in familial combined hyperlipidemia. A mechanism associating hepatic apolipoprotein B overproduction and insulin resistance. J.Clin./nvest. 1993;92:160-168.

25. Babirak SP, Brown BG, Brunzell JD. Familial combined hyperlipidemia and abnormal lipoprotein lipase. Arterioscler. Thromb. Vasc.Biol. 1992;12:1176-1183.

26. Reynisdottir $S$, Eriksson $M$, Angelin $B$, Arner $P$. Impaired activation of adipocyte lipolysis in familial combined hyperlipidemia. J.Clin./nvest. 1995;95:2161-2169.

27. Seed M, Mailly F, Vallance D, Doherty E, Winder A, Talmud P. Humphries SE. Lipoprotein lipase activity in patients with combined hyperlipidaemia. Clin./mvestig. 1994,72:100-106.

28. Cianflone $K_{*}$ Roncari DA, Maslowska M, Baldo A, Forden J, Sniderman AD. Adipsin/acylation stimulating protein system in human adipocytes: regulation of triacylglycerol synthesis. Biochemistry. 1994;33:9489-9495.

29. Kwiterovich-PO J, Motevalli M, Miller M. The effect of three serum basic proteins on the mass of lipids in normal and hyperapoB fibroblasts. Arterioscler Thromb. Vasc. Biol. 1994;14:1-7.

30. Reynisdottir $S$, Angelin $B$, Langin D, Lithell $H$, Eriksson M, Holm $C$, Arner P. Adipose tissille lipoprotein lipase and hormone-sensitive lipase. Contrasting findings in familiall combined hyperlipidemia and insulin resistance syndrome. Arterioscher. Thromb. Vasc.Biol. 1997;17:22872292.

31. Ylitalo K, Large V, Pajukanta P, Reynisdotür S, Porkka KV, Valkkilainen d, Nuotio I, Taskinen MR. Arner P. Reduced hormone-sensitive lipese activity is not a major metabolic defect in Finnish FCHL families. Atherosclerosis. 2000;153:373-381.

32. Aitman TJ, Glazier AM, Wallace CA, Cooper LD, Norsworthy PJ, Wahid FN, AI MK, Trembling PM, Mann CJ, Shoulders CC, Graf D, St Lezin E, Kurtz TW, Kren V, Pravenec M, Ibrahimi A Abumrad NA, Stanton LW, Scott J. Identification of Cd36 (Fat) as an insulin-resistance gene causing defective fatty acid and glucose metabolism in hypertensive rats. Nat Genet. $1999 ; 21: 76-83$.

33. Steppan CM, Bailey ST, Bhat S, Brown EJ, Banerjee RR, Wright CM, Patel HR, Ahima RS, Lazar MA. The hormone resistin links obesity to diabetes. Nature. 2001;409:307-312.

34. Ardern HA, Bienson GM, Suckling KE, Caslake MJ, Shepherd J, Packard CJ. Apolipoprotein B overproduction by the perfused liver of the St. Thomas' mixed hyperlipidemic (SMHL) rabbit. J.Lipid Res. 1999:40:2234-2243.

35. Castellani LW, Weinreb A, Bodnar J, Goto AM, Doolittle M, Mehrabian M, Demant P, Lusis A.J. Mapping a gene for combined hyperlipidaemia in a mutant mouse strain. Nat Genet. $1998 ; 18: 374-377$ 
36. Egcola-Gi $\mathbb{L}_{\mathrm{C}}$ Jufve J. Marzal-Casacuberta A, Ordonez-Llanos J, Gonzalez-Sastre $\mathrm{F}_{\mathrm{s}}$ BlancoVaca F. Expression of human apolipoprotein A-li in apolipoprotein E-deficient mice induces features of familial combined hypentipidemia. J.Lipid Res. 2000;41:1328-1338.

37: Pajukanta P, Bodnar JS, Sallinen $R$, Chu M, Airaksinen $T$, Xiao ON, Castellani LW, Sheth $S S$, Wessman $M$, Palotie $A$, Sinsheimer JS, Demant $P$, Lusis $A d$, Peltonen L. Fine mapping of Hyplipt and the human homolog, a potential locus for FCHL. Mamm.Gen. 2001:12:238-245.

38. Bodnar JS, Chatterjee A, Castellani LW, Ross DA, Ohmen $J$, Cavalcoli $J$, Wu $C$, Dains KM, Catanese $J$ Chu $M$, Sheth $S S$, Charugundla $K$, Demant $P$, West $D B$, de Jong $P$, Lusis $A$ J. Positional cloning of the combined hypertipidemia gene Hyplip1. Nat.Genet. 2002;30:110-116.

39. Shih $D M$, Welch $\mathrm{C}_{\mathrm{i}}$ Lusis AJ. New inisights into atherosclerosis from studies with mouse models. Mol Med. Today. 1995;1:364-372.

40. Lander $E$, Kruglyak $L$. Genetic dissection of complex traits: guidelines for interpreting and reporting linkage results. Nat Genet. 1995;11:241-247.

41. Kruglyak L, Daly MJ, Reeve-Daly MP, Lander ES. Parametric and nonparametric linkage analysis: a uniffed multipoint approach. Am.J. Hum. Genet 1996;58:1347-1363.

42. Strachan, T, and Read, A. P. Genetic mapping of complex characters. Human molecular genetics 2. second(12), 283-294. 1999.

43. Risch $\mathbb{N}^{\prime}$. Searching for genetic determinants in the new millennium. Nature. 2000;405:847856.

44. Carclon LR, Bell Jl. Association study designs for complex diseases. Nat.Rev.Genet. 2001;2:91-99.

45. Strachan, T and Read, A. P. Genetic mapping of complex characters. Human molecular genetics 2. second(19), 445-464. 1999.

46. Hunt SC, Wu LL, Hopkins PN, Stults BM, Kuida HRME, Lalouel JM, Williams RR. Apolipoprotein. low density lipoprotein subfraction, and insulin associations with familial combined hyperlipidemia: study of Utah patients with familial dyslipidemic hypertension. Arteriosclerosis. 1989;9:335-344.

47. Kwiterovich PO, White $S$, Forte $T$, Bachorik $P S$, Smith $H$, Sniderman $A$. Hyperapobetalipoprotenemia in a kindred with familial combined hyperlipidemia and familial hypercholesterolemia. Arteriosclerosis. 1987;7:211-225.

48. Bredle SJ, van DJ, Kiemeney LA, Demacker PN, Beaty TH, Stalenhoef AF. Segregation analysis of plasma apolipopratein B levels in familial combined hyperlipidemia. Arterioscler. Thromb. Vasc. Biol. 1997;17:834-840.

49. Wolf $G$. Fatty acids bind directly to and activate peroxisome proliferator-activated receptors alpha and gamma. Nutr.Rev. 1998;56:61-63.

50. Pol W, Bapon $H$, Muller MB, Knoblauch $H, A I$ Y'SA, Hui $R$, Wu X, Liu L, Busjahn A, Luft FC, Schuster $H$. Support for linkage of familial combined hyperlipidemia to chromosome 1q21-q23 in Chinese and German families. Clin. Genet 2000;57:29-34.

51. Coon H, Myers RM, Borecki IB, Arnett DK, Hunt SG, Province MA. Djousse L, Leppert MF. Replication of Linkage of Famillal Combined Hyperlipidemia to Chromosome 1q With Additional Heterogenous Effect on Apolipoprotein A-I/C-III/A-IV Locus. Anterioscler. Thromb. Vasc.Biol. $2000,20: 2275-2280$.

52. Soro $A$ Pajukanta $P$, Lilja HE, Ylitalo $K$, Hiekkalinna $T$, Perola $M$, Cantor RM, Viikari JS, Taskinen MR, Peltonen L. Genome scans provide evidence for low-HDL-C loci on chromosomes $8 \mathrm{q} 23,16 q 24.1-24.2$, and $20 \mathrm{q} 13.11$ in Finnish families. Am.d Hum Genet. $2002 ; 70: 1333-1340$.

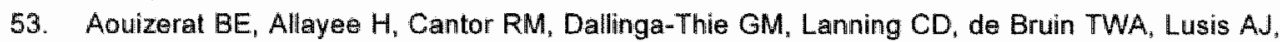
Rotter Jl. Linkage of a candidate gene locus to familial combined hyperlipidemia - Lecithin : cholesterol acyltransferase on 16q. Arterioscler Thromb. Vasc.Biol. 1999;19:2730-2736.

54. Allayee H, Dominguez KM, Aouizerat BE, Krauss RM, Rotter JI, Lu J, Cantor RM, de Bruin TWA, Lusis AJ. Contribution of the hepatic lipase gene to the atherogenic lipoprotein phenotype in familial combined hyperlipidemia. Jipid Res. 2000;41:245-252. 
55. Tahvanainen E. Pajukanta $P$, Porkka $K$, Nieminen $S_{4}$ Ikavalko $L$; Nuotio I, Taskinen MR, Peltonen L, Ehnholn C. Haplotypes of the ApoA-1/C-HII/A-IV gene cluster and familial combined hyperlipidemia. Arterioscler. Thromb. Vess. Biol. 1998;18:1810-1817.

56. Wijsman EM, Brunzell JD, Jarvik GP. Austin MA, Motulsky AG, Deeb SS. Evidence against linkage of familial combined hyperlipidemia to the apolipoprotein Al-CII-AIV gene complex. Arterioscler. Thromb. Vasc. Biol. 1998;18:215-226.

57. Xu CF, Talmud P, Schuster H. Houlston R. Miller G, Humphries S. Association between genetic variation at the APO Al-CIll-AlV gene cluster and familial combined hyperlipidaemia. Clin. Genet. 1994;46:385-397.

58. Wright AF, Carothers AD, Pirastu M. Population choice in mapping genes for complex diseases, Nat.Genet. 1999:23:397-404.

59. Hayden MR, Kirk H, Clark C, Frohlich J, Rabkin S, McLeod R, Hewitt J. DNA polymorphisms in and around the Apo-A1-C.ll genes and genetic hyperlipidemias. Am.J.Hum Genet. $1987 ; 40: 421-430$.

60. Dallinga-Thie $G M, B u X D$, van Linde-Sibenius $T M$, Rotter $J$, Lusis $A J$, de Bruin TWA. Apolipoprotein A-I/C-III/A-IV gene cluster in familial combined hyperlipidemia: effects on LDL. cholesterol and apolipoproteins B and C-Hll. J.Lipid Res. 1996;37:136-147.

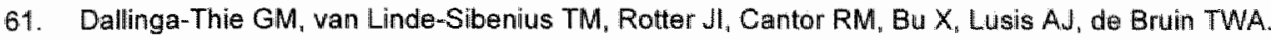
Complex genetic contribution of the Apo Al-CIll-AlV gene cluster to familial combined hyperlipidemia. Identification of different susceptibility haplotypes. J.Clin./nvest. 1997;99:953961.

62. Groenendijk M. Cantor RM, de Bruin TWA, Dallinga-Thile CM. New genetic variants in the apoA-1 and apoC.lll genes and familial combined hyperlipidemia. J.Lipid Res. 2001;42:188. 194.

63. Groenendijk M, de Bruin TWA, Dallinga-Thie GM. Two polymorphisms in the apo A-IV gene and familial combined hyperlipidemia. Atherosclerosis. 2001;158:369-376.

64. Ribalta J Figuera L, Fernandez-Ballart J, Vilella E, Castro-Cabezas M., Masana L, Joven J. Newly identified apolipoprotein AV gene predisposes to high plasma triglycerides in familial combined hyperlipidemia. Clin. Chem. 2002;48:1597-1600.

65. Voors-Pette $C$, de Bruin TWA. Excess coronary heart disease in Familial Combined Hyperlipidemia, in relation to genetic factors and central obesity. Atherosclerosis. 2001;157:481-489.

66. Yang WS, Nevin DN, Peng R, Brunzell JD, Deeb SS. A mutation in the promoter of the lipoprotein lipase (LPL) gene in a patient with familial combined hyperlipidemia and Iow LPL activity. Proc. Natl.Acad.Sci.U.S.A, 1995;92:4462-4466.

67. Yang WS. Nevin DN, Iwasaki L, Peng R. Brown BG, Brunzell JD, Deeb SS. Regulatory mutations in the human lipoprotein lipase geine in patients with familial combined hyperlipidemia and coronary antery disease. J.Lipid Res. 1996;37:2627-2637.

68. Reymer PW, Groenemeyer BE, Gagne E, Miao L, Appelman EE, Seidel JC, Kromhout D, Bijvoet $S M$, van de Oever $K$, Bruin $T$, et a. A frequently occurring mutation in the lipoprotein lipase gene (Asn291Ser) contributes to the expression of familial combined hyperlipidemia. Hum. Mol Genet. 1995:4:1543-1549.

69. Hoffer MJ, Bredie S.J, Boomsma DI, Reymer PW, Kastelein لJJ, Kniff Pd, Demacker PN, Stalenhoef AF. Havekes LM. Frants RR. The lipoprotein lipase (Asn291 ->Ser) mutation is associated with elevated lipid levels in families with familial combined hyperlipidaemia. Atherosclerosis. 1996;119:159-167.

70. de Bruin TWA, Mailly $F$, van Barlingen $H$, Fisher R, Castra-Cabezas M., Talmud $P$, DallingaThie GM, Humphries SE. Lipoprotein lipase gene mutations D9N and N291S in four pedigrees with familial combined hyperlipidaemia. Eur.J.Clin. Invest. 1996;26:631-639.

71. Campagna F, Montali A, Baroni MG, Maria AT, Ricci G, Antonini R, Verna R, Arca M. Common variants in the lipoprotein lipase gene, but not those in the insulin receptor substrate-4, the beta3-adrenergic receptor, and the intestinal fatty acid binding protein-2 genes, influence the 
lipid phenotypic expression in familal combined hyperfidemia. Metabolism. 2002;51:12981305.

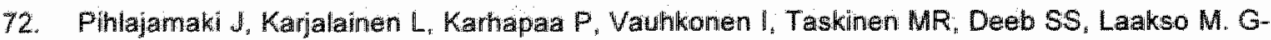
$250 \mathrm{~A}$ substitution in promoter of hepatic lipase gene is associated with dyslipidemia and insulin resistance in healthy control subjects and in members of families with familial combined hyperfipidemia. Anterioscler Thromb. Vasc Biol. 2000;20:1789-1795.

73. Hoffer Mid, Snieder H, Bredie SJ, Demacker PN, Kastelein JU, Frants RR, Stalenhoef AF. The $V 73 M$ mutation in the hepatic lipase gene ils associated with elevated cholesterol levels in four Dutch pedigrees with familial combined hyperlipidemila. Atherasclerosis. 2000;15:443-450.

74. Pihlajamaki $\mathrm{J}$, Miettinen $\mathbb{R}_{n}$ Vallve $\mathrm{R}_{\text {, }}$ Karjalainen L, Kuusisto J, Deeb S, Auwerx J, Laakso $M$. The Pro12Alia sibstitution in the peroxisome proliferator activated receptor gamma 2 is associated with an insulin-sensitive phenotype in families with familiall combined hyperlipidemia adn in non-diabetic elderly subjects with dyslipidemia. Atherosclerosis 2000;151:567-574.

75. Geurts JMW, Janssen RGJH, van Greevenbroek MMJ, wan der Kallen $C . J H$, Cantor RM, Bu X, Aouizerat $\mathrm{BE}$, Allayee $\mathrm{H}$, Rotter $\mathrm{J}$, de Bruin TWA. Identification of TNFRSF1B as a movel modifier gene in familial combined fyperlipidemia. Hum. Mol Genet. 2000;9:2067-2074.

76. Beeks, Janssen RGJH, Kroon AA, Keulen ETP, P, Geurts JM, de Leeuw $P_{4}$. de Bruin TWA. Association between the alpha-adducin Gly460Trp polymorphism and systolic blood pressure in familial combined hyperlipidemia. Am.J Hypertens. 2001;14:1185-1190.

77. Pihlajamaki J, Valve R, Karjalainen L, Karhapaa P, Vaulhkonen I, Laakso M. The hormone sensitive lipase gene in familiall combined hyperlipidemia and insulin resistance. Eur.d. Clin Invest. 2001:31:302-308.

78. Schoonjans $K$, Martin G, Staels $B$, Auwerx J. Peroxisome proliferator-activated receptors, orphans with ligands and functions. Cur. Opin.Lipidol. 1997;8:159-166.

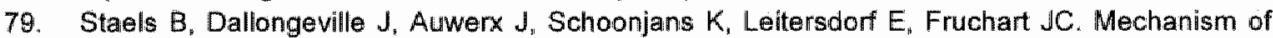
action of fibrates on lipid and lipoprotein metabolism. Circulation. 1998;98:2088-2093.

80. Bredie SJ, de Bruin TWA, Demacker PN, Kastelein JJ, Stalenhoef AF. Comparison of gemfibrozil versus simvastatin in familial combined hyperlipidemia and effects on apolipoprotein-B-containing lipoproteins, low-density lipoprotein subfraction profile, and lowdensity lipoprotein oxidizability. Am.J. Cardiol. 1995;75:348-353.

81. Bredie SJ, Westervell HT, Knipscheer HC, de Bruin TWA, Kastelein JJ, Stalenhoef AF. Effects of gemfibrozil or simvastatin on apolipoprotein-B-containing lipoproteins, apolipoprotein-CIII and lipoprotein(a) in familial combined hyperlipidaemia. Neth.J.Med. 1996;49:59-67.

82. Stefan N, Stumvoll M. Adiponectin - its role in metabolism and beyond. Horm. Metab.Res. 2002:34:469-474.

83. Diatchenko $L$, Lukyanow $S$, Lau $Y F$. Siebert PD. Suppression subtractive hybridization: a versatile method for identifying differentially expressed genes. Methods Enzymal. 1999;303:349-380.

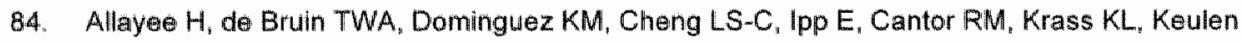
ETP. Aoulzerat BE. Lusis AJ, Rotter JI. Genome-scan for blood pressure in Ductch dyslipidemic families reveals linkage to a locus on chromosome 4p. Hypertension. 2001:38:773-778. 


\section{Chapter 2}

\section{Identification of differentially}

expressed genes in subcutaneous adipose tissue from subjects with Familial Combined Hyperlipidemia

PMH Eurlings, CJH van der Kallen, JMW Geurts, P Kouwenberg. WD Boeckx, TWA de Bruin 


\section{Abstract}

Subjects with familial combined hyperlipidemia (FCHL) are characterized by a complex metabolic phenotype with hyperlipidemia, insulin resistance and central obesity. FCHL is due to impaired adipose tissue function, superimposed on hepatic overproduction of lipoproteins. We investigated adipose tissue as an interesting target tissue for differential gene expression in FCHL. Human CDNA expression array analyses, in which adipose tissue from five $\mathrm{FCHL}$ patients was compared to that from four age, gender and BMI matched controls, resulted in the identification of 22 up-regulated and 3 down-regulated genes. The genes differentially expressed imply activation of the adipocyte cell cycle genes. Furthermore, the differential expression of the genes coding for tumor necrosis factor alpha, interleukin 6 and intracellular adhesion molecule 1, support a role for adipose tissue in insulin resistance in FCHL subjects. The observed changes represent a primary genetic defect, an adaptive response, or a contribution of both. 


\section{Introduction}

Familial Combined Hyperlipidemia ( $\mathrm{FCHL}$; MMM144250) is the most common genetic hyperlipidemia in man. FCHL is characterized by familial clustering of multiple type hyperlipidemia, with clinical manifestations of premature coronary artery disease (CAD), i.e before the age of 60 . Although FCHL was dellineated about 25 years ago, the complex genetics and metabolic phenotypes in FCHL are not fully understood at present. ${ }^{1-7}$ Hypercholesterolemia, hypertriglyceridemia, elevated plasma apolipoprotein $\mathrm{B}(\mathrm{apoB})$ and apoCIII concentrations are found in $\mathrm{FCHL}^{8}$ Studies have shown abnormalities in lipoprotein metabolism of FCHL patients, including hepatic hypersecretion of apoB containing lipoproteins and delayed clearance of atherogenic triglyceride-rich lipoprotein remnants, such as very low density lipoprotein (VLDL) remnants (intermediate density lipoproteins) and chylomicron remnants. ${ }^{8,9}$ Increased hepatic VLDL secretion contributes to elevated plasma triglycerides (TG), apoB, total cholesterol (TC), and low density lipoproteins $(L D L) .{ }^{10}$ The forces behind the increased hepatic lipoprotein secretion have not been identified yet.

Defects in adipose tissue function are believed to contribute to the FCHL phenotype, but the exact mechanisms are poorly understood. Expression of the FCHL phenotype has been shown to depend, in part, on body mass index (BMI), a marker of adipose tissue mass. ${ }^{11}$ In addition. FCHL patients have an abnormal free fatty acid (FFA) metabolism resulting in reduced clearance of FFA from the circulation in the postprandial state. ${ }^{12} \mathrm{FCHL}$ patients are also characterized by impaired insulin-mediated glucose uptake in peripheral tissues, such as muscle, and impaired insulin-mediated removal of plasma FFA. ${ }^{13-15}$ Besides, it has been shown that adipocytes as well as fibroblasts from FCHL patients exhibit an impaired response to the activity of the acylation-stimulating protein (ASP) that stimulates the synthesis of TG in peripheral tissues. ${ }^{16}$ High levels of FFA in the circulation can lead to a decrease in insulin-stimulated glucose uptake in skeletal muscle, as well as an increase in hepatic lipoprotein synthesis. ${ }^{17,18}$

Based on these observations, we investigated adipose tissue as an interesting target tissue for differential gene expression in FCHL using human CDNA expression arrays. Such differentially expressed genes represent good candidate genes or 
provide information about signaling pathways that are involved in FCHL adipocyte dysfunction. The primary data showed a consistently different gene expression pattern in FCHL adipose tissue compared to that from age, gender and BMI matched controls. In total 25 differentially expressed genes were identified in FCHL adipose tissue.

\section{Materials and Methods}

\section{Subjects}

FCHL probands and controls were recruited through the Lipid Clinic of the Maastricht University Hospital. FCHL families were ascertained as previously described. ${ }^{19}$ Briefly, FCHL probands had a primary hyperlipidemia with varying phenotypic expression including (untreated) fasting plasma $\mathrm{TC}>6.5 \mathrm{mM}$ (250 $\mathrm{mg} / \mathrm{dL})$ and fasting plasma $T G$ concentration $>2.3 \mathrm{mM}(200 \mathrm{mg} / \mathrm{dL})$, and a positive family history of premature CAD, i.e. before the age of 60 years. In addition, FCHL probands had no xanthomas, no apo E2/E2 genotype, and normal thyroidstimulating hormone $(\mathrm{TSH})$ concentrations. Obesity $(\mathrm{BMI}>30)$ or diabetes were exclusion criteria for the ascertainment of an $\mathrm{FCHL}$ proband. ${ }^{13}$ The affected FCHL subjects in the present study had each been ascertained as an affected FCHL relative in a FCHL family that contained at least two other first-degree relatives with a cholesterol and/or TG exceeding the above-mentioned diagnostic values. Pedigree analyses showed evidence of the multiple lipoprotein phenotype phenomena meaning that different relatives show different lipoprotein phenotypes (Ila, $\| \mathrm{b}_{\text {" }}$ or IV).

The control subjects had a fasting glucose $<5.5 \mathrm{mmol} / \mathrm{L}$, fasting $T C<6.5$ $\mathrm{mmol} / \mathrm{L}$, and fasting $T G<2.3 \mathrm{mmol} / \mathrm{L}$, and no family history of $C A D$. The Human Investigation Review Committee of the Academic Hospital Maastricht has approved the study protocol and all subjects gave informed consent.

\section{Sample preparation}

Four unrelated control subjects and five unrelated $\mathrm{FCHL}$ subjects were age, gender and BMI matched. Four FCHL subjects who used lipid-lowering medication 
had stopped their therapy for 14 days in order to obtain untreated plasma and adipose tissue samples. Three subjects used atorvastatin and one simvastatin as lipid lowering therapy. Before starting the procedure, venous blood was drawn in precooled EDTA ( $1 \mathrm{mg} / \mathrm{ml})$ tubes after an overnight fast $(12-14 \mathrm{~h})$ and prepared by immediate centrifugation for analytical analyses. Plasma lipids and glucose were measured as described before. ${ }^{19,20}$ Liposuction samples were taken caudal from the umbilicus under local anesthesia ( $1 \%$ Lidocaine) with a small liposuction cannula (Accelerator III, Byron, California, USA). ${ }^{21}$ From each subject, 3-5 ml adipose tissue was collected and processed immediately. Isolation of adipocytes was based on the method of Rodbell ${ }^{22}$, with minor modifications. Within minutes after obtaining the sample, adipose tissue was cut into small fragments and incubated with $2 \mathrm{mg} / \mathrm{ml}$ collagenase, followed by gently shaking in an incubator (humidified, $5 \% \mathrm{CO}_{2}$ and $95 \%$ air) at $37^{\circ} \mathrm{C}$ for $30-60 \mathrm{~min}$ in $\mathrm{KRBH}$ buffer (Krebs-Ringer bicarbonate

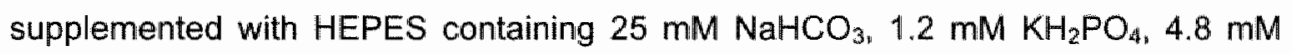
$\mathrm{KCl}, 1.2 \mathrm{mM} \mathrm{MgSO}_{4}, 118 \mathrm{mM} \mathrm{NaCl}, 1.25 \mathrm{mM} \mathrm{CaCl}_{2}$ and $10 \mathrm{mM}$ HEPES, $\mathrm{pH} 7.4$ ) containing $4 \%$ BSA. The cell suspension was then filtered through $500 \mu \mathrm{m}$ nylon mesh and spun at $220 \mathrm{~g}$ for $1 \mathrm{~min}$ to separate stromal vascular cells from mature adipocytes. Isolated adipocytes were washed 3 times with KRBH supplemented with $0.3 \%$ BSA. The purified mature adipocytes were stored in liquid nitrogen until further use.

\section{RNA preparation}

Total RNA extraction was performed using the TRlzol reagent (GibcoBRL, Grand Island, NY) according to the manufacturer's protocol. The RNeasy kit (QIAGEN, Germany) was used for total RNA clean up and its quality was assessed following the manufacturer's instructions. In the experiments $2-3.5 \mu \mathrm{g}$ total RNA was used.

\section{Atlas human cDNA expression array}

The Atlas human CDNA array kit was purchased from Clontech Laboraties (Palo Alto, CA, USA). All procedures for probe labeling were accomplished following the manufacturer's recommendations. Probe purification was done using ProbeQuant ${ }^{\mathrm{TM}}$ G-50 micro columns (Amersham, NJ, USA) according to the manufacturer's 
instructions. The probes were denatured at $95^{\circ} \mathrm{C}$ for 5 minutes. The membranes were hybridized in ExpressHyb solution overnight at $68^{\circ} \mathrm{C}$, washed according to the manufacturer's instructions, and exposed for varying time lengths to an imaging screen (BIORAD, Hercules, CA, USA). Stripping of the membranes was carried out according to the manufacturer's instructions and were re-used up to three times. In a typical experiment an FCHL subject was compared to a matched control subject resulting in a total of 5 experimental pairs.

The intensities of the spots were analyzed using the Quantity One program (BIORAD, CA, USA). Every gene was present in duplicate on the array and the average intensity of the duplicate spots was used for analyses. Gene hybridization intensities were determined after background subtraction. The intensities of the spots were corrected for mean background and mean intensities of the housekeeping genes on each array. First, normalized intensities of corresponding spots were compared between the FCHL array and the control array, but only those spots that were visible on the image and did have a homogenous and round shape were taken into account. Differences were expressed as a ratio of normalized spot intensities on the FCHL array and normalized spot intensities on the control array. The expression was considered differential if there was a 2-fold difference in intensity between the FCHL and control array. $A$ ratio $\geq 2.0$ indicated up-regulation and a ratio $\leq 0.5$ indicated down-regulation. Second, genes were considered differentially expressed in FCHL adipose tissue when in 60\%, or more, of the experiments the gene showed differential expression in the same direction, taking only in account those experiments in which the gene was expressed. Third, a minimum of two experiments with differential gene expression was required.

\section{Results}

The clinical characteristics of the study subjects are presented in Table 2.1. Venous blood was drawn after an overnight fast and the FCHL patients had stopped their lipid lowering medication for two weeks to ensure expression of their hypercholesterolemia and/or hypertriglyceridemia at the time of the abdominal fat biopsy (Table 2.1). Three subjects were hypertriglyceridemic and two were 
hypercholesterolemic. All FCHL subjects had elevated plasma apoB levels $>12 \mathrm{~g} / \mathrm{L}$ and were normoglycemic. Contrals were normolipidemic and nomoglycemic.

Table 2.1 Clinical characteristics study subjects.

\begin{tabular}{lll}
\hline Trait & $\begin{array}{l}\text { FCHL } \\
(\mathbf{n = 5})\end{array}$ & $\begin{array}{l}\text { Control } \\
(\mathbf{n}=4)\end{array}$ \\
\hline Male/Female & $2 / 3$ & $1 / 3$ \\
Age (years) & $52.4 \pm 2.4$ & $50.5 \pm 7.6$ \\
BMI & $25.7 \pm 1.4$ & $25.8 \pm 1.0$ \\
TG (mmol/L) & $2.25 \pm 0.89$ & $1.26 \pm 0.54$ \\
TC (mmol/L) & $6.4 \pm 0.7$ & $4.9 \pm 0.7$ \\
HDL-C (mmol/L) & $0.79 \pm 0.13$ & $0.92 \pm 0.05$ \\
Glucose (mmol/L) & $4.94 \pm 0.62$ & $5.14 \pm 0.24$ \\
FFA (mmol/L) & $0.35 \pm 0.18$ & $0.23 \pm 0.25$ \\
ApoAl (g/L) & $1.46 \pm 0.25$ & $1.35 \pm 0.07$ \\
ApoB (g/L) & $1.39 \pm 0.16$ & $0.86 \pm 0.21$ \\
\hline
\end{tabular}

Data represent mean \pm standard deviation $(S D)$.

Table 2.2 Comparison of the relative housekeeping gene intensities between the FCHL expression arrays and control expression arrays

\begin{tabular}{lcc}
\hline Housekeeping gene & FCHL (\%) & Spouses (\%) \\
\hline & $59.8 \pm 3.2$ & $64.5 \pm 4.2$ \\
Ubiquitin & $18.7 \pm 3.6$ & $15.2 \pm 3.2$ \\
GAPDH & $5.6 \pm 2.5$ & $4.4 \pm 1.9$ \\
ACTB & $13.8 \pm 2.6$ & $13.2 \pm 1.6$ \\
$23-k D a$ & $2.7 \pm 1.4$ \\
40S ribosomal protein & $2.1 \pm 0.8$ & 100 \\
\hline Total signal & 100 & \\
\hline
\end{tabular}

Data represent mean \pm SD. GAPDH, liver glyceraldehydes 3-phosphate dehydrogenase. ACTB, cytoplasmatic beta-actin. 
Clontech's Allas human CDNA expression arrays were used to screen for differential gene expression in FCHL adipose tissue, compared to age, gender and BMI matched conitrols. These arrays allowed the direct screening of 588 cDNAs, each spotted in duplicate in six functional quadrants. The membranes were hybridized with cDNA samples prepared from 2-3.5 $\mu \mathrm{g}$ total RNA from each FCHL and spouse control adipose tissue sample. Of the 588 genes spotted on a single Atlas expression array, on average $174(30 \%)$ genes showed detectable, i.e. visible, levels of expression, whereas $414(70 \%)$ genes were not expressed at detectable levels in adipocytes. As seen in Figure 2.1, the average expression ratios from the five experimental pairs have a gaussian distribution indicating that the arrays provided good quality results. Five of the nine housekeeping genes on the blot were expressed at detectable levels in adipose tissue. Ubiquitin had the highest and $40 \mathrm{~S}$

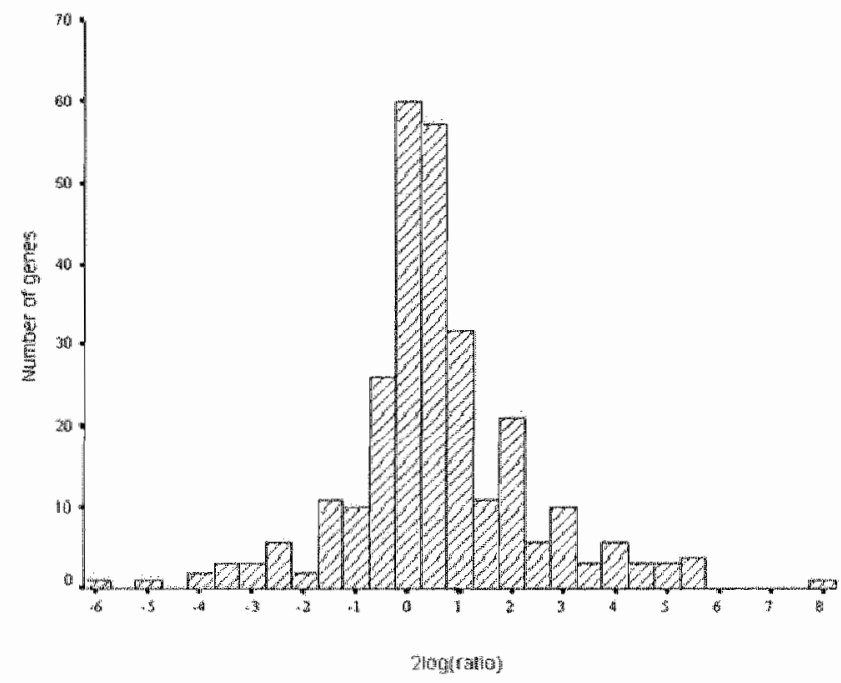

Figure 2.1 Quality assessment of the differential gene expression analyses.

The average expression ratios of the FCHL adipose tissue arrays versus the control adipose tissue arrays are plotted as ${ }^{2} \log ($ ratio). The gaussian distribution of the ratios illustrates that the experiments were of good quality. 
ribosomal protein the lowest expression level (Table 2.2). As expected, these housekeeping genes had similar and comparable relative intensities on the FCHL and control expression arrays, indicating that there is little variability in housekeeping gene expression between FCHL adipose tissue and that of controls (Table 2.2). These data support the reproducibility and reliability of the assay.

In total, 25 differentially expressed genes were identified. Table 2.3 lists all genes that fulfilled the criteria for differential expression in $\mathrm{FCHL}$ adipose tissue. The data are presented as signal intensities that were equal, or greater, than two-fold compared to the intensity of expression on the control array (up-regulation). Alternatively, the data are given as signal intensities that were equal or smaller than 0.5 -fold compared to the control array. Table 2.3 illustrates, for all five experimental pairs, whether a gene is up-regulated, down-regulated, not differentially expressed, or is not expressed at a detectable level. Figure 2.2 shows corresponding segments of an FCHL array and a control array, visually illustrating some of the observed differences in adipose tissue gene expression. It is important to note that the five experiments resulted in the identification of a consistent and uniform genetic fingerprint in $\mathrm{FCHL}$ adipose tissue that also showed consistent differences with the gene expression pattern observed in matched spouse controls.

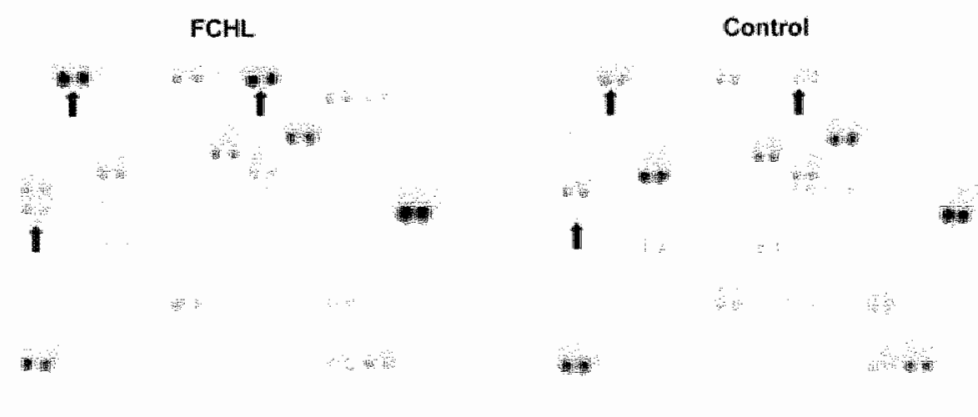

Figure 2.2 Gene expression fingerprint of FCHL adipose tissue.

The arrows indicate a subset of differentially expressed genes in FCHL. 


\section{Dilscussion}

In the present study the CDNA macro-array technique was used to identify candidate genes or signaling pathways for (subcutaneous) adipocyte dysfunction in $\mathrm{FCHL}$. It has been suspected that impaired function of adipose tissue can contribute to the FCHL phenotype by inadequate incorporation of FFA into TG in adipocytes. ${ }^{12.23-25}$ The resulting increased FFA flux can contribute to increased hepatic lipoprotein production as well as reduced insulin mediated glucose uptake and are both known FCHL phenotypes. ${ }^{17.23}$ To our knowledge we are the first to report on the identification of differentially expressed genes in FCHL adipose tissue using this approach. In total, 25 differentially expressed genes were identified in FCHL adipose tissue, of which 22 were up-regulated and 3 were down-regulated. This is a first approximation of the differential gene expression in FCHL adipose tissue given the limited number of genes tested.

A large subset of the differentially expressed genes identified in the present study play a prominent role in cell growth, i.e. c-Myc, c-Jun, G1/S-specific cyclin D1 (CCDN1), G1/S-specific cyclin D2 (CCDN2), DNA binding protein inhibitor ID1, DNA damage-inducible transcript 1 (GADD45), early growth response protein 1 (EGR1), cyclin-dependent kinase inhibitor $1 \mathrm{~A}$ (CDKN1A), and epidermal growth factor receptor $v$-erb-b2 erythroblastic leukemia viral oncogen homolog 3 (ERBB3). Each gene product is directly or indirectly involved in the transition of the cell cycle from the $\mathrm{G} 1$ to the $S$ phase. ${ }^{26-30}$ However, the function of these genes in cell cycle regulation of (pre)adipocytes, at least to our knowledge, has not been studied yet. Based upon the observation that c-Myc, C-Jun, CCDN1, CCDN2, ID1, and ERBB3, which stimulate cell cycle transition, are up-regulated in FCHL adipose tissue and that GADD45, which inhibits entry of cells into $S$ phase, is down-regulated, indicate cell cycle gene activation of subcutaneous adipocytes in FCHL subjects most likely due to hyperplasia. The fact that CDKN1A, an inhibitor of G1/S phase transition, ${ }^{31}$ is

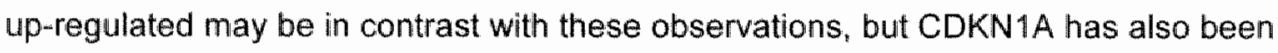
shown to act as a stimulator of cell growth, and, moreover, its role in adipocytes has not been described. Subcutaneous adipose tissue mass in FCHL is expanded, ${ }^{18}$ however, it is unknown whether this is due to increased adipocyte cell mass or cell 
Table 2.3 Evaluation of genes differentially expressed in FCHL adipose lissue.

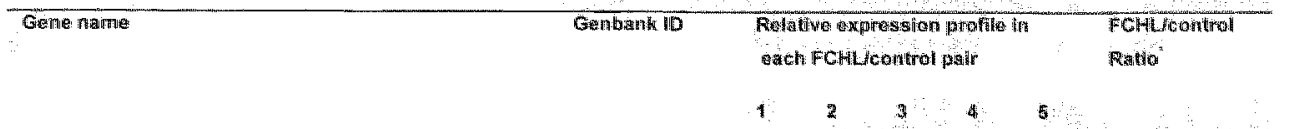

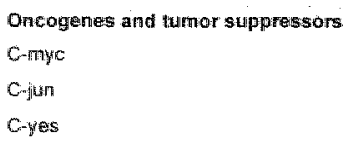

\begin{tabular}{|c|c|c|c|c|c|c|}
\hline W00568 & + & * & * & + & 9 & $76 \div 109$ \\
\hline 504111 & $*$ & 0 & 4 & o & *. & $3.5+3$ \\
\hline$M 15990$ & $x$ & x & $x$ & 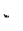 & - & $0.3 \pm 0.9$ \\
\hline M74088 & $x$ & $\mathrm{x}$ & 4 & $x$ & * & 80.78 \\
\hline \multicolumn{7}{|l|}{$M 73548$} \\
\hline D13869 & + & $x$ & 4 & $x$ & in & $3.2+0$ \\
\hline $459798:$ & + & + & + & $a$ & 4 & $4.2 \pm 25$ \\
\hline \multicolumn{7}{|l|}{104349} \\
\hline M90813;013639 & + & $+*$ & 0 & - & + & 29.23 \\
\hline L25124: D28472 & $x$ & + & 4 & $x$ & $\mathrm{x}$ & 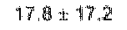 \\
\hline U05875 & $x$ & *t. & + & $x$ & $x$ & $4.8 \pm 0.5$ \\
\hline$x 01394$ & 4 & $x$ & $*$ & 4 & $x$ & $130 \times 7.6$ \\
\hline$\times 86779$ & $x$ & $*$ & * & $x$ & $a$ & 201.3 \\
\hline U32944:4 & + & $*$ & it: & o & a & $1.7+0.9$ \\
\hline A60974 & $x$ & - & $x$ & $x$ & - & $0.04+0.02$ \\
\hline 1.04282 & $x$ & * & $n$ & $x$ & \% & $0.4 \pm 0.2$ \\
\hline$\times 5254: M 62029$ & + & + & H. & 4 & a & 6.4 .7 \\
\hline 46283 & + & * & * & a & *⿻ & $2.6 \pm 1.4$ \\
\hline บ09579, L25610 & + & 0 & in & + & * & $3.8 \pm 27$ \\
\hline M29366 & + & 0 & 4 & * & i- & 60.85 \\
\hline \multicolumn{7}{|l|}{$M 34309$} \\
\hline 005623 & $x$ & $x$ & * & $x$ & 4 & 0.615 .6 \\
\hline M65928 & 4 & $x$ & $*$ & 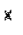 & $x$ & $207+26.0$ \\
\hline .093132 & + & .. & * & + & 0 & $2250 \times 504.4$ \\
\hline 433374 & + & it & 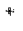 & a & - & $4,1: 3.2$ \\
\hline M245 54 & + & 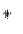 & ; & 4 & a & $11.6+102$ \\
\hline$\times 53799$ & + & $\#$ & $x$ & $*$ & - & $32+24$ \\
\hline$\times 04602 ; M 14584$ & $*$ & 0 & $*$ & 舟 & a & $2.2 \pm 1.4$ \\
\hline
\end{tabular}

Relative expression profille of each FCHU/control pair ( 1 10 5 ) illustratles whether a gene is up-regulated ( 4 ; FCHL/control ratio 2.0), down-regulated ( - FCHL/Conitrol ratio 0.5$)$, nof differentially expressed $(0 ; 0.5>\mathrm{FCH} / \mathrm{Con}$ trol ratio 2.0 ), or not expressed at a detectable level $(x)$. Data represent mean if 50 . 
number. We recently reported that BMI, a marker of adiposity, affects the expression of hyperlipidemia in FCHL. ${ }^{\text {it }}$ Continuously increased delivery of lipoproteins and their remnants from plasma to adipocytes in FCHL may increase cell cycle gene expression in order to accommodate the persistent lipid supply. Therefore the subset of cell cycle regulators differentially expressed in FCHL may reflect hyperplasia of adipocytes. This proposed mechanism does not imply that the compensatory hyperplasia of adipocytes is sufficient to maintain normal lipid or FFA metabolism in FCHL.

Impaired insulin action has been reported in $\mathrm{FCHL}^{13-15}$, and has been linked to altered metabolism of FFA ${ }^{23-25}$ and impaired reactivity of adipocyte lipolysis. ${ }^{32}$ Tumor $^{2}$ necrosis factor alpha (TNFa) gene expression was shown, in the present study, to be up-regulated in FCHL adipose tissue. It is of interest that the role of TNFa in the development of insulin resistance (IR) has been well dlocumented ${ }^{33}$, and a link between the TNFa signaling pathway and FCHL has recently been reported. ${ }^{20,34}$ TNF $\alpha$ is known to impair insulin signaling in adipose tissue through inhibition of the insulin receptor tyrosine kinase. ${ }^{35}$ TNF $\alpha$ also inhibits lipoprotein lipase (LPL) and stimullates lipolysis in adipocytes ${ }^{36}$, although there are conflicting data whether LPL activity is affected in FCHL. ${ }^{24,37}$ TNF $\alpha$ is also known to induce the synthesis of other proinflammatory molecules such as interleukin $6(\mathrm{IL}-6)^{38}$, and increased plasma IL-6 levels have been associated with $I_{R}{ }^{39-41} \|$ is interesting that IL-6 gene expression was clearly up-regulated in FCHL adipose tissue. Additionally, the interferon $\gamma$ receptor 2 (IFNGR2) was also up-regulated in FCHL adipose tissue, and IFN-y signaling has been shown to increase plasma IL-6. ${ }^{42}$ Interestingly, ICAM1, whose gene expression was also up-regulated in FCHL adipocytes in the present study, has been shown to be involved in insulin resistance through the TNFa system as well. ${ }^{43}$ Combined the differential gene expression of TNF $\alpha$, IL-6, IFNGR2, and ICAM1 in FCHL indicates common denominators in adipose tissue insulin resistance, or the existence of a pro-inflammatory state in $\mathrm{FCHL}$.

The fact that the observed changes in adipose tissue gene expression were consistent among the agle, gender and BMI matched FCHL/control pairs generates new perspectives for future research. Combined with results from FCHL genomewide screens, gene expression data can help to distinguish primary genetic FCHL defects from adaptive changes in $\mathrm{FCHL}$. Such a genomics approach has proven 
useful in other complex diseases such as hypertension ${ }^{44}$ and diabetes ${ }^{45}$; and will be instrumental for FCHL in the near future. The current data cannot distinguish between genes differentially expressed as a result of an adaptive response to hyperlipidemia or a genetic predisposition to $\mathrm{FCHL}$. Therefore, although beyond the scope of the present study. FCHL adipose tissue gene expression should be compared to that of subjects with a different hyperlipidemic disorder such as familial hypercholesterolemia or type 2 diabetes mellitus. On the other hand, in case that the observed changes in adipose tissue gene expression are specific for $\mathrm{FCHL}$, it offers the potential to diagnose FCHL with more certainty in individuals without a family study "providing a new tool for genetic and pathophysiological studies.

In conclusion, our results demonstrate a clear and consistent difference in gene expression in FCHL adipose tissue compared to that from matched healthy controls. Some of the genes identified point towards changes in adipose tissue activation of cell cycle genes. Additionally, genes previously described in other insulin resistance states are differentially expressed in FCHL. The present data show that gene expression analyses represent a useful tool to gain more insight into organ specific gene expression in a human complex disease such as FCHL. The question remains whether the observed changes in gene expression represent the results from a primary genetic defect or an adaptive response. 


\section{References}

1. Goldstein JL, Schrott HG, Hazzard WR, Bierman EL, Motulsiky AG. Hyperlipidemia in coronary heart disease. II. Genetic analysis of lipid levels in 176 familles and delineation of a new inherited disorder, combined hyperlipidemia. J.Clin. Invest. 1973;52:1544-1568.

2. Cullen $P$, Farren $B$, Scott $d$, Farrall M. Complex segregation analysis provides evidence for a major gene acting on serum triglyceride levels in 55 British families with familial combined thyperlipidemia. Arterioscler. Thromb. Vasc.Biol. 1994;14:1233-1249:

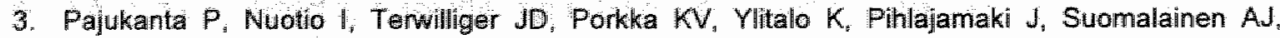

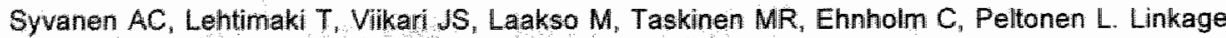
of famillial combined hyperlipidaemia to chromosome 1q21-q23. Nat. Genet. 1998;18:369-373.

4. Pajukkanta P, Terwilliger JD, Perola M, Hiekkalinna T, Nuotio I, Ellonen P, Parkkonen M, Hartiala J. Ylitalo K, Pihlajamaki $J$, Porkka $K$, Laakso M, Viikari J, Ehntholm C, Taskinen MR, Peltonen L. Genomewide scan for familial combined hyperlipidemia genes in finnish families, suggesting multiple susceptibility loci influencing triglyceride, cholesteral, and apolipoprotein B levels. Am. J Hum Genet. 1999;64:1453-1463.

5. Acuizerat $B E$, Allayee $H_{4}$ Cantor $R M$, Davis $R C$, Lanning $C D$, Wen $P Z$, Dallinga-Thie $G M$, de Bruin TWA, Rotter Jl, Lusis AJ. A genome scan for familial combined hyperlipidemia reveals evidence of linkage with a locus on chromosome 11. Am.J.Hum Genet. 1999;65:397-412.

6. Aouizeral BE, Allayee $H$, Cantor RM, Dallinga-Thie GM, Lanning CD, de Bruin TWA, Lusis AN, Ratter Jl. Linkage of a candidate gene locus to familial combined hyperlipidemia - Lecithin : cholesterol acyltransferase on 16q. Arterioscler. Thromb. Vasc. Biol. 1999;19:2730-2736.

7. Eurlings PMH, van der Kallen CJH, Geurts JMW, van Greevenbroek MMJ, de Bruin TWA. Genetic dissection of familial combined hyperlipidemia. Mol. Genet.Metab. 2001;74:98-104.

8. de Graaf $J_{s}$ Stalenhoef AF. Defects of lipoprotein metabolism in familial combined hyperlipidaemia. Curr. Opin Lipidol. 1998;9:189-196.

9. Castro-Cabezas $M$, de Bruin TWA, Jansen $H$, Kock LA, Kortlandt $W$, Erkelens DW. Impaired chylomicron remnant clearance in familial combined hyperlipidemia. Arterioscter. Thromb. Vasc. Biol. 1993:13:804-814.

10. Taskinen MR, Caslake MU, Packard C.J. Lipoprotein metabolism in FCHL. Eur.J.Clin.Inwest. 2001:31 Suppl 1:4-4.

11. van der Kallen CJH, Cantor RM, van Greevenbroek MMJ, Geurts JMW, Bouwman FG, Aouizerat BE, Allayee $H$, Buurman WA, Lusis AJl, Rotter $J l$, de Bruin TWA. Genome scan for adiposity in Dutch dyslipidemic families reveals novel quantitive trait loci for leptin, body mass index and soluble turmor necrosis factor receptor superfamily 1A. Mnt.J.Obes.Relat.Metab. Disord. $2000 ; 24: 1381-1391$.

12. Castro-Cabezas $M$, de Bruin TWA de Valk HW, Shoulders CC, Jansen H, Erkelens DW. Impaired fatty acid metabolism in familial combined hyperipidemia. A mechanism associating hepatic apolipoprotein B overproduction and insulin resistance. J.Clin./7vest. 1993:92:160-168.

13. Aitman $T J$, Godsland $I F$, Farren $B$, Crook $D$, Wong $H J$, Scott $J$. Defects of insulin action on fatty acid and carbohydrate metabolism in familial combined hyperlipidemia. Arterioscler. Thromb. Vasc. Biol. 1997;17:748-754.

14. Bredie SJ. Tack $C J$, Smits P. Stalenhoef AF. Nonobese patients with familial combined hyperlipidemia are insulin resistant compared with their nonaffected relatives. Artorioscher. Thromb. Vasc. Biol. 1997;17:1465-1471.

15. Karjalainen L, Pihlajamaki J, Karhapaa P, Laakso M. Impaired insulin-stimulated glucose oxidation and free fatty acid suppression in patients with familial combined hyperlipidemia: a precursor ciefect for dyslipidemia? Arterioscler. Thromb. Vasc. Biol. 1998; 18:1548-1553.

16. Kwiterovich-PO J, Motevalli M, Miller M. The effect of three serum basic proteins on the mass of lipids in nomall and hyperapoB fibroblasts. Arterioscler. Thromb. Vasc. Biol 1994;14:1-7.

17. Lewis GF, Steiner $G$. Acute effects of insulin in the control of VLDL production in humans. Implications for the insulin-resistant state. Diabetes Care. 1996:19:390-393. 
18. Pumell JQ, Kahn SE, Schwartz RS, Brunzell JD. Relationship of Insulin Sensitivity and ApoB levels to Intra-abdominal Fat in Subjects with Familial Combined Hyperlipidenia. Arterioscler. Thromb. Vasc. Biol. 2001;21:567-572.

19. Keulen ETP, Krujjshoop M, Schaper NC, Hoeks APG, de Bruin TWA. Increased intima-media thickness in Familial Combined Hyperlipidemia associated with apolipoprotein $B$. Arterioscler. Thromb. Wasc.Biol 2002;22:283-288.

20. Geurts JMW, Janssen RGJH, van Greevenbroek MMJ, van der Kallen CJH, Cantor RM, Bu $X_{\text {, }}$ Aouizerat BE, Allayee $\mathrm{H}$, Rotter Jl, de Bruin TWA. Identification of TNFRSFUB as a novel modifier gene in familiall combined hyperlipidemia. Hum Mol Genet 2000;9:2067-2074.

21. Kolaczynski JW, Morales LM, Moore JH, Considine RV, Pietrzkowski Z, Noto PF, Colberg J, Caro JF. A new technique for biopsy of human abdominal fat under local anaesthesia with Lidocaine. Int I. Obes. Relat. Metab. Disord. 1994;18:161-166.

22. Rodbell M. Metabolism of isolated fat cells. I. Effects of hormones on glucose metabilism and lipolysis. J.Biol.Chem. 1964;239:375-380.

23. Meijssen $S$, Castro-Cabezas $M_{4}$ Twickler TB, Jansen $H_{4}$ Eikelens DW. In vivo evidence of defective postprandial and postabsorptive free fatty acid metabolism in familial combined hyperlipidemia. J.Lipid Res. 2000;41:1096-1102.

24. Reynisdottir $S$, Angelin $B$, Langin $D$, Lithell $H$, Eriksson $M$, Holm $C$, Arner $P$. Adipose tissue lipoprotein lipase and hormone-sensitive lipase. Contrasting findings in familial combined hyperlipidemia and insulin resistance syndrome. Arterioscler. Thromb. Vasc. Biol. 1997;17:2287. 2292

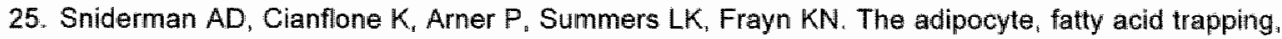
and atherogenesis. Arterioscler. Thromb. Vasc.Biol. 1998;18:147-151.

26. Shaulian E, Karin M. AP-1 in cell proliferation and survival. Oncogene. 2001;20:2390-2400.

27. Prabhu S, Ignatova A, Park ST, Sun XH. Regulation of the expression aff cyclin-dependent kinase inhibitor p21 by E2A and Id proteins. Mol. Cell Biol. 1997;17:5888-5896.

28. Smith ML, Chen IT, Zhan Q, Bae I, Chen CY, Gilmer TM, Kastan MB, O'Connor PM, Fornace AJ. Interaction of the p53-regulated protein Gadd45 with proliferating cell nuclear antigen. Science. $1994: 266: 1376-1380$.

29. Sherr CJ. Cancer cell cycles. Science. 1996;274:1672-1677.

30. Lange $\mathrm{CA}_{n}$ Richer $J \mathrm{~K}$, Shen $T$, Horwitz KB. Convergence of progesterone and epidermal growth factor signaling in breast cancer. Potentiation of mitogen-activated protein kinase pathways. J.Biol. Chem. 1998;273:31308-31316.

31. DimCunto F, Topley G, Calautti E, Hsiao J, Ong L, Seth PK, Dotto GP. Inhibitory function of p21Cip1MAF1 in differentiation of primary mouse keratinocytes independent of cell cycle control. Science. 1998;280:1069-1072.

32. Reynisdottir $S$, Eriksson $M$. Angelin $B$, Arner $P$. Impaired activation of adipocyte lipolysis in familial combined hyperlipidemia. J.Clin. Invest. 1995:95:2161-2169.

33. Peraldi $P$, Spiegelman B. TNF-alpha and insulin resistance: summary and future prospects. Mol. Cell Biochem. 1998;182:169-175.

34. van Greevenbroek MMJ, van der Kallen $C . J H$, Geurts JMW, Janssen RG, Buurman WA, de Bruin TWA. Soluble receptors for tumor necrosis factor-alpha (TNF-R p55 and TNF-F $p 75$ ) in familial combined hyperlipidemia. Atherosclerosis. 2000;153:1-8.

35. Hotamisligil GS, Budavari A, Murray D. Spiegelman BM. Reduced typosine kinase activity of the insulin receptor in obesity-diabetes. Central role of tumor necrosis factor-alpha. J.Clin.invest. 1994:94:1543-1549.

36. Patton JS, Shepard HM, Wilking H. Lewis G, Aggarwal BB, Eessalu TE "Gavin LA, Grunfeld C Interferons and tumor necrosis factors have similar catabolic effects on 3 T 3 L1 cells. Proc. Nath.Acad Sci.U.S.A. 1986;83:8313-8317

37. Babirak SP, Brown BG, Brunzell JD. Familial combined hyperlipidemia and abnormal lipoprotein lipase. Arterioscler. Thromb. Vasc.Biol. 1992:12:1176-1183.

38. Tracey $\mathrm{KJ}$, Cerami A. Tumor necrosis factor, other cytokines and disease. Annu.Rov.Cell Biol. $1993 ; 9317-43: 43$ 
39. Pickup JC, Chusney GD, Mattock MB. The innate immune response and type 2 diabetes: evidence that leptin is associated with a stress-related (acute-phase) reaction. Clin Endocrinol (Oxf). 2000,52:107:112.

40. Fried SK. Bunkin DA, Greenberg AS. Omental and subcutaneous adipose tissues of abese subjects release interletukin-6: depot difference and regulation by glucocorticoid. J. Clin. Endachinol Metab. 1998;83:847-850.

41. Wgontzas AN, Papanicolaou DA, Bixler EO, Kales A, Tyson K, Chrousos GP. Elevation of plasma cytokines in disorders of excessive daytime sleepiness role of sleep disturbance and obesity. AClin Endocrinol Metab. 1997;82:1313-1316.

42. de Metz J, Sprangers F, Endert E, Ackermans MT, ten-Berge IJ, Sauerwein HP. Romijn JA. Interferon-gamma has immunomodulatory effects with minor endacrine and metabolic effects in humans. J.Appl.Physiol: 1999;86:517-522.

43. Straczkowski M, Lewczuk P, Dzienis-Straczkowska S, Kowalska I, Stepien A, Kinalska I. Elevated soluble intercellular adhesion molecule- 1 levels in obesily: relationship to insulin resistance and tumor necrosis factor-alpha system activity. Metabolism. 2002; 51:75-78.

44. Aitman TJ, Glazier AM; Wallace CA, Cooper LD, Norsworthy PJ, Wahid FN, AI MK, Trembling

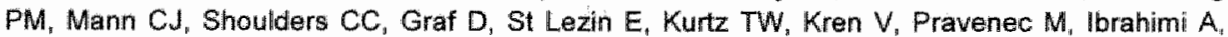
Abumrad NA, Stanton LW, Scott J. Identification of Cd36 (Fat) as an insulin-resistance gene causing defective fatty acid and glucose metabolism in hypertensive rats. Nat.Genet. $1999 ; 21: 76-83$ 


\section{Chapter 3}

\section{New candidate genes for adipose}

\section{tissue dysfunction in Familial \\ Combined Hyperlipidemia.}

PMH Eurlings " CJH van der Kallen, JMW Geurts, R Kuijs "CTA Evelo,

L Nanhekhan, WD Boeckx, TWA de Bruin 


\section{Abstract}

Familial Combined Hyperlipidemia ( $\mathrm{FCHL}$ ) is a common genetic lipid disorder of which the complex genetics and metabolic phenotypes are not fully undersiood at present. Impaired adipose tissue function is believed to contribute to the $\mathrm{FCHL}$ phenotype, predominantly through altered free fatty acid (FFA) metabolism. The aim of the present study was to identify new candidate genes for adipose tissue dysfunction using a combination of suppression subtractive hybridization ( $\mathrm{SSH}$ ) and macroarray technology. Comparison of subcutaneous adipose tissue from five unrelated hyperlipidemic FCHL subjects with five unrelated, normolipidemic, age and BMI matched control subjects resulted in the identification of 129 differentially expressed genes and gene products. The present findings illustrate that, in a heterogeneous disease such as FCHL, a consistent gene expression profile can be found among affected subjects. The genes differentially expressed imply inactivation of pro-apoptotic genes. Moreover, differential gene expression of genes involved in insulin signaling and fatty acid beta-oxidation, support the general finding of altered FFA metabolism in FCHL adipose tissue. 


\section{Introduction}

Familial Combined Hyperlipidemia ( $F C H L$ ) is a common genetic lipid disorder characterized by multiple type hyperlipidemia and a substantially, 5-fold, elevated risk of coronary artery disease (CAD). ${ }^{1.2}$ Several chromosomal locil $i^{3.6}$ as well as candidate genes ${ }^{7.9}$ have been shown to contribute to $\mathrm{FCHL}$, but the complex genetics and metabolic phenotypes are still not fully understood at present. There is evidence however that impaired function of adipose tissue can contribute to the FCHL phenotype by inadequate incorporation of free fatty acids (FFA) into triglycerides $(T G) .{ }^{10-13}$ It has been shown that adipocytes as well as fibroblasts from FCHL patients exhibit impaired acylation of $\mathrm{TG}^{14}$, and that $\mathrm{FCHL}$ adipocytes have a defect in adipocyte FFA re-esterification. ${ }^{15}$ The resulting post-prandially increased FFA flux can contribute to increased hepatic lipoprotein production as well as reduced insulin mediated glucose uptake, both hallmark characteristics of the FCHL phenotype. ${ }^{12,16}$

Based on these observations, adipose tissue is an interesting target tissue for differential gene expression. In our laboratory, we use three complementary strategies to identify differentially expressed genes in FCHL adipose tissue ${ }^{17}$ : (i) suppression subtractive hybridization (SSH), (ii) commercially available cDNA expression filters, (iii) DNA microarray technology. We recently showed, using commercially available cDNA expression filters, that consistent differences in gene expression exist in subcutaneous adipose tissue from unrelated FCHL subjects in comparison to that of matched controls. ${ }^{18}$ Based upon the highly heterogeneous character of $\mathrm{FCHL}$, it was highly surprising but an interesting finding that there is little variation in gene expression between $\mathrm{FCHL}$ subjects. Moreover, these findings suggest an important role for adipose tissue in the pathophysiology of FCHL. The aim of the present study was to identify differentially expressed genes in FCHL. adipose tissue using a combination of suppression subtractive hybridization $(\mathrm{SSH})^{19}$ and analyses of conceptual cardiovascular candidate genes, in order to obtain novel candidate genes for FCHL adipose tissue dysfunction. A total of $369 \mathrm{SSH}$ clones and 371 conceptual cardiovascular candidate genes were analyzed. The obtained data show a reproducible differential gene expression pattern in $\mathrm{FCHL}$ adipose tissue compared with that from age and BMI matched controls. In total, 129 differentially 
expressed genes were identified in FCHL adipose tissue, of which 113 were newly isolated using the $\mathrm{SSH}$ technique and 16 were chosen conceptual cardiovascular candidate genes.

\section{Materials and Methods}

\section{Subjects}

FCHL probands and controls were recruited through the Lipid Clinic of the Maastricht University Hospital. FCHL families were ascertained as previously described. ${ }^{20}$ Briefly, probands had a primary hyperlipidemia with a varying phenotypic expression including a fasting plasma total cholesterol (TC) $>6.5 \mathrm{mmol} / \mathrm{L}$ (250 $\mathrm{mg} / \mathrm{dL}$ ) and/or a fasting plasma $T G>2.3 \mathrm{mmol} / \mathrm{L}(200 \mathrm{mg} / \mathrm{dL})$. The affected FCHL subjects had each been ascertained as an affected $\mathrm{FCHL}$ relative in a FCHL family that contained at least two other first-degree relatives with a TC and/or TG

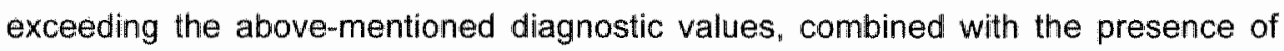
CAD within the family. ${ }^{21}$ The control subjects had a fasting glucose $<5.5 \mathrm{mmol} L$, fasting $T C<6.5 \mathrm{mmol} / \mathrm{L}$, and fasting $T G<2.3 \mathrm{mmol} / \mathrm{L}$, and no family history of $C A D$. The Human Investigation Review Committee of the Academic Hospital Maastricht has approved the study protocol and all subjects gave informed consent.

\section{Blood and adipose tissue sample preparation}

Seven unrelated control subjects and seven unrelated FCHL subjects were age and BMI matched. Five out of seven FCHL subjects used lipid-lowering medication, and had stopped their therapy for 14 days in order to obtain hyperlipidemic plasma samples. Three subjects used atorvastatin, one had simvastatin, and one used pravastatin as lipid lowering therapy. Before starting the procedure, venous blood was drawn, after an overnight fast $(12-14 \mathrm{~h})$, in pre-cooled EDTA (1 $\mathrm{mg} / \mathrm{ml})$ tubes and prepared by immediate centrifugation for analytical analyses and stored at -20 ${ }^{\circ} \mathrm{C}$. Plasma lipids, lipoproteins and glucose were measured as described before. ${ }^{20}$ Liposuction samples were taken caudal from the umbilicus under local anesthesia (1\% Lidocaine) with a small liposuction cannula (Accelerator III, Byron, California, 
USA). From each subject, $3-5 \mathrm{ml}$ of adipose tissue were collected and processed immediately, Isolation of adipocytes was performed exactly as described. ${ }^{18}$

\section{RNA preparation}

Total RNA extraction was performed using the TRIzol reagent (GibcoBRL, Grand Island, NY) according to the manufacturer"s protocol. Subsequently, the RNeasy kit (QIAGEN, Germany) was used for total RNA clean up and the quality was assessed following the manufacturer's instructions.

\section{Suppression Subtractive Hybridization}

Total RNA isolated from human subcutaneous adipose tissue prepared from a single FCHL subject and a single BMI and gender matched control subject, was used for suppression subtractive hybridization. The SMART PCR CDNA Synthesis Kit (Clontech, Palo Alto, CA, USA) was used for preparation and amplification of double stranded CDNA according to the manufacturer's instructions. Subtractive hybridization was carried out using the PCR-Select cDNA Subtraction Kit (Clontech), according to the manufacturer's instructions. The amplified differentially expressed CDNAs were gel-purified using the QIAEX gel subtraction kit (QIAGEN), and cloned into the pGEMT-easy vector before transformation into highly competent Escherichia coli JM109 cells (Promega, Leiden, The Netherlands). In the present study 369 clones were randomly selected for analyses.

\section{Sequencing}

The SSH clones were sequenced using the T7 and SP6 primers and the Dye Terminator Sequencing Kit (Applied Biosystems, Nieuwerkerk a/d IJssel, The Netherlands) on an ABI310 genetic analyzer (Applied Biosystems).

As a quality control check, 32 of the 271 commercially obtained clones were sequenced, using the Dye Terminator Sequencing Kit (Applied Biosystems) and M13 primers, to verify their CDNA content. In all, $15 \%$ of the clones did not contain the insert guaranteed by the supplier. Therefore, all differentially expressed commercial 
clones, and all clones relevant to the present study based on their biological function, even when not differentially expressed, were sequence verified.

\section{Sequence identification of SSH clones}

The identities of the SSH clones were determined in the following way: Sequence files in $A B I$ sequencer format were analyzed using the Staden $2000^{22}$ package. Basecalling with added quality values was performed by the Phred basecaller $r^{23,24}$ from within the Staden preprocessor Pregap4. The sequencer parameter file for Phred was extended with a line describing the sequencing conditions used: "DT POP6\{BD Set-Any Primer\}"; chemistry: "terminator"; dye: "big-dye" and sequencing machine: "ABI_3700". The reads were then clipped for bad quality and for the presence of the vector and adaptor sequences used. Since the number of possible vector and adaptor sequence orientations exceeds the number of orientations that normally occurs in a shotgun-sequencing project, a modified vector_clip module was needed. This was kindly provided by $\mathrm{Dr}$. Rodger Staden (MRC Laboratory of Molecular Biology, Cambridge, UK). These modifications in the vector_clip module became standard in the Staden 2001 release. The cleaned reads were assembled into contigs, thus lowering the number of sequences that needed validation, and increasing the average length of the sequences. A small Perl script was used to list the names of the reads for each contig from the "contigs to readings" output of the Staden contig builder Gap4. Perl scripting was also used to concatenate the remaining contig files and to evaluate them using the megaBLAST ${ }^{25}$ tool on the Unigene $^{26}$ database. MegaBLAST allows for fast BLAST ${ }^{27}$ evaluation of a large number of sequences in a single BLAST run. The megaBLAST results were parsed using a dedicated Perl script, that also adds additional information from the Unigene database using command line SRS. Final, automated steps in the data analyses included the transfer of BLAST contigs with spurious BLAST hits to repeat sequences to a separate table. A total of 8 contigs representing 12 sequence reads containing leucine repeats, Alu repeats, trinucleotide repeats and telomeric repeat binding factor repeats were removed in this way. The remaining data were sorted with respect to the primary Unigene cluster identification number, allowing easy recognition of contigs that are products from the same gene. This approach resulted in the identification of the SSH gene products. 


\section{Macroarray analysis}

Clones derived by SSH and commercially obtained clones, selected based on their putative role in cardiovascular disease, lipid, gllucose or fatty acid metabolism and their availability by the supplier (Research Genetics, AL, U.S.A), were tested for differential expression by macroarray analyses. Inserts were amplified by PCR using the T7/Sp6 primer set or the M13 primer set.

PCR products were purified using a 96-wells PCR filtration system (Millipore. Bedford, USA). Subsequently the PCR products were spotted in duplicate on nylon filters using a BioRobotics gridder (Eurogentec, Seraing, Belgium), and denatured in $0.66 \mathrm{M} \mathrm{NaCL}$ and $0.5 \mathrm{M} \mathrm{NaOH}$, neutralized in $40 \mathrm{mM}$ phosphate buffer $\mathrm{pH} 7.3$, and subsequently UV cross-linked to the membrane. The macro-arrays were hybridized with an $\alpha-{ }^{32} \mathrm{P}[\mathrm{dATP}]$ labeled cDNA probe generated from $10 \mu \mathrm{g}$ of total RNA from either a FCHL or control subject using an oligo(dT) 12.18 $_{18}$ primer using standard procedures. Probe purification was done using ProbeQuant ${ }^{\mathrm{TM}}$ G-50 micro columns (Amersham, NJ, USA). The arrays were preincubated for $30 \mathrm{~min}$ in $5 \mathrm{ml}$ ExpressHyb hybridization solution (Clontech) with denatured salmon sperm DNA $(100 \mu \mathrm{g} / \mathrm{ml}$, Invitrogen, Merelbeke, Belgium) at $55^{\circ} \mathrm{C}$. Subsequently, denatured probes, and 25 $\mu \mathrm{g}$ of CoT-1 DNA (Invitrogen), were hybridized to the arrays for $16 \mathrm{~h}$ at $55^{\circ} \mathrm{C}$. The arrays were washed once with $2 \times S S C / 1 \%$ SDS and twice with $0.1 \times S S C 10.5 \%$ SDS, and exposed for varying time lengths to an imaging screen (BIORAD, Hercules, CA, USA).

\section{Macroarray data analysis}

The radiation-intensities of the spots were analyzed using the Quantity One program (BIORAD) as previously described. ${ }^{18}$ The average intensity of the dupllicate spots was used for analyses. Gene hybridization intensities were determined after background subtraction. The intensities of the spots were corrected for mean background and mean intensity of the housekeeping genes on each array. Only those spots that were visible on the image and did have a homogenous and round shape, and spots that had a variation of less than $15 \%$ with their duplicate spot, were included in the analyses. The expression was considered differential if there was a 2 -folld difference in intensity between the paired FCHL and control array. A 
ratio $\geq 2.0$ indicated up-regulation and a ratio $\leq 0.5$ indicated down-regulation. Genes were considered differentially expressed in $\mathrm{FCHL}$ adipose tissue when in $60 \%$ or more of the experiments the gene showed differential expression in the same direction, with a minimum of three experiments in which the gene was differentially expressed, and taking only into account those experiments in which the gene was expressed.

\section{Reall-Time PCR mRNA confirmation}

Real-time PCR was carried out using the GPCR for SYBR Green Core kit (Eurogentec) on an ABI PRISM 7700 sequence detection system (Applied Biosystems). Primers for CCR4-NOT transcription complex subunit 8 (CNOT8), p-53 responsive gene 3 (PGR3), matrix metalloproteinase 7(MMP7), prostaglandin $E$ receptor 3 (PTGER3) and 18S rRNA were designed using the Primer Express Software (Applied Biosystems):

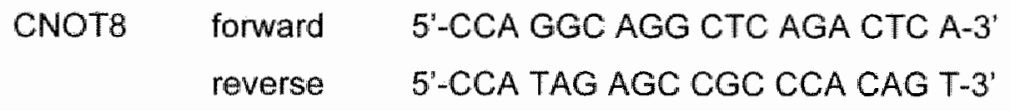

\begin{tabular}{|c|c|c|}
\hline PGR3 & forward & 5'-CAA GCC GGG TGC ACT G-3' \\
\hline & & $5^{\circ}-G A G$ CCG GCC CAC ATA C \\
\hline
\end{tabular}

$\begin{array}{lll}\text { MMP7 forward } & 5^{\prime}-\text { GGA TGG TAG CAG TCT AGG GAT TAA CT-3' } \\ & \text { reverse } & 5^{\prime} \text {-GGA ATG TCC CAT ACC CAA AGA A-3' }\end{array}$

PTGER3 forward 5'-GAC GGC CAT TCA GCT TAT GG-3'

reverse 5'-TGA AGA TCA TTT TCA ACA TCA TTA TCA G-3'

185 IRNA forward 5'-TGC ATG GCC GTT CTT TAG TTG-3'

reverse 5'-AGT TAG CAT GCC AGA GTC TCG TT-3'

Reactions were carried out in $25 \mu$ following the manufacturer's instructions, using final concentrations of $300 \mathrm{nM}$ for the CNOT8, PRG3, MMP7, and PTGER3 primers, 
and $50 \mathrm{nM}$ for the 18S IRNA primers. Target gene MRNA levels were normalized to 18S IRNA and anallyzed using the $2^{-\Delta \Delta C} \mathrm{~T}$ method. ${ }^{28}$ Statistical analyses were carried out by Mann-Whitney test.

\section{Results}

\section{Generation SSH library and FCHL macroarray}

SSH resulted in the generation of both a forward library containing upregulated FCHL clones in subcutaneous adipose tissue and a reverse library containing downregulated clones in $\mathrm{FCHL}$, generated from subcutaneous adipose tissue mRNA from a single FCHL patient and a BMI and gender matched control subject (Table 3.1). In total, 369 clones were selected from both libraries for verification of differential gene expression using macroarrays. In addition, 271 commercially obtained conceptual cardiovascular and metabolic candidate gene clones (Research Genetics) were combined with the $369 \mathrm{SSH}$ clones on a nylon macroarray.

\section{FCHL and control subjects for FCHL macroarray analyses}

The macroarray analyses were performed using five age and BMI matched FCHL/control pairs, and these subjects were different from the pair of subjects used to generate the SSH library. The clinical characteristics of the study subjects are presented in Table 3.2. Venous blood was drawn after an overnight fast. FCHL patients had stopped their lipid lowering medication for two weeks to ensure expression of their hyperlipidemia and/or hypertriglyceridemia at the time of abdominal fat biopsy (Table 3.2). Two FCHL subjects were hypertriglyceridemic, two hypercholesterolemic, and one presented with a combined hyperlipidemic phenotype. Each of the FCHL subjects had characteristically elevated plasma apoB levels $>1.2 \mathrm{~g} / \mathrm{L}$, and were normaglycemic. Control subjects were normolipidemic and normoglycemic. 
Table 3.1 Clinical characteristics of the matched FCHL control pair used for suppression subtractive hybridization.

\begin{tabular}{|c|c|c|}
\hline Trait & FCHL & Control \\
\hline Gender & Female & Female \\
\hline Age (yrs) & 47 & 39 \\
\hline BMI $\left(\mathrm{kg} / \mathrm{m}^{2}\right)$ & 26.8 & 25.0 \\
\hline TG (mmolll) & 2.26 & 0.69 \\
\hline TC (mmolld $)$ & 7.77 & 5.59 \\
\hline HDL-C (mimollL) & 1.08 & 1.41 \\
\hline Glucose (mmol/L) & 5.28 & 5.64 \\
\hline FFA (mmoldL) & 0.35 & 0.47 \\
\hline ApoB (guL) & 1.55 & 0.89 \\
\hline
\end{tabular}

$\mathrm{BMI}_{;}$body mass index, HDL-C; high-density lipoprotein cholesterol, $\mathrm{ApoB}$; apolipoprotein $\mathrm{B}$.

Table 3.2 Clinical characteristics of study subjects used for macroarray and/or real-time PCR analyses of subcutaneous adipose tissue.

\begin{tabular}{lcc}
\hline Trait & $\begin{array}{c}\text { FCHL } \\
(\mathrm{n}=6)\end{array}$ & $\begin{array}{c}\text { Control } \\
(\mathrm{n}=6)\end{array}$ \\
\hline Male/female & $3 / 3$ & $1 / 5$ \\
Age $(\mathrm{yrs})$ & $54.0 \pm 5.3$ & $47.7 \pm 7.6$ \\
BMI (kg/m $\left.{ }^{2}\right)$ & $26.1 \pm 1.7$ & $24.2 \pm 2.1$ \\
TG (mmol/L) & $2.3 \pm 0.65$ & $1.18 \pm 0.51$ \\
TC (mmol/L) & $6.60 \pm 0.83$ & $4.99 \pm 0.34$ \\
HDL-C (mmol/L) & $0.80 \pm 0.12$ & 0.95 \\
Glucose (mmol/L) & $5.4 \pm 1.2$ & $5.0 \pm 0.37$ \\
ApoB (g/L) & $1.36 \pm 0.21$ & $0.91 \pm 0.10$ \\
\hline
\end{tabular}

Datal represent mean $\pm S D$. 


\section{Reliability assessment FCHL macroarray analyses}

Three housekeeping genes, i.e. $23-\mathrm{kDa}$ basic protein, hypoxanthine phosphoribosyltransferase (HPRT), and cytoplasmatic betaractin (ACTB), were present in sextuplicate on the macroarray. As expected these housekeeping genes had similar and comparable relative intensities on the FCHL and control macroarrays, indicating that there is limited variability in housekeeping gene expression in FCHL adipose tissue compared to that of controls (Table 3.3). To validate the first analytical approach, the spots on the macroarrays were corrected for mean background and mean intensity of all spots in a second analysis (see legend Table 3.4), yielding, to a high degree, similar results as those obtained with correction for housekeeping genes. All data presented were obtained using the first method. These findings support the reproducibility and reliability of the presently used arrays and analyses. In a typical experiment an FCHL subject was compared to the BMI and age matched control subject, resulting in a total of 5 experimentall pairs.

Table 3.3 Comparison of the relative housekeeping gene intensities between the FCHL macroarrays and control macroarrays

\begin{tabular}{lcc}
\hline Housekeeping gene & $\begin{array}{c}\text { FCHL (\%) } \\
\mathrm{n}=\mathbf{5}\end{array}$ & $\begin{array}{c}\text { Control (\%) } \\
\mathrm{n}=\mathbf{5}\end{array}$ \\
\hline 23-kDa basic protein & $18.3 \pm 5.5$ & $24.6 \pm 4.4$ \\
HPRT & $6.3 \pm 4.8$ & $12.5 \pm 3.5$ \\
ACTB & $75.4 \pm 9.3$ & $63.0 \pm 6.1$ \\
\hline Total signal & 100 & 100 \\
\hline
\end{tabular}

Data represent mean $\% \pm S D$.

\section{Identification of FCHL SSH genes}

All SSH clones were sequenced and subsequently identified, using the method described (See Methods). The cleaned sequence reads, i.e. SSH clone sequences without adlaptor and vector sequences, were assembled into contigs, thus lowering 
the number of sequences to be evaluated ${ }_{i}$ and increasing the average length of the sequences. In this way, the original number of 547 sequences, representing 369 different clones, was reduced to 264 contigs. Megablast searches with these 264 contigs against the unigene database showed that 167 contigs obtained a significant blast hit $\left(E<10^{-3}\right.$; sequence identity $>95 \%$ ), which represented 73 unique genes and 65 unique ESTs. With 97 contigs, no significant blast hits were obtained. The housekeeping genes $23 \mathrm{kDA}$ basic protein, HPRT, and ACTB were not present in the SSH library.

\section{Identification of differentially expressed genes in FCHL subcutaneous adipose} tissue

Macroarray analyses resulted in the identification of, in total, 129 differentially expressed genes. Figure 3.1 shows two corresponding segments of an FCHL array and a control array, visually illustrating some of the observed differences in adipose tissue gene expression, and conveying the general down-regulation of genes and gene products present on the FCHL macroarray. The 129 genes identified represent: 57 unique genes, listed in full in Table 3.4, of which 1 was up-regulated and 56 were down-regulated. In addition, 35 unique ESTs were found (Table 3.4), of which 3 were up-regulated and 32 down-regulated, and 37 sequences that revealed no significant unigene blast hit, of which 2 were up-regulated and 35 down-regulated (data not shown). The genes that fulfilled the criteria for differential gene expression in $\mathrm{FCHL}$ adipose tissue, were divided in the following categories: i) SSH library known genes, ii) SSH library ESTs, and iii) Research Genetics, and are listed in Table 3.4. The expression profile obtained with each gene in every FCHL/control pair is given, as well as the average ( \pm standard deviation) ratio in the 5 pairs. The majority of the 'SSH library known genes' identified, i.e. 25 out of 41 genes, have been confirmed by both methods of calculating relative gene expression (Table 3.4). The chromosomal location of the differentially expressed genes is given as well to enable the cross-reference to chromosomal regions shown to be in linkage with $\mathrm{FCHL}$, or composite traits (QTLs) identified in the published genome scans. 


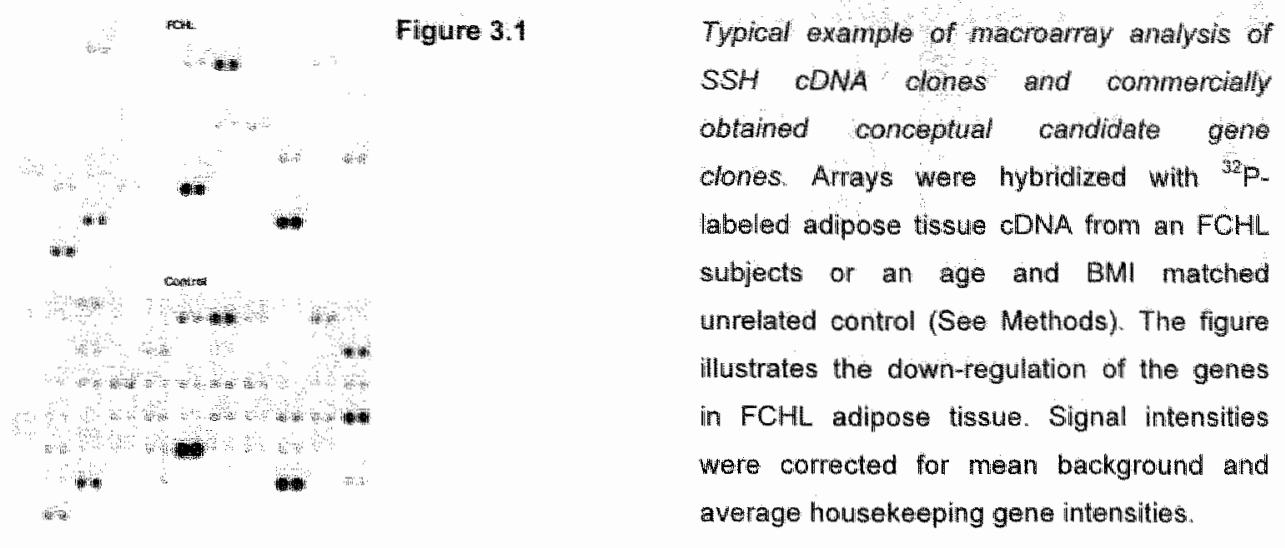

Several obvious conceptual candidate genes, involved in lipid and lipoprotein metabolism, for FCHL adipose tissue dysfunction, including lipoprotein lipase (LPL), perilipin, hepatic lipase (HL), and adipose differentiation related protein (adipophilin), were not differentially expressed (data not shown). Interestingly, gene expression of CD36 antigen (i.e. fatty acid translocase), and fatty acid binding protein 4 (FABP4) showed borderline expression differences (1.5-fold higher in FCHL adipose tissue compared to control tissue). However, these data are not shown because they did not meet the strict 2-fold cut-off criteria for differential gene expression used in the present study.

\section{Confirmation of differential gene expression by real-time PCR}

Finally, to provide independent evidence for the validity and reliability of the macro-array analyses, real-time RT-PCR quantification was carried out. Expression patterns of CNOT8, PGR3, MMP7, and PTGER3 were determined in the same experimental $\mathrm{FCHL} /$ control pairs as used in the macroarray analysis, including an additional experimental pair $(N=6)$. A significant reduction in CNOT8 (2.21-fold, $P<0.05$, Figure 3.2A), MMP7 (5-fold, $P<0.01$, Figure 3.2C), and PTGER3 (2.13-fold, $\mathrm{P}<0.05$, Figure $3.2 \mathrm{D}$ ) expression in $\mathrm{FCHL}$ adipose tissue was confirmed. PRG3 expression was also decreased (1.59-fold, Figure 3.2B) but this was not significant. These findings are in complete agreement with the observed down-regulation established by macroarray analysis (Table 3.4). 
Table 3:4 "Evaluation of genes differentially expressed in FCHL adipose tissue compared to control aidiposie tissue.

\begin{tabular}{|c|c|c|c|c|c|c|c|c|c|}
\hline \multirow[b]{2}{*}{ Gente Hame } & \multirow[b]{2}{*}{ Gembarita 10} & \multirow[b]{2}{*}{ Honigune iD } & \multirow[b]{2}{*}{ Chromicome } & \multicolumn{4}{|c|}{$\begin{array}{l}\text { Rigilative Expression } \\
\text { Profhle in Each } \\
\text { FCHUdControl Pair }\end{array}$} & \multirow[b]{2}{*}{5} & \multirow[b]{2}{*}{$\begin{array}{l}\text { FCHU } \\
\text { combrol: } \\
\text { Ratio: }\end{array}$} \\
\hline & & & & \#t & 2 & 3 & 4 & & \\
\hline \multicolumn{10}{|l|}{ \$SH liburary krown gemes } \\
\hline 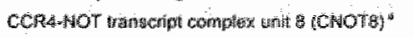 & Mond & Hils 28073 & $5934-q 33$ & . & - & - & . & . & 0.2230 .17 \\
\hline 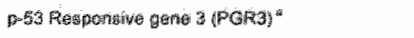 & $\mathrm{A} K \mathrm{KO} 27409$ & His 117062 & $10 \mathrm{Q} 223$ & - & - & - & 0 & * & $0.20 \div 0.20$ \\
\hline 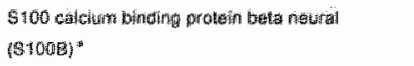 & WHath 272 & His 83324 & 219223 & - & . & $=$ & . & - & $0.26+0.12$ \\
\hline 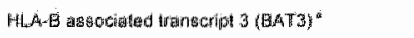 & AF 129754 & Hs 27430 & 60213 & - & . & * & 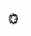 & - & $0.34+0.19$ \\
\hline 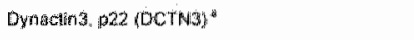 & Nit4024348 & His 15561 & $g$ & . & . & * & 0 & . & $0.21 \div 0.18$ \\
\hline Rirte finger frotain CaHCA lype B (RNFB) & NMOOSOSB & Hs 24439 & eptra & . & . & - & - & . & $0.22: 0.14$ \\
\hline Calpain 2 un ll farge buburnt (CAPN2) & NHAdOA 78 & $1+476299$ & $1941+042$ & . & . & a & - & . & $0.35 \div 0.6$ \\
\hline 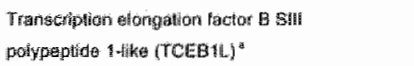 & NMOO3 & W & 5q 31 & . & . & o & . & * & $0.24+0.18$ \\
\hline 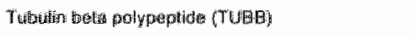 & SAM001069 & 4336700 & epż & " & - & a & . & - & $0.36 \pm 0,33$ \\
\hline 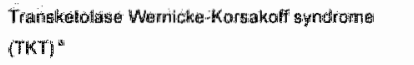 & NAMONO1064 & $H: 69043$ & 3pis.3 & - & $\infty$ & $a$ & - & - & $0.32 \pm 0.25$ \\
\hline 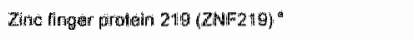 & NHAOH 6423 & $\mathrm{H}+8 \mathrm{z} 5 \mathrm{f} 4 \mathrm{9g}$ & $14 q 11$ & 。 & - & 0 & . & * & $0.35 \leq 0.22$ \\
\hline 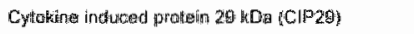 & NM032304 & He 69908 & $12 q 12$ & . & - & 0 & & . & $0.32+0.29$ \\
\hline Replication protelm A2 $32 \mathrm{kD}(\mathrm{RPA} A)^{\circ}$ & NHOO020148 & Hos 790 幽1 & $1 \rho 95$ & - & - & 0 & . & 。 & $0.34 \pm 0.34$ \\
\hline Ribosomal protein 39 (APSSg) ${ }^{4}$ & NHOO1013 & $H \leqslant 160920$ & $\operatorname{19g} 33.4$ & - & - & i & . & . & $0.259 \pm 0.23$ \\
\hline 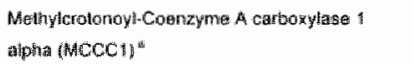 & MMO20169 & H: $4: 7649$ & $3 \div 27$ & - & . & 0 & 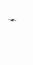 & - & $0.32+0.24$ \\
\hline Gintarmyl-prodyl-tRNA synthatase (EPAPS) & NHODAd 46 & Hs $5592 \pi$ & $1941-042$ & - & . & o & - & - & $0.20 \div 0.29$ \\
\hline $\begin{array}{l}\text { IQ mofil containing GTFase acilvating proteins } \\
\text { UQQAPH) }\end{array}$ & NM003870 & His 1742 & $15 q 26.1$ & . & - & D & * & - & $0.41 \mathrm{~s}: 0.1 \mathrm{~g}$ \\
\hline $\begin{array}{l}\text { Giutathione peroxidase } 4 \text { phospholiphids } \\
\text { hydroperoxidase (GPXA) }\end{array}$ & NHOOQ2015: & $\mathrm{Hs} 270 \mathrm{~s}$ & 19913.3 & - & - & 0 & $=$ & - & $0.29+0.32$ \\
\hline SH3-domain protein 5 ponsin (SHBDS) & NWOA15385 & $\mathrm{Hs} 108924$ & $\log 23.3-q 24,1$ & - & & a & - & - & $0.39 \pm 0.33$ \\
\hline 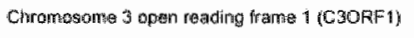 & NWOO16589 & Hs: 79530 & 3913.33 & - & - & 0 & - & . & 0.43 .0 .33 \\
\hline Comprement componemis $3(\mathrm{C} 3)$ & NMO00064 & $\operatorname{ms} 284394$ & $19 p$ :3.3-pt3.2 & - & - & $a$ & . & " & $0.35+0.21$ \\
\hline 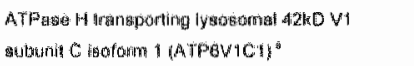 & NMOD 19696 & 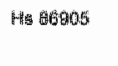 & $\operatorname{sq} 22.3$ & . & - & 0 & . & . & $0.27 \pm 0.22$ \\
\hline 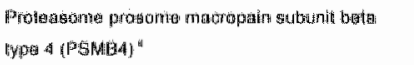 & MaOO2\%OSO & His 345 & 1021 & - & - & o & - & - & $0.32: 0.32$ \\
\hline 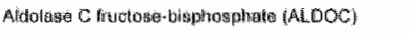 & NH1000165 & His 155247 & $i 7$ & - & - & o & - & - & $0.3 \div 0.29$ \\
\hline 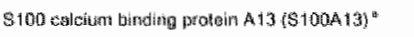 & NMoos 979 & 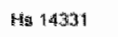 & $1 \mathrm{q} 21$ & - & - & 0 & - & " & $0.23 \div 0.25$ \\
\hline 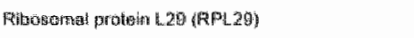 & 186202780 & His 350008 & $3 q 213-9212$ & . & - & 0 & $*$ & . & $0.30 \div 0.21$ \\
\hline Calnexin (CANAX) & NAMOCH 74 C & His 15500 & $5 q 35$ & - & - & 0 & . & - & $0.50 \div 0.15$ \\
\hline 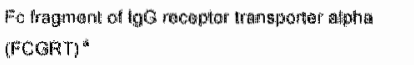 & NHMO04 107 & Hs 141903 & $\operatorname{lgq} 13.3$ & - & - & $\circ$ & . & - & $0.34 \div 0.25$ \\
\hline 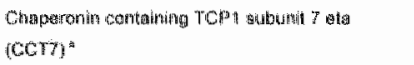 & NMOOOGA29 & HS 108809 & $2 p 12$ & . & . & 0 & - & - & $0.30+0.39$ \\
\hline 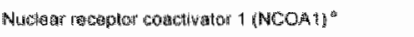 & NMoos? 43 & Ms 740002 & $2 p 23$ & - & - & 0 & . & * & $0.43 \pm 0.31$ \\
\hline ThAF-bunding pretsim domain (TRABBD " & A. 285060 & Hisi 26320 & 10026.13 & . & - & 0 & - & . & $0.26 \div 0.39$ \\
\hline DET1 Homblog & NAM 0058g: & Misi 23103 & $7 \mathrm{q} 21+1.922$ & - & . & 0 & - & $*$ & $0.34 \pm 0.27$ \\
\hline 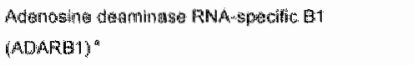 & NMO15839 & Hs. 85302 & 24922.3 & - & . & 0 & - & - & $0.27 \div 0.21$ \\
\hline Tumor reilection andigen goses 1 (TRA) & NHOWJ90 & IHs 82689 & $12 q 24,2-q 24,3$ & - & - & 0 & . & - & $0.50 \div 0.68$ \\
\hline 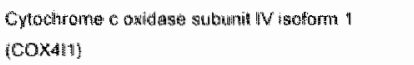 & NHO0186I & His 347969 & $16 q 22$ & * & . & a & . & . & $0.415 \times 0.51$ \\
\hline
\end{tabular}




\begin{tabular}{|c|c|c|c|c|c|c|c|c|c|}
\hline \multirow[b]{2}{*}{ Gentane Name } & \multirow[b]{2}{*}{ Gitabannir id } & \multirow[b]{2}{*}{ Unigend ro } & \multirow[b]{2}{*}{ Ghromasiamie } & \multicolumn{4}{|c|}{ 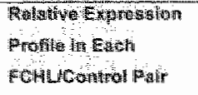 } & \multirow[b]{2}{*}{ s } & \multirow[b]{2}{*}{$\begin{array}{l}\text { Fowh } \\
\text { Cantrat } \\
\text { Ratio" }\end{array}$} \\
\hline & & & & 1 & 2 & 3 & 4 & & \\
\hline \multicolumn{10}{|l|}{ SSH library known genes } \\
\hline HiteA interacting protein 5 (HURIPS) & MMON5700 & Hs 17358 & $2 p 1503$ & . & $\therefore$ & 0 & $=$ & - & $0,43.043$ \\
\hline Suppression of tumerigenicty $13(\mathrm{ST} 13)^{2}$ & NMONo383 & Hs 1.9222 & $22 \mathrm{q} 13.2$ & 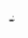 & $\therefore$ & 0 & " & $\cdots$ & $0.52 \div 0.49$ \\
\hline $\begin{array}{l}\text { Piatelet-derived groweth factor receptar alphis } \\
\text { pestypeptide (PDGFRA)" }\end{array}$ & Matoos 206 & 4574685 & मधन है। & - & - & 0 & - & $\checkmark$ & $0.39: 0.30$ \\
\hline YUEY-HKe I (YWESLIT) & NMOHA260 & Hs 200525 & toppin & - & - & $a$ & - & $=$ & 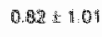 \\
\hline Whitrotubuta-associated protein A llwAP4) & 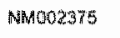 & Hs 239298 & $3 p 21$ & - & - & a &. & - & $0 . \sin 40.41$ \\
\hline Laminin receptor $甘$ (LAMRN) & 80010054 & He 356.264 & $3 p 2 \div 3$ & . & - & o & $\therefore$ & - & $0.52+0.44$ \\
\hline \multicolumn{10}{|l|}{ SSH Library EST: } \\
\hline $\mathrm{EST}^{*}$ & AKO000270 & Hs 35045 & & - & " & - & “ & 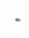 & $0.21+0.19$ \\
\hline EST thypothetical protein DCA2 (OCA2) & AKD25746: & $H: 720005$ & 3923 & - & ح & - & 0 & - & $0.40 \% 0.11$ \\
\hline 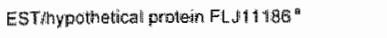 & $A B D Q 6790$ & $\mathrm{His}, 8 \mathrm{~g} 2 \mathrm{HB}$ & 190211 & - & - & - & - & . & $0.21+0.09$ \\
\hline EST & 9018.2189 & $H S 148120$ & & - & - & ต & - & . & 0.25 :10.198 \\
\hline EST inypothetical protein MGCaY200" & NMDO32905 & Has 908 & 20,12 & - & - & 0 & - & $=$ & $0.25 \pm 0.20$ \\
\hline $\mathrm{EST}^{\mathrm{C}}$ & Al133418 & $H s 181841$ & & . & - & 0 & - & - & $0.33 \pm 0.25$ \\
\hline $\begin{array}{l}\text { EST Weakly simitlar to } 10024 \mathrm{D} \text { cytochrome } \\
\text { oxidase } \|^{\circ}\end{array}$ & Al133419 & $H: 314941$ & & - & - & D & - & - & 0.32 .10 .24 \\
\hline $\mathrm{EST}^{2}$ & Ai499057 & 40230869 & & - & - & a & - & - & $0.31=0.35$ \\
\hline EST* & A 13590062 & $4: 4: 271$ & 3 & - & - & : & - & - & $0.36+10.210$ \\
\hline EST & AW9g9468 & 149188738 & 3 & . & - & $a$ & . & - & $0.45: 0.30$ \\
\hline \multicolumn{10}{|l|}{$F L=220234^{2}$} \\
\hline ESThWakly sintillar to neufonal thread proteiln & BG200046i & His 190264 & & . & " & a & - & - & $0.52 \div 0.28$ \\
\hline ESTTKIAAD0408 grene product" & NAOONATD2 & Hs 118744 & $6 \ln _{2} 33$ & . & " & 0 & - & - & $0.30 \pm 0.27$ \\
\hline EST" & AWGTG721 & $\mathrm{Hs} 293327$ & & . & . & 0 & - & - & $0.35 \pm 0.31$ \\
\hline EST $^{*}$ & AK023D36 & Hs3อ17234 & & 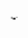 & - & 0 & - & . & $0.22 \pm 0.25$ \\
\hline EST & Al444575 & Hs $28 \% 4918$ & & $\therefore$ & $"$ & to & - & - & $0.37,0.30$ \\
\hline EST & BE28004: & 145301809 & & . & - & $a$ & - & - & $0.35 \div 0.32$ \\
\hline ESTKKIAA1146 prot:in & NHO 48692 & Ms 227602 & en $25.5, y-925.3$ & . & 。 & o & . & - & $0.43: 0.15$ \\
\hline EST & AK023450 & Hs. 5897 & & - & " & - & - & - & $0.43 \pm 0.28$ \\
\hline EST & BGZ2Z10B & Hs. 127922 & & 。 & . & . & . & . & $0.33+0.28$ \\
\hline Es $r^{8}$ & 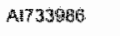 & $46.9357 \mathrm{~A}$ & & . & - & . & $\therefore$ & . & $0.42 \div 03$ \\
\hline 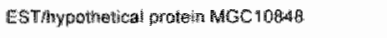 & NW0305691 & HE. 207443 & 10414 & - & . & (i) & . & . & $0.45: 0.78$ \\
\hline ESTHKIAAOER a gene prontuct & ABOHASB2 & He. 9000 & 94231 & . & . & a & . & - & $0.38 \div 0.93$ \\
\hline ESThupotheticel protein FLutilo: & NHot 828 & Hot 21275 & 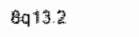 & - & . & a & $=$ & . & $0.36 \div 028$ \\
\hline ESThyposthetical protein FLJ21070 & Aw977609 & He 130: 15 & 20 & . & $=$ & 0 & . & & $0.51=024$ \\
\hline EST & AKOSEGSG3i & His 2358067 & 1 & - & 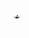 & o & " & " & $0.42: 0.44$ \\
\hline Est & BE: $62: 142$ & 14204309 & & . & - & $b$ & . & . & 0.821055 \\
\hline est & BCo12142 & Hs 372429 & 2 & - & - & $\Rightarrow$ & - & . & $0.31 \leq 040$ \\
\hline ESTIKIAA, 3 38 T proftein & AED37. & Hs 301434 & 20161 & . & - & 0 & - & - & $0.43: 0.46$ \\
\hline EST & 86212219 & $H s: 317629$ & & - & - & $\square$ & - & - & $0.00+0.40$ \\
\hline 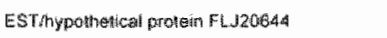 & WHON 7917 & HE 49376 & 17012 & $=$ & $\cdot$ & 10 & - & - & $0.39+0.54$ \\
\hline EST & AWGT124: & Hs 333466 & & - & . & 0 & - & - & $0.43 \pm 0.67$ \\
\hline EST" & AlGizabas & lis 273198 & & * & 0 & * & - & * & $1.81 \pm 1.11$ \\
\hline Est & $B 64.27 .469$ & Hes 352048 & & 4 & * & * & . & - & $238+190$ \\
\hline EST" & BFy & He 321477 & & 4 & * & 0 & 0 & + & 2401078 \\
\hline \multicolumn{10}{|l|}{ Revereareh Gonetics } \\
\hline Integrin beta 5 (ATICBS) & BCongsta & 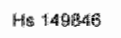 & $3 \log 21.3$ & $x$ & . & $x$ & " & . & $0.40: 0006$ \\
\hline Punti-related transcription factior I (RUNX) & DA3569 & Hits 120914 & $2 \lg 223$ & - & - & 0 & - & 0 & $0.48+0.11$ \\
\hline Nitfic oixide synthase $2 \mathrm{~A}$ (NOS2A)" & U315t1 & HS $119378 B$ & $\operatorname{17q112.412}$ & 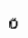 & . & 0 & . & . & 0.5610 .18 \\
\hline
\end{tabular}




\begin{tabular}{|c|c|c|c|c|c|c|c|c|c|}
\hline \multirow[b]{2}{*}{ Genen and } & \multirow[b]{2}{*}{ Gentsank D } & \multirow[b]{2}{*}{ Wingenta } & \multirow[b]{2}{*}{ 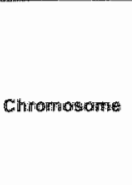 } & \multicolumn{4}{|c|}{ 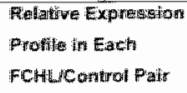 } & \multirow[b]{2}{*}{5} & \multirow[b]{2}{*}{$\begin{array}{l}\text { FCHL } \\
\text { Constrol } \\
\text { Reation }\end{array}$} \\
\hline & & & & 1 & 2 & 3 & 4 & & \\
\hline \multicolumn{10}{|l|}{ 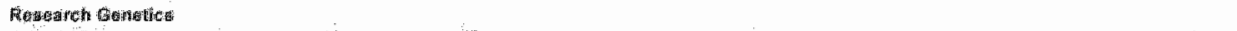 } \\
\hline 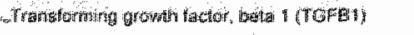 & xoretiz & Hs 1109 & 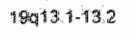 & - & a & 0 & . & • & $0.3 \pm 03$ \\
\hline 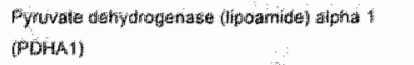 & L.13ate & Hsioza & $x_{p} 2^{2} 2: 2-022$ & - & - & 0 & “ & $\cdot$ & 0.391016 \\
\hline 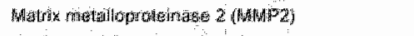 & AHOORIESA & $H=11130$ & 16913021 & " & - & io & " & • & $0.40 \pm 0.31$ \\
\hline 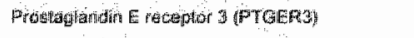 & Cx 650000 & 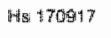 & 10312 & - & $a$ & 0 & - & - & $0.45 \pm 0.22$ \\
\hline 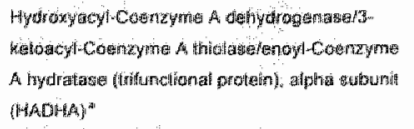 & ABO2081 & HES 75860 & $2 \mathrm{p} 23$ & : & $\cdot$ &. & o & - & $0.54 \div 0.5$ \\
\hline 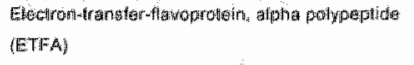 & 104058 & $8 \cdot+596919$ & 15023,025 & • & $\cdot$ & a & - & - & $0.46=0.25$ \\
\hline Apesipaprotsin C-F (APOCA) & U32576 & 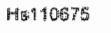 & 1901132 & - & - & $a$ & * & - & $057 \div 0.40$ \\
\hline Sinteit y f SURFF) & Yง7212 & Hs.396 & 9034.2 & . & - & 0 & . & $\because$ & $075: 0.73$ \\
\hline 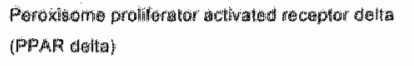 & NTCo7sg2 & & Eิp21. & - & - & 0 & $\cdots$ & n & $0.58 \div 0.46$ \\
\hline 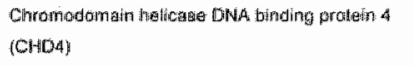 & $x 86001$ & Wh 744 A & $12 p \| 3$ & . & * & 9 & - & - & $0.29: 024$ \\
\hline 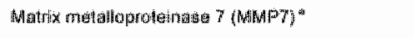 & 1.22519 & Mg. 2250 & $1+921-922$ & $\cdot$ & - & 0 & . & - & 0.471055 \\
\hline Laminin bater 2 (LAMB2) & M6Q:75 & Hs $776: 34$ & 16023.3 & - & . & D & . & 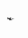 & $0.58 \pm 0.74$ \\
\hline $\begin{array}{l}\text { Farty-acid-Conzyme A ligase; lory-chain } 2 \\
\text { (FACLZ) }\end{array}$ & Dioota & Hs 154890 & $44-34-q 38$ & * & + & + & * & a & $171: 1.09$ \\
\hline
\end{tabular}

Relatiwe expression profile of each FCHL/control pair (1 to 5), obtained after conection for mean backgraund and

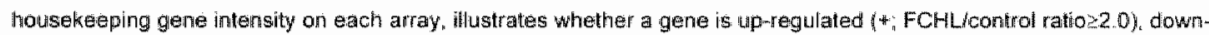
Fegulaied $(-; \mathrm{FCHL} / \mathrm{control}$ ratios 0.5$)$, not differentially expressed $(0 ; 0.5 \times \mathrm{FCHL} / \mathrm{control}$ ratio 2.0$)$, or not expressed at a detectable level $(\mathrm{x})$. Data represent mean $\mathrm{I}$ SD. "identified as differientially expressed in both analyses methods: i.e. correction for housekeeping glene intensities on the array and correction for total signai intensity on the array.

\section{Discussion}

In the present study, a combination of SSH and macroarray technology has resulted in the identification of 129 differentially expressed genes and gene products in subcutaneous FCHL adipose tissue. In total, 113 of these genes were isolated by SSH technique and 16 genes represented commercially obtained cardiovascular candidate genes. These findings illustrate the power of the SSH technique in isolating differentially expressed sequences. The current macroarray results support our previous observation that consistent gene expression patterns are found in FCHL adipose tissue. ${ }^{18}$ In the present study, quantitative PCR was used to validate the macroarray analyses, and confirmed the decrease in gene expression of CNOT8, PRG3, MMP7, and PTGER3 in FCHL adipose tissue. 
A
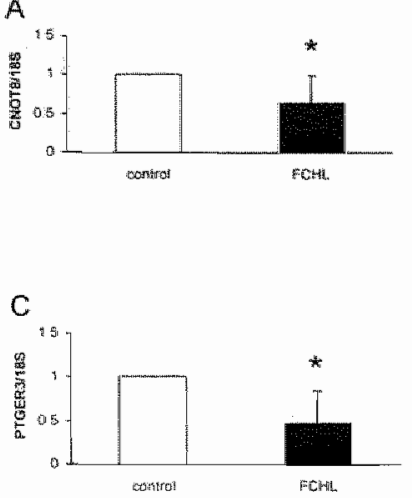

B

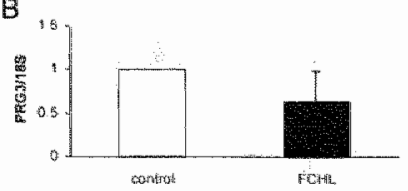

D

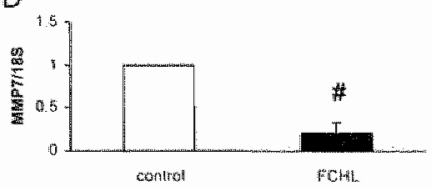

Figure 3.2 FCHL adipose tissue CNOT8 (A), PGR3 (B), MMP7 (C), and PTGER3 (D) mRNA gene expression, normalized to 185 rRNA content, is expressed relative to age and BMI-matched control mRNA levels (which has been set at 1.0). Data are expressied as mean $\pm S D$. * $P<0.05, P<0.01$.

The average $\Delta \mathrm{C}_{\mathrm{t}}$ values in the control samples were as follows; $4.82 \pm 1.76$ for CNOT8, $3.62 \pm 0.93$ for PRG3, $7.85 \pm 1.98$ for MMP7, and $3.03 \pm 1.51$ for PTGER3.

Of the $264 \mathrm{SSH}$ contigs $113(42 \%)$ were differentially expressed, illustrating a high yield of differentially expressed genes with the SSH technique. Only $5.9 \%$ (16 out of 271) of the commercially obtained clones were identified as differentially expressed. Based on the fact that the commercially obtained clones were selected for cardiovascular disease in general and not specifically for a role in adipose tissue this is not surprisingly. The validity of the obtained expression data is illustrated by the fact that all genes taken into regard were at least in four out of five experimental pairs differentially expressed. Furthermore, the known genes that were differentially expressed could be categorized into several pathways or functional processes such as cell cycle regulation, FFA metabolism and insulin signalling. These will be discussed in more detail below.

Subcutaneous adipose tissue is an interesting target for differential gene expression because impaired function of adipose tissue is believed to contribute to the complex hyperlipidemic phenotype of FCHL by inadequate re-esterification of 
FFA, derived form adipocyte TG lipolysis. ${ }^{10-1315}$ The resulting post-prandially increased FFA flux to the liver can ultimately contribute to hepatic overproduction of apoB rich lipoproteins. ${ }^{13}$ In general, plasma FFA concentrations are the resullt from combined actions of lipolysis, FFA uptake, and FFA oxidation. Evidence, from in vitro experiments, points towards a defect in intracellular FFA re-esterification rather than a defect in lipolysis. 15 Possibly, impaired adaptation of mitochondrial oxidation pathways could also contribute to the increased FFA flux. The present study, using independent methodology compared to our recent report on differential gene expression ${ }^{18}$, confirms a role of adipose tissue in the pathophysialogy of FCHL.

A large subset of the differentially expressed genes identified in the present study play a prominent role in cell-cycle regulation i.e. CNOT8, PRG3, S100 calcium binding protein B (S100B), HLA-B associated transcript 3 (BAT3), calpain 2 (CAPN2), cytokine induced protein $29 \mathrm{kDa}$ (CIP29), IQ motif containing GTPase activating protein 1 (IQCAP1), $\$ 100$ calcium binding protein A13 (S100A13), and chaperonin containing TCP1 subunit 7 eta (CCT7). ${ }^{29-37}$ Each gene product is directly or indirectly involved in the decision whether the cell will undergo apoptosis or will proceed through the cell cycle. ${ }^{29-37}$ For instance, PRG3 and $5100 \mathrm{~B}$ gene expression is normally induced under p53 apoptotic conditions $s^{30,31}$, and both genes were found to be down-regulated. PRG3 mediated apoptosis can be blocked by $H S P 70^{30}$ and interestingly BAT3, which regulates HSP70, is also down-regulated in FCHL. ${ }^{32}$ CAPN2, down-regulated in FCHL adipose tissue, is a member of the calpain cysteine protease family and plays a role of in the disassembly of cells during cell death. ${ }^{33}$ Notably, c-Jun and cyclin D1, whose expression favor progression through the cell cycle, are both calpain substrates ${ }^{33}$ and were shown to be up-regulated in FCHL adipose tissue previously. ${ }^{18}$ This may imply that CAPN2 down-regulation is a compensatory mechanism. The fact that all these pro-apoptotic genes are downregulated in FCHL adipose tissue, indicates that the propensity of the adipocyte to undergo apoptosis is low. This anti-apoptotic gene expression pattern is in agreement with our previous, independent, finding that genes, known to stimulate transition from $\mathrm{G} 1$ to $\mathrm{S}$ phase during the cell cycle are up-regulated in $\mathrm{FCHL}$ adipocytes. ${ }^{11}$ This supports our hypothesis that the observed gene expression pattern may reflect hyperplasia of adipocytes. Continuously increased delivery of lipoproteins and their remnants from plasma to adipocytes in FCHL may increase cell cycle gene expression, and decrease pro-apoptotic gene expression, in order to 
accommodate the persistent lipid supply. This proposed mechanism does not imply that the compensatory hyperplasia of adipocytes is sufficient to maintain normal lipid or FFA metabolism in FCHL. ${ }^{15}$

It has been suggested that acylation-stimulating protein (ASP) affects glucose and FFA ${ }^{13,14}$ metabolism in peripheral tissues, and that ASP-mediated FFA uptake is disturbed in FCHL. ${ }^{12.13}$ ASP is identical to complement component $3 a$ which is one of the immunologically inactive cleavage products of complement component $3(\mathrm{C} 3)^{38}$ In this light, it is interesting that $\mathrm{C} 3$ mRNA levels were decreased in FCHL adipocytes. In Finnish FCHL subjects no change in C3 mRNA levels in FCHL adipose tissue were observed compared to that of controls. ${ }^{39}$ Combined, these findings suggest that high plasma $\mathrm{C} 3$ levels in $\mathrm{FCHL}$ subjects are not generated in adipose tissue. Therefore, the role of adipose tissue in the disturbed post-prandial $\mathrm{C} 3$ response in FCHL subjects may be different than originally proposed. ${ }^{40,41}$

Impaired insulin action has been reported in $\mathrm{FCHL}^{21,42,43}$, and has been linked to altered metabolism of FFA ${ }^{12,13,44}$ and impaired reactivity of adipocyte lipolysis. ${ }^{11}$ Although, several obvious candidate genes for adipose tissue insulin resistance such as the insulin receptor (INSR), insulin-like growth factor 1 receptor (IGF1R), and insulin-like growth factor 1 (IGF1) were not differentially expressed, it is interesting that several other genes involved in FFA and/or insulin signaling were differentially expressed in FCHL adipose tissue. Hydroxyacyl-Coenzyme A dehydrogenase/3ketoacyl-Coenzyme $A$ thiolase/enoyl-Coenzyme $A$ hydratase alpha (HADHA), an enzyme involved in mitochondrial fatty acid beta-oxidation ${ }^{45}$ was down-regulated in FCHL adipocytes. Fatty-acid-Coenzyme $A$ ligase ( $F A C L 2$ ), an enzyme involved in the conversion of free long-chain fatty acids into fatty acyl-CoA esters and thus playing a key role in lipid biosynthesis and fatty acid oxidation, was up-regulated. Insulin has been suggested to increase the specific activity of FACL2 ${ }^{46}$, thus it may be possible that FACL2 is up-regulated in response to the impaired insulin signaling in FCHL adipose tissue. CBL-associated protein (CAP, also known as: sorbin and SH3 domain containing 1 (SORPS1)) gene expression was shown to be downregulated in FCHL adipose tissue. CAP is essential for insulin-mediated translocation of GLUT4 from the intracellular lipid raft to the cell-surface, and thus glucose transport. ${ }^{47.48}$ In relation to recent data showing that FFA esterification in FCHL. adipocytes is impaired ${ }^{15}$. HADHA down-regulation and FACL2 up-regulation in FCHL adipose tissue may reflect compensatory mechanisms for increased intracellular 
FFA concentrations, and thus support the finding of attered FFA metabolism in FCHL adipose tissue. However, further research will be needed to distinguish between alterations in insulin signaling and FFA metabolic pathways in FCHL adipose tissue due to genetic predisposition or adaptation.

It is our strong opinion that differential gene expression studies will help to unravel the molecular basis of $\mathrm{FCHL}$, especially in combination with genetic linkage data, because such a combined approach yields information on the pathways identified. For instance, in Finnish FCHL families significant linkage was found with chromosome 1q21-23 (log of odds (LOD) score 5.94). ${ }^{3}$ Proteasome prosome macropain subunit beta type 4 (PSMB4) and S100A13, both found to be downregulated, are situated at this chromosomal location. In Dutch families, linkage was obtained with chromosome $1 \mathrm{p} 31^{49}$ and, interestingly, PTGER3 gene corresponds to this region. These novel candidate genes are therefore interesting target for further analyses, although they are not directly related to lipoprotein and lipid synthesis, secretion or metabolism, and may therefore not represent major FCHL genes.

In conclusion, our results demonstrate that "in a heterogeneous and complex genetic disease such as FCHL, a consistent gene expression profile in subcutaneous adipose tissue can be found among affected subjects. Hepatic lipoprotein overproduction, hallmark of FCHL, results in an increased lipoprotein flux towards peripheral tissues such as adipose tissue. Compensatory mechanisms such as FFA re-esterification and oxidation may not be able to accommodate the persistent lipid supply and may stimulate adipose tissue expansion through cell proliferation, and continue the insulin resistant state with ensuing impaired lipid distribution. 


\section{References}

1. Goldstein JL, Schrott HG, Hazzard WR, Bierman EL, Motulsky AG. Hyperlipidemia in coronary heart disease. II. Genetic analysis of lipid levels in 176 families and defineation of a new inherited disorder, combined hyperlipidemia. J.Clin. Invest. 1973,52:1544-1568.

2. Voors-Pette $C$, de Bruin TWA. Excess coronary heart disease in Familial Combined Hyperlipidemia in relation to genetic factors and central obesity. Athorosclerosis. 2001:157:481489.

3. Pajukanta P, Nuotio I, Tenwilliger JD, Porkka KV, Ylitalo $K$, Pihlajamaki J, Suomalainen AJ, Syvanen AC, Lehtimaki T, Viikari IS, Laakso M, Taskinen MR, Ehnholm C. Peltonen L. Linkage of familial combined hyperlipidaemia to chromosome 1q21-q23. Nat. Genet. 1998;18:369-373.

4. Aouizerat $B E$, Allayee $H$, Cantor $R M_{3}$, Davis RC, Lanning $C D$, Wen $P Z$, Dallinga-Thie $G M$, de

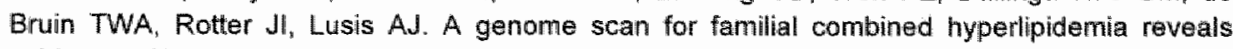
evidence of linkage with a locus on chromosome 11. Am.J.Hum. Genet. 1999;65:397-412.

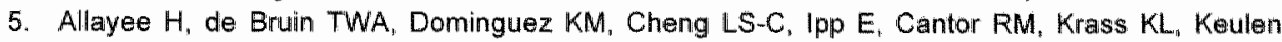
ETP, Aouizerat BE, Lusis Ad, Rotter JI. Genome-scan for blood pressure in Ductch dyslipidemic families reveals linkage to a locus on chromosome 4p. Hypertension. 2001; 38:773-778.

6. van der Kallen CJH, Cantor RM, van Greevenbroek MMJ, Geurts JMW, Bouwman FG, Aouizerat BE, Allayee H, Buurman WA, Lusis AJ, Rotter Jl, de Bruin TWA. Genome scan for adiposity in Dutch dyslipidemic families reveals novel quantitive trait loci for leptin, body mass index and soluble tumor necrosis factor receptor superfamily 1A. Int.J.Obes.Relat.Metab.Disord. $2000 ; 24: 1381-1391$.

7. de Bruin TWA, Mailly $F$, van Barlingen $H_{n}$ Fisher $R$, Castro-Cabezas $M$, Talmud $P$, Dallinga-Thie GM. Humphries SE. Lipoprotein lipase gene mutations. D9N and N291S in four pedigrees with fiamilial combined hyperlipidaemia. Eur.J.Clin.Invest. 1996;26;631-639.

8. Dallinga-Thie GM, van Linde-Sibenius TM, Rotter Jl, Cantor RM, Bu X, Lusis AJ, de Bruin TWA. Complex genetic contribution of the Apo Al-Clll-AIV gene cluster to famillial combined hyperlipidemia. Identification of different susceptibility haplotypes. J.Clin.Inwest. 1997;99:953961.

9. Pihlajamaki J, Miettinen R, Valve R., Karjalainen L, Kuusisto J Deeb S, Auwerx J, Laakso M. The Pro12Ala substitution in the peroxisome proliferator activated receptor gamma 2 is associated with an insulin-sensitive phenotype in families with familial combined hyperlipidemia adn in nondiabetic elderly subjects with dyslipidemia. Atherosclerosis. 2000;151:567-574.

10. Castro-Cabezas $M$, de Bruin TWA, de Valk HW, Shoulders $C C$, Jansen $H$, Erkelens DW. Impaired fatty acid metabolism in familial combined hyperlipidemia. A machanism associating hepatic apolipoprotein B overproduction and insulin resistance. J.Clin. Invest. 1993;92:160-168.

11. Reynisdottir $S$, Eriksson $M_{4}$ Angelin $B$, Amer $P$. Impaired activation of adipocyte lipolysis in familial combined hyperlipidemia. J.Clin Invest. 1995:95:2161-2169.

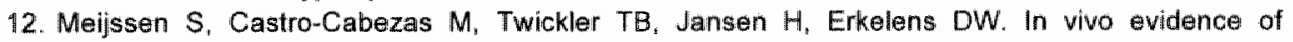
defective postprandial and postabsorptive free fatty acid metabolism in familial combined hyperlipidemia. J.Lipid Res. 2000;41:1096-1102.

13. Sniderman $A D$, Cianflone $K$, Arner $P$, Summers $L K$, Frayn $K \mathbb{N}$. The adipocyte, fatty acid trapping, and atherogenesis. Arterioscler. Thromb. Vasc Biol, 1998;18:147-151.

14. Kwiterovich.PO J, Motevalli M. Miller M. The effect of three serum basic proteins on the mass of lipids in narmal and hyperapoB fibroblasts. Arterioscler. Thromb. Vaso. Biol. 1994:14:1-7

15. van der Kallen CJH, Voors-Pette $C$, Bouwman FG, Keizer HA, Lu JY, van de Hulst RRWJ, Bianchi R, Janssen M-J, Keulen ETP, Boeckx WD, Rotter Jl, de Bruin TWA. Evidence of Insulin Resistant Lipid Metabolism of Adipose Tissue in Familial Combined Hyperlipidemia, but not in type 2 Diabetes. Atherasclerosis. 2002;164:337-346.

16. Lewis $G F$, Steiner $G$. Acule effects of insulin in the control of VLDL production in humans. IImplications for the insulin-resistant state. Diabotes Care. 1996;19:390-393.

17. Eurlings PMH, van der Kallen CJJH, Geurts JMW, van Greevenbroek MMJ, de Bruin TWA. Genetic dissection of familial combined hyperlipidemia. Mol Genet.Metab, 2001,74:98-104. 
18. Eurlings PMM, van der Kallen CJH, Geurts JMW, Kouwenberg $P$, Boeckx WD, de Bruin TWA. Identification of differentially expressed genes in subcutaneous adipose tissue from subjects with familial combined hyperlipidemia. J.Lipid Res. 2002;43:930-935.

19. Diatchenko L, Lukyanov S, Lau YF. Siebert PD. Suppression subtractive hybridization: a versatile method for identifying differentially expressed genes. Methods Enzymol. 1999;303:349-380.

20. Keulen ETP. Kruilshoop M. Schaper NC. Hoeks APG, de Bruin TWA. Increased intima-media thickness in Familial Combined Hyperlipidemia associated with apolipoprotein B. Arterioscler. Thromb. Vasc. Biol. 2002,22:283-288.

21. Aitman $T J$, Godsland IF; Farren $B$; Crook $D$, Wong $H J$, Scott $J$. Defects of insulin action on fatty acid and carbohydrate metabolism in familial combined hyperlipidemia. Arterioscler. Thromb. Vasc Biol. 1997; 17:748-754.

22. Staden $\mathbb{R}_{i 1}$ Beal KF, Bonfield JK. The Staden packagle, 1998. Methods Mol Bol. 2000;132:115130.

23. Ewing $B$, Green P. Base-calling of automated sequencer traces using phred. Il. Error probabilities. Genome Res. 1998;8:186-194.

24. Ewing $B$, Hillier $L$, Wendl $M C$, Green $P$. Base-calling of automated sequencer traces using phred. 1. Accuracy assessment. Genome Res. 1998;8:175-185.

25. Zhang $Z$, Sctwartz $S$, Wagner L. Miller W. A greedy algorithm for aligning DNA sequences. J Comput. Biol. 2000; 7:203-214.

26. Advancing genomic research: the unigene collection. NCBI news. 1996;

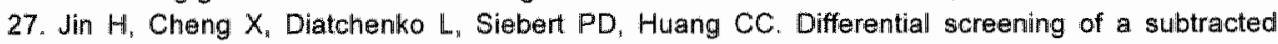
cDNA library: a method to search for genes preferentially expressed in multiple tissues. Biotechniques. 1997;23:1084-1086.

28. Livak Ku, Schmittgen TD. Analysis of relative gene expression data using real-time quantitative PCR and the 2(-Delta Delta C(T)) Method. Mothods. 2001;25:402-408.

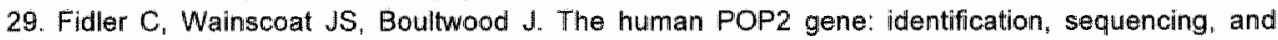
mapping to the critical region of the 5q- syndrome. Genomics. 1999;56:134-136.

30. Ohiro $Y$, Garkavtsev I, Kobayashi $S$, Sreekumar $K R$, Nantz $R$, Higashikubo BT, Duffy SL, Higlashikubo R, Usheva A, Gius D, Kley N, Horikoshi N. A novel p53-inducible apoptogenic gene, PRG3, encodes a homologue of the apoptosis-inducing factor (AIF). FEBS Lett. 2002;524:163171.

31. Scotto C, Deloulme JC, Rousseau D, Chambaz E, Baudier J. Calcium and S100B regulation of p53-dependent cell growth arrest and apoptosis. Mol. Cell Biol. 1998;18:4272-4281.

32. Manchen ST, Hubberstey AV. Human Scythe contains a functional nuclear localization sequence and remains in the nucleus during staurosporine-induced apoptosis. Biochem. Biophys. Res. Commun. 2001:287:1075-1082.

33. Chan SL, Mattson MP. Caspase and calpain substrates: roles in synaptic plasticity and cell death J.Neurosci.Res. 1999;58:167-190.

34. Fukuda S, Wu DW, Stark K, Pelus LM. Cloning and characterization of a proliferation-associated cytokine-inducible protein, CIP29. Biochem. Biophys. Res. Commun. 2002;292:593-600.

35. Swart-Mataraza JM, Li Z, Sacks DB. IQGAP1 is a component of Cdc42 signaling to the cytoskeleton. J.Biol.Chem, 2002;277:24753-24763.

36. Hsieh HL, Schafer BW, Cox JA, Heizmann CW. S100A13 and S100A6 exhibit distinct translocation pathways in endothelial cells. J.Cell Sci. 2002;115:3149-3158.

37. Won KA, Schumacher RJ, Farr GW, Horwich AL, Reed SI. Maturation of human cyclim E requires the function of eulkaryotic chaperonin CCT. Mol. Cell Biol. 1998;18:7584-7589.

38. Baldo A, Sniderman AD, St-Luce S, Avramoglu RK, Maslowska M, Hoang B, Monge JC, Bell A, Mulay $S$, Cianflone $K$. The adipsin-acylation stimulating protein system and regulation of intracellular triglyceride synthesis. J Clin.Invest. 1993;92:1543-1547.

39. Ylitalo $K_{n}$ Nuotio I, Viikari $J$, Auwerx $J$, Vidal $H$, Taskinen MR. C3, hormone-sensitive lipase, and peroxisome proliferator-activated receptor gamma expression in adipose tissue of familial combined hyperlipidemia patients. Metabolism. 2002;51:664-670. 
40. Ylitalo $K_{t}$ Pajukanta $P$, Meri $S$, Cantor RM, Meromatikainen N, Vakkilainen J Nuoto I, Taskinen MR. Serum C3 but not plasma acylation-stimulating protein is elevated in Finnish pratients with familial combined hyperlipidemia. Arterioscler. Thromb Vasc Biol 2001,21:838-843.

41. Meijssen $S$, wan Dijk $H$, Verseyden $C$. Erkelens DW. Castro-Cabiezas M. Delayed and exaggerated postprandial complement component 3 response in familial combined hyperlipidemia. Anterioscler. Thromb. Vasc. Biol 2002;22:811-816.

42. Karjalainen L, Pihlajamaki ل J. Karhapaa $P$, Laakso M. Impaired insulin-stimulated glucose oxidation and free fatty acid suppression in patients with familial combined hyperlipidemia: a precursar defect for dyslipidemia? Arterioscler. Thromb. Vasc.Biol. 1998:18:1548-1553.

43. Bredie SJ, Tack $C J$, Smits $P$, Stalenhoef AF. Nonobese patients with familial combined hyperlipidemia are insulin resistant compared with their nonaffected relatives. Arterioscler. Thromb. Vasc. Biol. 1997;17:1465-1471.

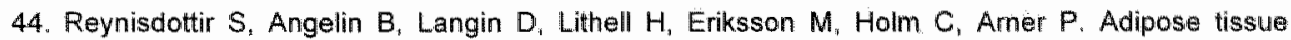
lipoprotein lipase and hormone-sensitive lipase. Contrasting findings in familial combined hyperlipidemia and insulin resistance syndrome. Arterioscler. Thromb. Vasc. Biol. 1997:17:22872292.

45. Aoyama $T$, Wakui $K_{n}$ Orii KE, Hashimoto $T$, Fukushima $Y$. Fluorescence in situ hybridization mapping of the alpha and beta subunits (HADHA and HADHB) of human mitochondrial fatty acild beta-oxidation multienzyme complex to $2 \mathrm{p} 23$ and their evolution. Cytogenetcell Genet. 1997;79:221-224.

46. Jason C.J, Polokoff MA, Bell RM. Triacylglycerol synthesis in isolated fat cells. An effect of insulin on microsomal fatty acid coenzyme A ligase activity. J.Biol.Chem. 1976;251:1.488-1492.

47. Ros-Baro A, Lopez-Iglesias C, Peiro S, Bellidio D, Palacin M, Zorzano A, Camps M. Lipid rafts are required for GLUT4 internalization in adipose cells. Proc.Natl.Acad Sci.U.S.A. 2001,98:1205012055. 


\section{Chapter 4}

\section{Variants in the PPARG gene affect fatty acid and glycerol metabolism in Familial Combined Hyperlipidemia}

PMH Eurlings ${ }_{\text {॥ }} \mathrm{CJH}$ van der Kallen, VMM-J Vermeulen, TWA de Bruin 


\section{Abstract}

Familial Combined Hyperlipidemia ( $\mathrm{FCHL}$ ) is a common genetic lipid disorder characterized by premature coronary artery disease, dyslipidemia, insulin resistance, and impaired adipose tissue free fatty acid (FFA) metabolism. Increased adipose tissue FFA flux may, in part, contribute to reduced insulin sensitivity and hyperlipidemia in FCHL. It was the objective of the present study to evaluate the contribution of the peroxisome proliferator-activated receptor gamma (PPARG) gene to $\mathrm{FCHL}$ traits related to adipocyte lipid metabolism, dyslipidemia and insulin resistance. In a case-control panel consisting of $79 \mathrm{FCHL}$ probands and 124 spouse controls, polymorphic marker D3S1259 and 3 intragenic PPARG variants, i.e. C161T, Pro12Ala, and Pro115Gin, were studied. The Pro115Gin variant was not found in any of the subjects. Allele frequencies of the $\mathrm{C} 161 \mathrm{~T}$, Pro12Ala variants and D3S1259 did not differ significantly between FCHL probands and spouses. In FCHL probands, carriers of the 12Ala allele had lower concentrations of plasma glycerol $(\mathrm{P}<0.05)$ compared to non-carriers, and $161 \mathrm{~T}$ allele carriers had lower plasma concentrations of FFA $(P<0.05)$ and glycerol $(P<0.01)$. No significant associations were found in spouses. These findings identify PPARG as a modifier gene in FCHL, and suggest an insulin sensitizing action of PPARG variants C161T and Pro12Ala in FCHL. 


\section{Introduction}

Familial Combined Hyperlipidemia (FCHL) is a common lipid disorder characterized by multiple type hyperlipidemia, insulin resistance $(\mathrm{IR})$, and clinical manifestations of premature coronary artery disease (CAD). ${ }^{1.3} \mathrm{FCHL}$ subjects are characterized by elevated plasma cholesterol $(>6.5 \mathrm{mmol} / \mathrm{L})$ and/or triglyceride $(>2.3$ $\mathrm{mmol} / \mathrm{L}$ ) levels, secondary to increased hepatic secretion and impaired removal of lipoproteins. In addition, these subjects exhibited an increased postprandial free fatty acid (FFA) flux ${ }^{4}$, as well as impaired insulin-mediated removal of plasma FFA and impaired insulin-mediated glucose uptake in peripheral tissues ${ }^{5-7}$. Interestingly, hyperlipidemic FCHL subject are as insulin resistant for glucose uptake as subjects with type 2 diabetes mellitus (DM2). ${ }^{8}$

Abnormal adipose tissue FFA metabolism has been identified as a major contributor to the increased plasma FFA flux in FCHL. ${ }^{4,8-12}$ We recently reported that FFA re-esterification is reduced in FCHL adipocytes and this phenomenon can contribute to the increased postprandial FFA efflux into the circulation. ${ }^{4}$ Both lipoprotein lipase (LPL), which hydrolyses triglycerides (TG) from very-low density lipoproteins (VLDL) and chylomicrons into FFA and glycerol, and hormone sensitive lipase (HSL), which mediates the intracellular hydrolysis of TG into glycerol and FFA in adipocytes, have been implicated in impaired FFA metabolism in FCHL. 0,12 However, these associated pathways cannot explain all above mentioned observations in FCHL, and the LPL and HSL genes were ruled out as major genes in FCHL linkage analysis. 3 Therefore, the scientific challenge is to identify and characterize other molecular mechanisms that contribute to the abnomal lipid metabolism in FCHL and potentially explain the increased risk of premature CAD.

At present the complex genetics and metabolic phenotypes in FCHL are not fully understood, but several chromosomal $\operatorname{loci}^{14-17}$ as well as candidate genes ${ }^{18-21}$ have been reported to contribute to FCHL. Interesting targets for further genetic study are genes that regulate adipocyte lipid metabolism. The peroxisome proliferatoractivated receptor gamma (PPARG) gene, situated on chromosome 3p25, is an interesting conceptual candidate gene with regard to both hyperlipidemia and insulin resistance in FCHL. The PPARy protein is a nuclear receptor which acts as a pivotal adipocyte transcription factor, and regulates genes such as $L P L_{\text {" }}$ fatty acid transport 
protein (FATP), CD36 and adipophilin 22 involved in control of uptake, transport, storage, and disposal of lipids. ${ }^{23}$ Natural ligands for PPARy are fatty acids but synthetic ligands such as antidiabetic thiazolidinediones bind PPAR $\gamma$ with high affinity. ${ }^{24}$ The insulin sensitizing action of thiazolidinediones has been attributed to PPARy activation. ${ }^{25.26}$

A recent study addressed the role of the PPARG Pro12Ala polymorphism in Finnish FCHL subjects. ${ }^{20}$ The $12 \mathrm{Ala}$ allele was found to be associated with less severe manifestations of both insulin resistance and the unfavorable lipid and lipoprotein phenotypes in FCHL. ${ }^{20}$ The aim of the present study was to assess the potential involvement of the PPARG gene in Dutch FCHL subjects. A polymorphic marker at the PPARG locus, and three intragenic PPARG polymorphisms, i.e. the Pro12Ala, the Pro115Gln, and $\mathrm{C} 161 \mathrm{~T}$, were evaluated in a formal case-control association study.

\section{Methods}

\section{Subjects}

The case-control study population consisted of 79 genetically unrelated FCHL probands, each representing one FCHL family, and 124 unrelated spouses, recruited through the Lipid Clinics of both the Maastricht and Utrecht University Hospitals. FCHL families were ascertained as previously described. ${ }^{27}$ Probands had a primary hyperlipidemia with a varying phenotypic expression including a fasting plasma cholesterol $>6.5 \mathrm{mmol} / \mathrm{L}$ and/or a fasting plasma triglyceride $>2.3 \mathrm{mmol} / \mathrm{L}$, usually combined with the presence of CAD. Spouses represent a common environment, nutrition, and age matched control group. The excess of spouse individuals in this study is explained by the inclusion of i) spouses whose partner had deceased due to complications of $\mathrm{FCHL}_{\text {n }}$ and ii) spouses of (un)affected FCHL relatives. The study protocol was approved by both Human Investigation Review Committees of the University Hospitals of Maastricht and Utrecht, and all subjects gave informed consent. 


\section{Biochemical analyses}

Venous blood was drawn after an overnight fast (12-14 h) in pre-cooled EDTA (1 $\mathrm{mg} / \mathrm{mll}$ ) tubes and prepared by immediate centrifugation for analytical analyses. All subjects on hyperlipidemic drugs were withdrawn from this treatment for two weeks in order to obtain untreated plasma samples. When lipid-lowering therapy is stopped, subjects who were originally hyperlipidemic return to a hyperlipidemic phenotype (unpublished abservations, TdB). Plasma concentrations of total cholesterol (TC), triglycerides (TG), HDL-cholesterol (HDL-C), FFA, glycerol, glucose, insulin, apoAl, and apoB were measured as described before, ${ }^{17,28} \mathrm{LDL}$ particle size was measured as previously reported. ${ }^{28}$

\section{PPARG locus genotyping}

CA-repeat marker D3S1259 was used for genotyping. PCR amplification was performed using the following primer set:

Forward

Reverse
(FAM) 5"-GCT GGA CTA TAT TTG AAA CTC ATT-3'

$$
\text { 5'-TTT CAG TGA GCC AAG ATC GT-3' }
$$

The heterozygosity index of this marker is $0.75 .^{29}$ Amplified products were sizeresolved by capillary electrophoresis on an ABI-310 PRISM Genetic Analyzer (Applied Biosystems, Nieuwerkerk a/d/ IJssel, The Netherlands) using performance optimized polymer 4 (Applied Biosystems). Alleles were designated according to the size of the PCR product (Genescan analysis 2.0), using the Genescan-400 HD ROX (Applied Biosystems). Alleles with a frequency of more than $5 \%$ in both the $\mathrm{FCHL}$ and spouse groups were used in the analyses. These alleles were: CA185 (185 nucleotides), CA191, CA193, CA195, CA197, CA201, CA203, and CA205.

\section{PPARG intragenic genotyping}

Three intragenic PPARG single nucleotide polymorphisms (SNP) were studied, i.e. Pro12Ala in PPAR $\gamma 2$ specific exon 2, Pro115Gin and C161T in exon 6. All three SNPs were determined as previously described..$^{30,31}$ 


\section{Statistical analyses}

Deviations of the Hardy-Weinberg equilibrium were tested with a $x^{2}$-test. Differences in allelic distribution between cases and controls were determined by $\chi^{2}$. test. The relationship between each of the PPARG genotypes and plasma parameters was analyzed by Student's t-test, and/or by logistic regression analysis adjusting for age, gender and body mass index (BMI). Plasma $T G$, insulin, and glycerol concentrations were not nomally distributed and therefore log transformed. Statistical significance was considered at the $P<0.05$ level (two-sided).

\section{Results}

The clinical characteristics of the FCHL case-control panel are given in Table 4.1. FCHL subjects had significantly higher body mass index (BMI) and waist hip ratio (WHR), and significantly higher concentrations of plasma TC, TG, glucose, insulin, and apoB compared to spouse controls. In addition, FCHL subjects had significantly lower plasma HDL-C and apoAl concentrations compared to spouses.

To assess the role of the PPARG gene in the genetics of FCHL, the association between polymorphic marker D3S1259, situated $0.2 \mathrm{Mb}$ from the PPARG gene, and three intragenic polymorphisms, i.e Pro115GIn, Pro12Ala, and C161T, and FCHL was examined. The allele distribution of D3S1259 in the case-control panel was fully consistent with the distribution predicted by Hardy-Weinberg equilibrium. The overall allele frequency distribution of D3S1259 alleles did not differ between $\mathbb{F C H L}$ probands and spouses $(P=0.39$; Table 4.2). The genotype distributions of the Pro12Ala and C161T polymorphisms were also in Hardy-Weinberg equilibrium. The Pro115GIn variant was not found in any of the subjects examined. The Pro12Ala polymorphism was present in $16.5 \%(95 \% \mathrm{Cl}: 11.0-23.0 \%)$ of the probands and in $13.3 \%(95 \% \mathrm{Cl}: 9.1-18.0 \%)$ of the spouses ( $P=0.37)$. Subsequently, the frequency of the C161T variant was assessed in FCHL probands, which was $16.5 \%(95 \% \mathrm{Cl}$ : $9.2 \%-21.0 \%)$, and found to be $13.3 \%(95 \% \mathrm{Cl}: 9.2 \%-21.0 \%)$ in spouses $(P=0.39)$. 
Table 4.1 Clinical characteristics of the case-control study population.

\begin{tabular}{lcc}
\hline Traits & $\begin{array}{c}\text { Spouses } \\
(\mathrm{n}=124)\end{array}$ & $\begin{array}{c}\text { FCHL } \\
(\mathrm{n}=79)\end{array}$ \\
\hline Male/Female & $50 / 74$ & $47 / 32$ \\
Age (years) & $51.1 \pm 11.1$ & $50.4 \pm 10.9$ \\
BMI $\left(\mathrm{kg} / \mathrm{m}^{2}\right)$ & $25.3 \pm 3.9$ & $27.2 \pm 3.0^{\circ}$ \\
TC $(\mathrm{mmol} / \mathrm{L})$ & $5.54 \pm 1.02$ & $6.90 \pm 1.56^{\circ}$ \\
TG $(\mathrm{mmol} / \mathrm{L})$ & $1.33 \pm 0.61$ & $4.47 \pm 9.08^{\circ}$ \\
HDL-C (mmol/L) & $1.21 \pm 0.39$ & $0.94 \pm 0.27^{\circ}$ \\
FFA $(\mathrm{mmol} / \mathrm{L})$ & $0.48 \pm 0.84$ & $0.47 \pm 0.22$ \\
Glycerol $(\mu \mathrm{mol} / \mathrm{L})$ & $108.3 \pm 69.5$ & $125.3 \pm 150.7$ \\
Glucose $(\mathrm{mmol} / \mathrm{L})$ & $4.90 \pm 0.84$ & $5.35 \pm 0.78^{\circ}$ \\
Insulin $(\mu \mathrm{U} / \mathrm{ml})$ & $6.46 \pm 8.80$ & $10.5 \pm 6.11^{\circ}$ \\
ApoAl $(\mathrm{g} / \mathrm{L})$ & $1.44 \pm 0.24$ & $1.32 \pm 0.29^{\circ}$ \\
ApoB $(\mathrm{g} / \mathrm{L})$ & $1.00 \pm 0.25$ & $1.40 \pm 0.35^{\circ}$ \\
\hline
\end{tabular}

Data represent mean \pm standard deviation (SD).

$t_{P<0.01}$ spouses versus FCHL.

¿ $P<0.001$ spouses versus FCHL.

Table 4.2 D3S1259 allele frequencies in FCHL probands compared to spouses.

\begin{tabular}{|c|c|c|c|}
\hline D3S1259 & FCHL $n(\%)$ & Spouses $\mathrm{n}(\%)$ & $\mathbf{P}$ \\
\hline CA185 & $11(7.3)$ & $\| 8(7.6)$ & \\
\hline CA191 & $15(9.9)$ & $11(4.6)$ & \\
\hline CA193 & $7(4.7)$ & $15(6.3)$ & \\
\hline CA195 & $31(20.5)$ & $53 \cdot(22.3)$ & \\
\hline CA197 & $26 \cdot(17.2)$ & $50(21.0)$ & \\
\hline CA201 & $21(13.9)$ & $33(13.9)$ & \\
\hline CA203 & $19(12.6)$ & $36(15.1)$ & \\
\hline CA205 & $21(13.9)$ & $22(9.2)$ & \\
\hline Overall frequency difference & & & 0.39 \\
\hline Number of chromasomes (\%) & $151(100)$ & $238(100)$ & \\
\hline
\end{tabular}


In FCHL probands, carriers of the 12Ala allele had lower concentrations of plasma glycerol $(P<0.05)$ compared to noncarriers (Table 4.3). However, this association was not significant after correction for age "gender and BMI (Table 4.3). In spouses, no significant associations were observed with any of the plasma traits tested (Table 4.3).

Analysis of the $\mathrm{C} 161 \mathrm{~T}$ polymorphism in $\mathrm{FCHL}$ probands showed that the presence of the $T$ allele was assoclated with lower plasma FFA concentrations $(P<0.05)$ and glycerol concentrations $(P<0.01$; Table 4.4$)$ compared to non-carriers. These associations remained significant after adjustment for age, gender and BMI. In spouses, no significant associations were observed with any of the plasma lipid traits tested (Table 4.4).

Table 4.3 Clinical and lipid traits tested for association with the PPARG Pro12Ala geinotypes

\begin{tabular}{|c|c|c|c|c|}
\hline \multirow[t]{2}{*}{ Trait } & \multicolumn{2}{|c|}{ FCHL probands $(n=79)$} & \multicolumn{2}{|c|}{ Spouses $(n=124)$} \\
\hline & $\begin{array}{l}\text { Pro/Pro } \\
(n=57)\end{array}$ & $\begin{array}{l}\text { Pro/Ala and } \\
\text { Ala/Ala }(n=22)\end{array}$ & $\begin{array}{l}\text { Pro/Pro } \\
(n=93)\end{array}$ & $\begin{array}{l}\text { ProlAla and } \\
\text { Ala/Ala } \\
(n=31)\end{array}$ \\
\hline $\mathrm{BM} \|\left(\mathrm{kg} / \mathrm{m}^{2}\right)$ & $27.2 \pm 2.9$ & $27.2 \pm 3.5$ & $25.3 \pm 3.6$ & $25.7 \pm 4.7$ \\
\hline TC (mmol/L) & $6.97 \pm 1.59$ & $6.77 \pm 1.52$ & $5.59 \pm 1.02$ & $5.37 \pm 1.05$ \\
\hline To (mmol/L) & $4.86 \pm 10.6$ & $3.58 \pm 3.18$ & $1.35 \pm 0.61$ & $1.27 \pm 0.61$ \\
\hline HDL-C (mmol/L) & $0.95 \pm 0.30$ & $0.90 \pm 0.16$ & $1.21 \pm 0.41$ & $1.20 \pm 0.28$ \\
\hline FFA (mimol/L) & $0.50 \pm 0.23$ & $0.41 \pm 0.18$ & $0.46 \pm 0.20$ & $0.54 \pm 0.23$ \\
\hline Glycerol ( $\mu$ mól/L) & $112.9 \pm 49.3$ & $87.1 \pm 41.9^{\circ}$ & $103.7 \pm 71.6$ & $125.2 \pm 60.3$ \\
\hline Glucose $(\mathrm{mmol} / \mathrm{L})$ & $5.27 \pm 0.72$ & $5.56 \pm 0.94$ & $4.91 \pm 0.92$ & $4.88 \pm 0.50$ \\
\hline Insulin $(\mu \mathrm{U} / \mathrm{m}))$ & $10.7 \pm 6.11$ & $9.86 \pm 6.19$ & $6.49 \pm 9.49$ & $6.51 \pm 6.33$ \\
\hline ApoAl $(g / L)$ & $1.35 \pm 0.31$ & $1.23 \pm 0.21$ & $1.44 \pm 0.25$ & $1.44 \pm 0.22$ \\
\hline $\operatorname{ApaB}(g / L)$ & $1.43 \pm 0.35$ & $1.34 \pm 0.33$ & $1.01 \pm 0.25$ & $0.95 \pm 0.25$ \\
\hline
\end{tabular}

Data represent mean $1 \mathrm{SD}$.

"P<0.05; Pro/Pro versus Pro/Ala and Ala/Ala using Student's t-test. 
Table 4.4 Clinical and lipid traits tested for association with the PPARG CISIT genotypes.

\begin{tabular}{|c|c|c|c|c|}
\hline \multirow[t]{2}{*}{ Trait } & \multicolumn{2}{|c|}{ FCHL probands $(n=79)$} & \multicolumn{2}{|c|}{ Spouses (n=122) } \\
\hline & $\mathrm{ClC}(n=57)$ & $\begin{array}{c}\mathrm{C} / \mathrm{T} \text { and } \mathrm{T} / \mathrm{T} \\
(\mathrm{n}=22)\end{array}$ & $\mathrm{C} / \mathrm{C}(\mathrm{n}=90)$ & $\begin{array}{c}\text { CI ad TIT } \\
(n=32)\end{array}$ \\
\hline $\mathrm{BM} /\left(\mathrm{kg} / \mathrm{m}^{2}\right)$ & $27.9 \pm 29$ & $27.5 \pm 3.4$ & $25.6 \pm 3.7$ & $24.9 \pm 4.4$ \\
\hline TC (mmolls) & $6.98 \pm 1.57$ & $6.71 \pm 1.57$ & $5.52 \pm 1.00$ & $5.48 \pm 0.98$ \\
\hline TG $(\mathrm{mmol} / \mathrm{L})$ & $3.49 \pm 2.54$ & $7.33 \pm 17.3$ & $1.36 \pm 0.62$ & $1.26 \pm 0.59$ \\
\hline HDL-C (mmalli $)$ & $0.96 \pm 0.29$ & $0.87 \pm 0.16$ & $1.21 \pm 0.41$ & $1.20 \pm 0.28$ \\
\hline FFA (mmol/L) & $0.51 \pm 0.23$ & $0.37 \pm 0.14^{4}$ & $0.47 \pm 0.20$ & $0.53 \pm 0.23$ \\
\hline Glycerol ( $\mu \mathrm{mol} / \mathrm{L})$ & $119.0 \pm 49.8$ & $76.9 \pm 30.0^{1}$ & $102.1 \pm 71.4$ & $127.3 \pm 62.8$ \\
\hline Glucose (mmol/L) & $5.28 \pm 0.71$ & $5.53 \pm 0.96$ & $4.95 \pm 0.92$ & $4.74 \pm 0.52$ \\
\hline Insulin $(\mu \mathrm{U} / \mathrm{ml})$ & $10.4 \pm 6.0$ & $10.0 \pm 5.0$ & $6.63 \pm 9.65$ & $6.0 \pm 5.9$ \\
\hline ApoAl $(g / L)$ & $1.34 \pm 0.31$ & $1.25 \pm 0.19$ & $1.42 \pm 0.24$ & $1.42 \pm 0.25$ \\
\hline ApoB $(g / L)$ & $1.40 \pm 0.31$ & $1.40 \pm 0.43$ & 1.01 坚 0.24 & $0.94+0.27$ \\
\hline
\end{tabular}

Data represent mean $\pm \mathrm{SD}$.

" $P<0.05 ; C / C$ versus $C / T$ and $T / T$ using Student's t-test.

${ }^{\top} P<0.05$; $C / C$ versus $C / T$ and $T / T$ adjusted for age, gender and $B M I$ using logistic regression.

\section{Discussion}

The objective of the present study was to assess the role of the PPARG gene in the genetic pathophysiology of FCHL. The allele frequency distribution of marker D3S1259 and two intragenic polymorphisms C161T and Pro12Ala did not differ between FCHL cases and spouse controls. However, the $161 \mathrm{~T}$ allele, from the C161T variant, was associated with plasma FFA and glycerol concentrations and the $12 \mathrm{Ala}$ allele, from the Pro12Ala variant, was associated with plasma glycerol concentrations in FCHL probands, but not in spouses. We are the first, to our knowledge, to report on an association between PPARG variants and plasma FFA and glycerol concentrations in a complex genetic disorder. Recently the association between the Pro12Ala variant and plasma FFA concentrations in healthy subjects was studied, but no significant associations were observed ${ }^{32}$, supporting the lack of association in spouses in the present study. These findings identify the PPARG gene 
as a modifier gene acting on adipose tissue insulin resistance traits in Dutch FCHL subjects, supporting previous findings in a Finnish FCHL population. ${ }^{20}$

At present, the role of PPARy in mediating effects of fatty acids on gene expression and adipose cell fate has been firmly established (reviewed in ${ }^{24}$ ). PPARy is abundantly expressed in adipose tissue and a major factor in adipocyte differentiation. ${ }^{24}$ Altered or impared PPARy gene expression can, therefore, affect multiple processes in adipose tissue. Impaired adipose tissue function is believed to contribute to $\mathrm{FCHL}^{4,5,8-11,17}$ and, recently, our laboratory reported that FFA utilization in FCHL adipocytes is impaired. ${ }^{8}$ The present finding that in FCHL the $161 \mathrm{~T}$ allele is associated with lower plasma FFA and glycerol concentrations and the 12Ala allele is associated with low plasma glycerol concentrations are in line with these observations. Interestingly, in Finnish FCHL subjects the 12Ala allele was found to be associated with lower fasting insulin plasma concentrations ${ }^{20}$, but plasma FFA and glycerol concentrations were not studied. FFA released from adipose tissue TG via lipolysis are key mediators of impaired insulin sensitivity. ${ }^{33}$ Therefore, adipose tissue may act better in its buffer function ${ }^{33}$ in FCHL subjects carrying the $161 \mathrm{~T}$ or 12Ala allele compared to non-carriers, this suggests more adequate lipogenesis and FFA re-esterification, processes that are impaired in FCHL. ${ }^{8}$ Thus, the present findings suggest an insulin sensitizing action of the Pro12Ala and C161T PPARG variants.

Interestingly, the associations of the Pro12Ala and C161T variants were specifically observed in FCHL cases and not in spouses. This can be explained by the fact that subjects with $\mathrm{FCHL}$ are characterized by whole body insulin resistance for glucose uptake in a similar degree to that of subjects with DM2. ${ }^{8}$ Although the insulin resistance is predominantly at the level of muscle in FCHL, FCHL subjects show insulin resistant adipose tissue lipid metabolism in contrast to type 2 diabetes. ${ }^{8}$ The hyperlipidemic and insulin resistant FCHL phenotype is the result of multiple genetic and environmental factors, and combined will ultimately determine whether a gene will act as a modifier gene, i.e. affecting a trait positively or negatively, or not. This suggests that the genetic background can determine whether a genetic effect is observed for a modifier gene. With regard to PPARG, support for this concept has been obtained recently in subjects with acanthosis nigricans combined with severe $I .^{34}$ Recently, we identified the peroxisome proliferator-activator receptor alpha 
(PPARA) gene as a modifier gene in FCHL, predominantly affecting plasma apoCill concentrations and the expression of the combined hyperlipidemic FCHL phenotype. ${ }^{21}$ The combined involvement in FCHL of PPARA, which exerts its function predominantly in liver and muscle ${ }^{35}$, and $P P A R G$, which predominantly plays a critical role in adipogenesis ${ }^{35.36}$ "is a clear illustration of the complex genetic nature of FCHL.

Apart from a role in insulin signaling and lipid metabolism, PPARy has also been shown to induce apoptosis in fully differentiated large adipocytes. ${ }^{37}$ The ability of PPARy to induce apoptosis in combination with its capacity to enhance differentiation of pre-adipocytes into mature adipocytes, favors the formation of small adipocytes. ${ }^{37}$ This process has been suggested to be an important mechanism through which elevated plasma lipid levels are normalized. ${ }^{37}$ Interestingly, we recently showed that cell cycle genes were up-regulated in $\mathrm{FCHL}$ adipose tissue ${ }^{38}$, whereas several proapoptotic genes were down-regulated in $\mathrm{FCHL}$ adipose tissue (unpublished data, 2002). This expression pattern may reflect hyperplasia of adipocytes in FCHL, and is, at least in theory, in agreement with a role of adipose tissue in the expression of FCHL. Continuously increased delivery of lipoproteins and their remnants from plasma to adipocytes in FCHL may increase cell cycle gene expression and reduce apoptosis in order to accommodate the persistent lipid supply. PPAR $\gamma$ may be central to the abnormalities in cell cycle and apoptosis gene expression, but at present there is no evidence of differential PPARG gene expression in FCHL adipose tissue. ${ }^{39}$ This suggests that alternative mechanisms, such as posttranscriptional modifications, abnormal substrate delivery to the PPAR $\gamma$ protein, or changes in hetero-dimerization with the retinoid $X$ receptor, may explain the altered PPARy signaling in FCHL adipose tissue.

In conclusion, the present data showed that PPARG acts as a modifier gene in FCHL, affecting plasma concentrations of FFA, and glycerol. These data suggest an insulin sensitizing action of PPARG variants specifically in FCHL cases, but not in controls, and may identify PPARG as a new target for treatment with PPARG ligands in FCHL. The present findings illustrate that in FCHL genetic predisposition, such as variants in PPARG, can significantly affect adipose tissue related insulin resistance. 


\section{References}

1. Goldstein JL, Schrott HG, Hazzard WR, Bierman EL, Motulsky AG. Hyperlipidemia in coronany heart disease. II. Genetic analysis of lipid levels in 176 families and delineation of a new inherited disorder, combined hypenipidemia. J Clin.lnvest. 1973,52:1544-1568.

2. Voors-Pette $\mathrm{C}$, de Bruin TWA. Excess coronany heart disease in Famillial Combined Hyperlipidemia, in relation to genetic factors and central obesity. Atherosclerosis. 2001;157:481489.

3. Pikilajamaki $J$, Karjalainen $L_{\text {* }}$ Karhapaa $P$ "Vauhkonen $I$, Laakso M. Impaired free fatty acid suppression during hyperinsulinemia is a characteristic finding in familial combined hyperlipidemia, but insulin resistance is observed only in hypertiglyceridemic patients. Anterioscler. Thromb. Vasc. Biol. 2000;20:164-170.

4. Castro-Cabezas $M_{1}$ de Bruin TWA de Valk $H W$, Shoulders $C C_{\text {, Jansen }} H_{2}$ Erkelens DW. Impaired fatty acid metabolism in familial combined hyperlipidemia. A mechanism associating hepatic apolipoprotein $B$ overproduction and insulin resistance. J.Clin./nvest. 1993;92:160-168.

5. Aittman TJ, Godsland IF, Farren B, Crook D, Wong HJ, Scott J. Defects of insulin action on fatty acid and carbohydrate metabolism in familial combined hyperlipidemia. Arterioscler. Thromb. Vasc.Biol 1997; 17:748-754.

6. Bredie SJ, Tack CJ, Smits P. Stalenhoef AF. Nonobese patients with familial combined hyperlipidemia are insulin resistant compared with their nonaffected relatives. Arterioscler. Thromb. Vasc.Biol. 1997;17:1465 1471.

7. Karjalainen $L$, Pihlajamaki $J$, Karhapaa $P$, Laakso $M$. Impaired insulin-stimulated glucose oxidation and free fatty acid suppression in patients with familial combined hyperlipidemia: $a$ precursor defect for dyslipidemia? Arterioscler. Thromb. Vasc.Biol. 1998;18:1548-1553.

8. van der Kallen CuH, Voors-Pette C. Bouwman FG, Keizer HA, Lu JY, van de Hulst RRWJ, Bianchi $R$, Janssen $M-J$, Keulen ETP. Boeckx WD, Rotter Jl, de Bruin TWA. Evidence of Insulin Resistant Lipid Metabolism of Adipose Tissue in Familial Combined Hyperlipidemia, but not in type 2 Diabetes. Atherosclerosis. 2002;164:337-346.

9. Reynisdottir $S$, Eriksson $M_{7}$ Angelin $B$, Arner $P$. Impaired activation of adipocyte lipolysis in familial combined hyperlipidemia. J.Clin.Invest. 1995;95:2161-2160.

10. Meijssen $S$, Castro-Cabezas M. Twickler TB, Jansen $H$, Erkellens DW. In vivo evidence of defective postprandial and postabsorptive free fatty acid metabolism in familial combined hypertipidemia. J Lipid Res. 2000;41:1096-1102.

11. Sniderman $A D$, Cianflone K, Arner $P$, Summers LK, Frayn KN. The adipocyte, fatty acid trapping, and atherogenesis. Anterioscler. Thromb. Vasc Bial 1998;18:147-151.

12. Babirak SP, Brown BG, Brunzell JD. Familial combined hyperlipidemia and abnormal lipoprotein lipase. Arterioscler. Thromb. Visc.Biol. 1992;12:1176-1183.

13. Pajukanta $P$. Porkka KV. Antikainen M. Taskinen MR. Perola M, Murtomaki RS, Ehnhholm $S$, Nusotio I. Suurinkeroinen L. Lahdenkari AT, Syvanen AC, Viikari JS, Ehnholm C, Peltonen L. No evidence of linkage between familial combined hyperlipidemia and genes encoding lipolytic enzymes in Finnish families. Arterioscler Thromb. Vasc. Biol. 1997;17:841-850.

14. Pajukanta P. Nuotio I, Terwilliger JD, Porkka KV. Ylitalo $K$. Pihlajamaki J Suomalainen AJ" Syvanen $A C$, Lehtimaki T, Vilkari JS, Laakso $M_{8}$ Taskinen MR, Ehnholm C. Peltonen L. Linkage of familial combined hyperlipidaemia to chromosome $1 q 21$-q23. Nat Genet. 1998;18:369-373.

15. Aouizerat BE. Allayee $H$, Cantor RM, Davis RC, Lanning $C D$, Wen $P Z$, Dallinga-Thie $G M$, de Bruin TWA, Rotter Jl: Lusis AJ. A genome scan for familial combined hyperlipidemia reveals evidence of linkage with a locus on chromosome 11. Am.J.Hum. Genet. 1999;65:397-412.

16. Allayee $\mathrm{H}$, de Bruin TWA, Dominguez KM, Cheng LS-C, Ipp $E$, Cantor RM, Krass KL, Keulen ETP, Aouizerat BE, Lusis AJ, Rotter Jl. Genome-scan for blood pressure in Ductch dyslipidemic families, reveals linkage to a locus on chromosome 4p. Hypertension, 2001;38:773-778.

17. van der Kallen C.JH, Cantor RM, van Greevenbroek MMJ, Geurts JMW. Bouwman FG, Aouizerat

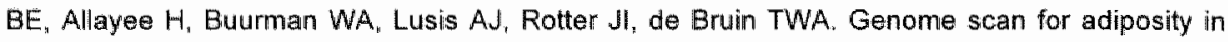
Dutch dyslipidemic families reveals novel quantitive trait loci for leptin, body mass index and 
soluble tumor necrosis factor receptor superfamily 1A. ImUJObes.Relat.Melab. Oisord. $2000 ; 24: 1381-1391$

18. de Bruin TWA, Mailly $F$, van Barlingen $H$, Fisher $\mathbb{R}_{*}$ Castro-Cabezas $M$, Talmud $P$, Dallinga-Thie GM. Humphries SE. Lipoprotein lipase gene mutations. D9N and N291S in four pedigrees with familial combined hypertipidaemia. Eur.J. Clin. Invest. 1996;26:631-639.

19. Dallinga-Thie GM, van Linde-Sibenius TM, Rotter Jl, Cantor RM, Bu X, Lusis AJ, de Bruiln TWA. Complex genetic contribution of the Apo Al-CIII-AlV gene cluster to familiall combined hyperlipidemia. Identification of different susceptibility haplotypes. J Clin Invest. 1997;99:953. 961.

20. Pihlajamaki J, Miettinen $R_{n}$ Valve $R$., Karjalainen L, Kuusisto J, Deeb $S$, Auwerx J, Laakso M. The Pro12Ala substitution in the peroxisome prollferator activated receptor gamma 2 is associated with an insulin-sensitive phenotype in families with familial combined hyperlipidemia adn in nondiabetic elderly subjects with dyslipidemia. Atherosclorosis. 2000;151:567-574.

21. Eurlings $P M H_{x}$ van der Kallen C.JH, Geurts JMW, Flavell DM, de Bruin TWA. Identification of the PPARA locus on chromosome $22 \mathrm{q} 13.3$ as a modifier gene in familial combined hyperlipidemia. Mol. Genet.Metab. 2002;77:274-281.

22. Rosen ED, Walkey $C J$, Puigserver $P$, Spiegelman BM. Transcriptional regulation of adipogenesis. Genes Dev. 2000;14:1293-1307.

23. Walczak R, Tontonoz P. PPARadigms and PPARadoxes: expanding roles for PPARgamma in the control of lipid metabolism. J.Lipid Res. 2002;43:177-186.

24. Hihi AK, Michalik L, Wahli W. PPARs: transcriptional effectors of fatty acids and their derivatives. Cell Mol Life Sci. 2002; 59:790-798.

25. Lehmann JM, Moore LB, Smith×Oliver TA, Wilkison WO, Willson TM, Kliewer SA. An antidiabetic thiazolidinedione is a high affinity ligand for peroxisome proliferator-activated receptor gamma (PPAR gamma). J.Biol Chem. 1995;270:12953-12956.

26. Zhang B, Berger J, Zhou $G$, Elbrecht A, Biswas S, White-Carrington S, Szalkowski D, Moller DE. Insulin- and mitogen-activated protein kinase-mediated phosphorylation and activation of peroxisome proliferator-activated receptor gamma. J.Biol. Chem. 1996;271:31771-31774.

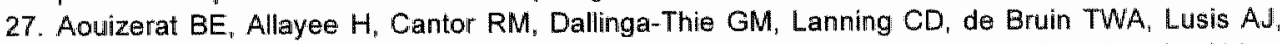
Rotter Jl. Linkage of a candidate gene locus to familial combined hyperlipidemia - Lecithin cholesterol acyltransferase on 16q. Arterioscler. Thromb. Vasc. Biol. 1999:19:2730-2736.

28. Geurts JMW, Janssen RGJH, van Greevenbroek MMJ, van der Kallen C.JH, Cantor RM, Bu X, Aouizerat BE, Allayee $H_{\text {w }}$ Rotter Jl, de Bruin TWA. Identification of TNFRSF1B as a novel modifier gene in familial combined hyperlipidemia. Hum. Mol. Genet. 2000;9:2067-2074.

29. http://www. gidb.org.

30. EK d, Urhammer SA Sorensen TI, Andersen T. Auwerx d, Pedersen O. Homozygosity of the Pro12Ala variant of the peroxisome proliferation-activated receptor-gamma2 (PPAR-gamma2): divergent modulating effects on body mass index in obese and lean Caucasian men. Diabetologia. 1999;42:892-895.

31. Wang XL. Oosterhof J, Duarte $N$. Peroxisome proliferator-activated receptor gamma $\mathrm{C} \| 61,-\mathrm{T}$ polymorphism and coronary artery disease. Cardiovasc. Res. 1999;44:588-594.

32. Vaccaro $O$, Mancini FP, Ruffa $G$, Sabatino $L$, lovine $C$, Masulli $M$, Colantuoni V. Riccardi $G$. Fasting plasma free fatty acid concentrations and Pro12Ala polymorphism of the peroxisome proliferator-activated receptor (PPAR) gamma2 gene in healthy individuals. Clin. Endocrinol.(Oxf.). 2002;57:481-486.

33. Frayn KN. Adipose tissue as a buffer for daily lipid flux. Diabetologia. 2002;45:1201-1210.

34. Savage DB. Agostini M, Barroso I, Gurnell M, Luan J, Meirhaeghe A, Harding AH, Ihrke G. Rajanayagam O, Soos MA, George S, Berger D, Thomas EL, Bell JD, Meeran K. Ross R.J, VidalPuig A, Wareham NIJ, ORahilly $S$, Chatterjee VK, Schafer AJ. Digenic inheritance of severe insulin resistance in a human pedigree. Nat. Genet. 2002,31:379-384.

35. Schoonjans $K_{x}$ Martin G, Staels B, Auwerx J. Peroxisome proliferator-activated receptors, orphans with ligands and functions. Curr. Opin. Lipidol. 1997;8:159-166.

36. Auwerx J. PPARgamma, the ultimate thrifty gene. Diabetologia. 1999:42:1033-1049. 


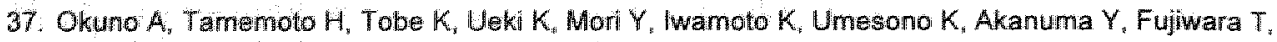
Horikoshi $H$. Yazaki $Y$, Kadowaki $T$. Troglitazone increases the number of small adipocytes without the change of white adipose tissue mass in obese Zucker rats. J.Clin.fonvest. $1998 ; 101: 1354-1361$

38. Eurlings $P M H$, van der Kallen C.JH, Geurts $\triangle M W$, Kouwenberg P, Boeckx WD, de Bruin TWA. Identification of differentially expressed genes in subcutaneous adipose tissue from subjects with familial combined hyperlipidemia. J.Lipid Res. 2002;43:930-935. 
Chapter 5

\section{Identification of the PPARA locus on}

\section{chromosome 22q13.3 as a modifier}

gene in Familial Combined

\section{Hyperlipidemia}

PMH Eurlings, CJH van der Kallen, JMW Geurts, DM Flavell, TWA de Bruin 


\section{Abstract}

Familial combined hyperlipidemia ( $\mathrm{FCHL}$ ) is a common genetic lipid disorder that is present in 10 percent of patients with premature coronary artery disease (CAD). It was the objective of the present study to evaluate the possible involvement of the PPARA locus in the pathophysiology of FCHL. Mutation detection analyses of the six coding PPARA exons resulted in the identification of four novel variants, $[\mathrm{C} / T]$ intron 3, S234G, [G/A] intron 5, and [C/A] $3^{2}$ UTR in three $\mathrm{FCHL}$ probands, whereas no novel variants were identified in spouses, In a case-control study. markers D22S275 and D22S928 were shown not to be associated with FCHL. However, D22S928, mapped within $1 \mathrm{Mb}$ of the PPARA gene, was shown to have a modifying effect on plasma apoCIII concentrations $(P=0.011)$ and the combined hyperlipidemic $\mathrm{FCHL}$ phenotype $(P=0.038)$. In addition two PPARA polymorphisms in intron 2 and 7 were studied, but these were not associated with $\mathrm{FCHL}$. The frequency of the $\mathrm{L} 162 \mathrm{~V}$ variant was less in $\mathrm{FCHL}$ probands (1.98\%) compared to that in spouses $(4.84 \%$ ). These results clearly demonstrate the genetically complex nature of $\mathrm{FCHL}$ and identify the PPARA gene as a modifier of the FCHL phenotype. 


\section{Introduction}

Familial combined hyperlipidemia ( $\mathrm{FCHL}$ ) is a common genetic lipid disorder that is present in 10 percent of patients with premature coronary artery disease (CAD). FCHL is defined by elevated plasma cholesterol $(>6.5 \mathrm{mmol} / \mathrm{L})$ and/or triglyceride levels (>2.3 mmol/L). In addition, hepatic apolipoprotein (apo) B overproduction, elevated plasma apoB concentrations, small dense low density lipoprotein (LDL), low levels of high density lipoprotein (HDL), elevated postprandial free fatty acids (FFA) and insulin resistance have been associated with $\mathrm{FCHL}{ }^{2-4} \mathrm{FCHL}$ was presumed to have a Mendelian dominant pattern of inheritance, ${ }^{1}$ but recent analyses indicated that this disorder is genetically more complex. ${ }^{5.6}$ At present, a major FCHL locus, Hyplip 1, has been identified on chromosome 1 in a Finnish population. ${ }^{7}$ In our Dutch FCHL families, chromosomal loci have been identified that contribute to hyperlipidemia, plasma leptin levels (a marker of adiposity), and systolic blood pressure, indicating a genetic propensity to the insulin resistance syndrome..$^{8-10}$

In search of novel genes for $\mathrm{FCHL}$, the peroxisome proliferator-activated receptor alpha (PPARA) gene is an interesting candidate. PPAR $\alpha$ acts as a nuclear transcription factor regulating genes involved in intra- and extracellular lipid metabolism, such as lipolysis and mitochondrial $\beta$-oxidation. ${ }^{11}$ PPAR $\alpha$ is activated by natural ligands derived from fatty acids such as $8(S)$ hydroxyeicosatetraenoic acid,

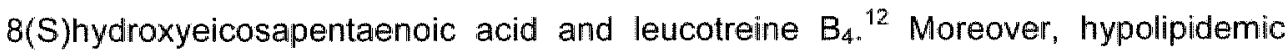
drugs, such as fibrates, are ligands for PPAR $\alpha .^{13}$ Fibrate treatment has been shown to be effective in the management of $\mathrm{FCHL}$, with a predominant effect on the correction of hypertriglyceridemia and low HDL-cholesterol levels. ${ }^{14}$ In addition, PPAR $\alpha$ has also been implicated in changes in plasma apoB concentrations. ${ }^{15}$

Recently, we reported a linkage study with 14 candidate gene loci in Dutch FCHL families. ${ }^{5}$ In this report, the PPARA gene (marker D22S275) showed no linkage with $F C H L$ (adjusted $P$-value for multiple testing: $P=0.06$ ), but in the report it was not mentioned that the unadjusted $P$-value was significant $(P=0.004)$. Although of considerable interest, this study may have lacked sufficient power to detect significant linkage, since multiple candidate genes and a limited number of genetically independent FCHL individuals were tested. Therefore, the present 
objective was to assess the involvement of the PPARA locus on chromosome 22913.3 in FCHL by mutation detection experiments and a formal association study.

\section{Methods}

\section{Subjects}

The case-control study population consisted of 102 genetically unrelated FCHL probands (of which 18 were used in the candidate gene study), each representing one FCHL family, and 124 unrelated spouses, recruited through the Lipid Clinics of both the Maastricht and Utrecht University Hospitals. FCHL families were ascertained as previously described. ${ }^{5}$ Probands had a primary hyperlipidemia with a varying phenotypic expression including a fasting plasma cholesterol $>6.5 \mathrm{mmol} / \mathrm{L}$ and/or a fasting plasma triglyceride $>2.3 \mathrm{mmol} / \mathrm{L}$ sometimes combined with the presence of CAD. Spouses represent a common environment, nutrition, and age matched control group without hyperlipidemia. The excess of spouse individuals in this study is explained by the inclusion of i) spouses whose partner had deceased due to complications of FCHL, and ii) spouses of unaffected FCHL relatives. The study protocol was approved by both of the Human Investigation Review Committees of the University Hospitals of Maastricht and Utrecht, and all subjects gave informed consent.

\section{Biochemicall analyses}

Venous blood was drawn after an overnight fast $(12-14 \mathrm{~h})$ in pre-cooled EDTA (1 $\mathrm{mg} / \mathrm{ml}$ ) tubes and prepared by immediate centrifugation for analytical analyses. All subjects on hyperlipidemic drugs were withheld from therapy for two weeks in order to obtain untreated plasma samples from all subjects. It is known that subjects who were originally hyperlipidemic then return to a hyperlipidemic phenotype (unpublished observations). Plasma concentrations of total cholesterol (TC), triglycerides (TG), HDL-cholesterol (HDL-C), HDL-triglycerides (HDL-TG), FFA, apo $\mathrm{Al}$, and apoB were measured as described before. ${ }^{16} \mathrm{LDL}$ particle size was also measured as previously reported. ${ }^{16}$ Plasma apoClll concentrations were measured 


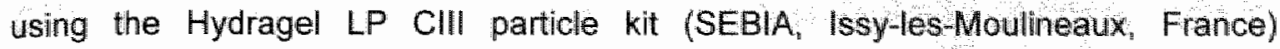
according to the manufacturers instructions.

\section{PPARA mutation analysis}

Denaturing high-performance liquid chromatography (DHPLC)-based mutation detection analysis was performed using the WAVE DNA Fragment Analysis System (Transgenomic, Omaha, NB). ${ }^{16}$ All six coding PPARA exons (exons 3 to 8 ) were screened in $52 \mathrm{FCHL}$ probands and 78 spouses from the case-control population. The following primer sets were used for polymerase chain reaction (PCR) amplification:

Exon 3 forward 5"-CAA GTG AAC GTT GTT ATA ACG-3" reverse 5'-GTT TCT TCC TCC AAG AAA AG-3'

Exon 4 forward 5'-GAA GCC TCG TAT GCG AAA TC-3' reverse 5-TGT TAT CCG GGA CTT TCT GC-3:

Exon 5 forward 5'-AGT AAA GCA AGT GCG CTG GT-3' reverse 5'-GAT CTG TTC CCT TGG AGC AA-3'

Exon 6 forward 5'-TCC ATA GTG GAA AGC CGA AT-3' reverse 5'-GGT TCC ATG TTG CCA AGA GA-3'

Exon 7 forward 5'-ATA GCG CAT CCC ACA TCA C-3' reverse 5'-ACA GCT CAG GCT GGT ACT GG-3'

Exon 8 forward 5'-TGA TAA GCA GTT CTT GGG TGA-3' reverse 5'-GCA TTG ATT AAC ATC GGG TGA-3'

Runs were performed at temperatures varying from $57^{\circ} \mathrm{C}$ to $61^{\circ} \mathrm{C}$. The nucleotide sequences of the samples showing aberrant WAVE chromatograms were determined by fluorescence-based automated sequencing on an ABI-310 PRISM Genetic analyzer (Applied Biosystems, Nieuwerkerk a/d/ IJssel, The Netherlands). 


\section{PPARA intragenic genotyping}

Two intragenic PPARA single nucleotide polymorphisms (SNP) in intron 2 and intron 7 were studied. The intron 2 SNP ( $G$ to A substitution) was determined as described before. ${ }^{17} \mathrm{~A}$ restriction enzyme digestion assay was designed for the intron 7 SNP (G to $C$ substitution, nucleotide 82158 of Genbank sequence AL032818). PCR amplification was performed using forward primer 5'- ACA ATC ACT CCT TAA ATA TGG TGG-3' and reverse primer 5'-AAG TAG GGA CAG ACA GGA CCA GTA3'. The polymorphism was subsequently digested with Taql (New England Biolabs, Beverly, MA). In addition the L162V variant was determined by WAVE analysis as described above and a forced-site assay as described previously. ${ }^{17}$

\section{PPARA locus genotyping}

The CA-repeat markers D22S275, and D22S928, were used for genotyping. PCR amplification was performed using the following primer sets:

$\begin{array}{cc}\text { D22S275 forward } & \text { (FAM) } 5^{\prime}-\text { CTC CAG CCT GTG CAA CAGA G-3' } \\ \text { reverse } & 5^{\prime} \text {-GGC TCA ACC CAT CCT CCT-3' }\end{array}$

$\begin{array}{lrr}\text { D22S928 forward } & \text { (FAM) 5'-TGC AAA GTG CTG GAG G-3' } \\ & \text { reverse } & 5^{\prime} \text {-TGA AGA TGG CTA GTA CGG G-3' }\end{array}$

The heterozygosity index of the markers D22S275 and D22S928 is 0.82 and 0.79 respectively. ${ }^{18}$ Amplified products were size-resolved by capillary electrophoresis on an ABI-310 PRISM Genetic Analyzer (Applied Biosystems) using performance optimized polymer 4 (Applied Biosystems). Alleles were designated according to the size of the PCR product (Genescan analysis 2.0), using the Genescan-400 HD ROX or the Genescan-500 TAMRA size standard (Applied Biosystems). Alleles with a frequency of more than $5 \%$ in both the FCHL and spouse groups were used for analyses. These alleles were for each marker:

D22S275: CA160 (160 nucleotides), CA162, CA164, CA166, CA168, D22S928: CA149, CA157, CA173, CA175. 


\section{Statistical analyses}

Differences in allelic distribution between cases and controls were determined by $x^{2}$-test. P-values were corrected for multiple testing using a Bonferroni correction when individual allele frequencies were tested. Deviations of the Hardy-Weinberg equilibrium were tested with a $\chi^{2}$-test. The relationship between each of the PPARA genotypes and plasma parameters was analyzed by Student's t-test ${ }_{\text {" }}$ and by logistic regression analysis adjusting for age and body mass index (BMI). Plasma TG was not normally distributed and therefore log transformed. Statistical significance was considered at the $P<0.05$ level (two-sided).

\section{Results}

\section{Novel variations in the PPARA gene}

PPARA gene mutation detection experiments were done by WAVE DHPLC technology ${ }^{16}$ in search for mutations or variants associated with FCHL. Each of the coding PPARA exons was screened in $52 \mathrm{FCHL}$ probands and 78 spouses. We identified four novel variants in three separate $\mathrm{FCHL}$ subjects, but none in spouses (Figure 4.1). In one proband two variants were identified, a $\mathrm{C}$ to $\mathrm{T}$ substitution -71 bases of exon $4([\mathrm{C} / T]$ intron 3, affecting nucleotide 101787 of Genbank sequence ALD32818), and an $A$ to $G$ substitution resulting in a Serine to Glycine substitution at codon 234 (S234G, affecting nucleotide 96886 of Genbank sequence AL032818). Moreover, a $G$ to $A$ substitution -84 bp from exon 6 ([G/A] intron 5 , affecting nucleotide 97161 of Genbank sequence AL032818), and a $\mathrm{C}$ to $\mathrm{A}$ substitution in the 3'-UTR ([C/A] 3' UTR exon 8, affecting nucleotide 81336 of Genbank sequence AL032818) were found in two different FCHL probands. The $3 \mathrm{FCHL}$ carriers of the variant alleles $[\mathrm{C} / \mathrm{T}]$ intron $3, \mathrm{~S} 234 \mathrm{G}$ and [C/A] 3 UTR, or [G/A] intron 5 did not present with exceptional phenotypes except for remarkably low plasma HDL-C concentrations being $0.79,071$, and $0.68 \mathrm{mmol} / \mathrm{L}$ respectively. Analyses of the genotypes of first-degree relatives of the FCHL probands carrying the $[\mathrm{C} / \mathrm{T}]$ intron 3 , S234G, [G/A] intron 5, and [C/A] $5^{\prime}$ UTR variant did not result in the identification of additional carriers. 


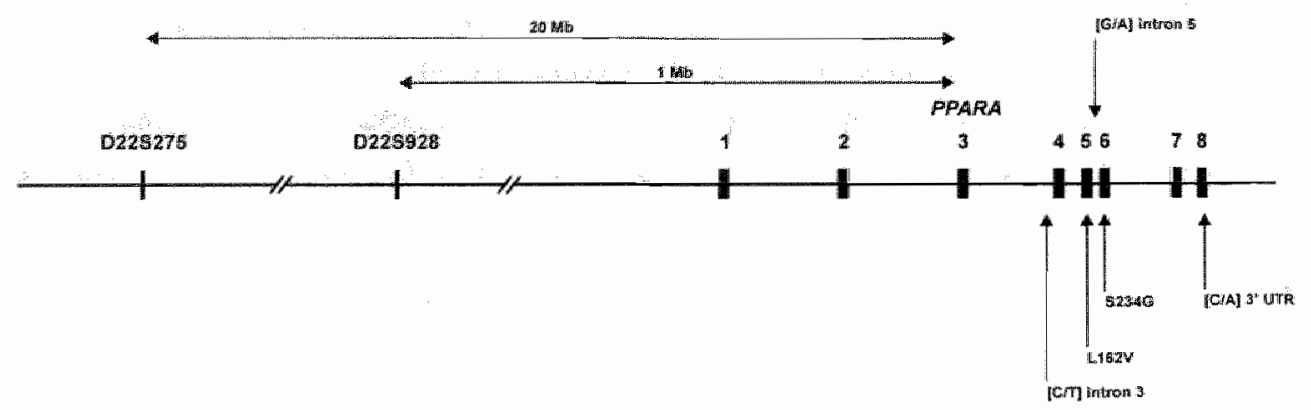

Figure 4.1 Schematic overview marker positions in relation to the PPARA locus.

Positions of markers D22S275, D22S928 and the genomic organization of the PPARA gene are based on data available in the Ensemble, Whitehead and Sanger public databases (last consultation 24 January 2002).

Ensemble: hittp://www.ensemble.org/

Whitehead: http://www-genome.wi.mit-edu/

Sanger: http://www.sanger.ac.uk/HGP/Chr22/

\section{PPARA intragenic genotyping}

The frequency and phenotypic associations of PPARA genotypes were analyzed in $102 \mathrm{FCHL}$ probands and 124 spouses. Table 4.1 presents the clinical characteristics of the case-control study population.

The WAVE DHPLC technology resulted in the identification of the recently reported $L 162 \mathrm{~V}$ variant as well. ${ }^{17}$ The $\mathrm{V} 162$ allele was present in $1.98 \%(95 \% \mathrm{Cl}$ $0.042-3.88)$ of the probands and in $4.84 \%(95 \% \mathrm{Cl} 2.15-7.55 \%)$ of the spouses $(P=0.10$; Table 4.2). Interestingly, the $L 162 \mathrm{~V}$ frequency in $\mathrm{FCHL}$ probands $(1.98 \%)$ is notably lower than that reported in other Caucasian populations (varying between $2.8 \%$ and $12.8 \%$, on average being $7 \%$ ), suggesting that the $162 \mathrm{~V}$ allele protects against expression of FCHL. Based on the limited number of individuals in the casecontrol panel carrying the $L 162 \mathrm{~V}$ variant no additional statistical analyses were warranted. Therefore, a case-control association study was performed using two more frequent PPARA polymorphisms, an intron $2[\mathrm{G} / \mathrm{A}]^{17}$ and an intron $7[\mathrm{G} / \mathrm{C}]$ 
Table 4.1 Clinicall characteristics of the case-control study population.

\begin{tabular}{lccc}
\hline Trait & $\begin{array}{c}\text { FCHL } \\
(\mathrm{n}=102)\end{array}$ & $\begin{array}{c}\text { Spouses } \\
(\mathrm{n}=124)\end{array}$ & $P$ \\
\hline Male/Female & $41 / 61$ & $73 / 51$ & 0.003 \\
Age $(\mathrm{yr})$ & $51.4 \pm 10.8$ & $51.1 \pm 11.1$ & $\mathrm{NS}$ \\
BMI $\left(\mathrm{kg} / \mathrm{m}^{2}\right)$ & $27.4 \pm 3.25$ & $25.3 \pm 3.88$ & $\leq 0.001$ \\
TC $(\mathrm{mmol} / \mathrm{L})$ & $6.90 \pm 2.4$ & $5.5 \pm 1.0$ & $\leq 0.001$ \\
HDL-C $(\mathrm{mmol} / \mathrm{L})$ & $0.92 \pm 0.26$ & $1.22 \pm 0.39$ & $\leq 0.001$ \\
TG $(\mathrm{mmol} / \mathrm{L})$ & $4.4 \pm 8.3$ & $1.3 \pm 0.6$ & $\leq 0.001$ \\
ApoAll $(\mathrm{g} / \mathrm{L})$ & $1.33 \pm 0.27$ & $1.44 \pm 0.24$ & 0.004 \\
ApoB $(\mathrm{g} / \mathrm{L})$ & $1.4 \pm 0.34$ & $1.0 \pm 0.25$ & $\leq 0.001$ \\
ApoCIII $(\mathrm{mg} / 100 \mathrm{ml})$ & $5.87 \pm 1.85$ & $4.37 \pm 1.17$ & $\leq 0.001$ \\
LDL-size $\left(1.10^{-10} \mathrm{~m}\right)$ & $259.7 \pm 1.73$ & $271.2 \pm 7.88$ & $\leq 0.001$ \\
\hline
\end{tabular}

Data represent mean $\pm S D$.

Table 4.2 Clinical characteristics of PPARA L162L and L162V allele carriers.

\begin{tabular}{|c|c|c|c|c|}
\hline \multirow[t]{2}{*}{ Traits } & \multicolumn{2}{|c|}{ FCHL probands ( $n=102$ ) } & \multicolumn{2}{|c|}{ Spouses $(n=124)$} \\
\hline & L/L $(n=98)$ & $L N(n=4)$ & L/L $(n=112)$ & $L N(n=12)$ \\
\hline Gender (F/M) & $48 / 60$ & $3 / 11$ & $68 / 44$ & $6 / 6$ \\
\hline Age & $51.4 \pm 10.8$ & $52.3 \pm 13.5$ & $51.4 \pm 11.3$ & $48.3 \pm 9.37$ \\
\hline BMII $\left(\mathrm{kg}^{\prime} \mathrm{m}^{2}\right)$ & $27.3 \pm 3.2$ & $30.1 \pm 3.5$ & $25.2 \pm 3.9$ & $26.6 \pm 3.4$ \\
\hline TC $(\mathrm{mmol} / \mathrm{L})$ & $6.93 \pm 2.46$ & $6.29 \pm 1.49$ & $5.52 \pm 1.02$ & $5.69 \pm 1.02$ \\
\hline HDL-C (mmol/L) & $0.91 \pm 0.25$ & $1.14 \pm 0.30$ & $1.23 \pm 0.38$ & $1.12+0.42$ \\
\hline $\mathrm{TG}(\mathrm{mmol} / \mathrm{L})$ & $4.35 \pm 8.27$ & $1.74 \pm 0.27$ & $1.31 \pm 0.59$ & $1.47 \pm 0.73$ \\
\hline ApoAl $(g / L)$ & $1.34 \pm 0.28$ & $1.25 \pm 0.25$ & $1.45 \pm 0.23$ & $1.34 \pm 0.31$ \\
\hline $\mathrm{ApoB}(\mathrm{g} / \mathrm{L})$ & $1.40 \pm 0.32$ & $1.23 \pm 0.61$ & $0.99 \pm 0.25$ & $1.01 \pm 0.30$ \\
\hline
\end{tabular}

Data represent mean $\pm \mathrm{SD}$. 
polymorphism, which had become available after completion of the mutation detection analyses. ${ }^{17,19}$ These polymorphisms were studied in one hundred and twenty-four spouses and one hundred and wo unrelated FCHL probands. The genotype distribution of both polymorphisms was in Hardy-Weinberg equilibrium in the case-control panel. The intron $2 \mathrm{~A}$ allele was present in $9.41 \%(95 \% \mathrm{Cl} 5.35$ $13 \%$ ) of the FCHL probands and $9.68 \%(95 \% \mathrm{Cl} 5.97-13 \%)$ spouses $(P=0.92)$ whereas the intron $7 \mathrm{C}$ allele was present in $17 \%(95 \% \mathrm{Cl} 11-22 \%)$ of the $\mathrm{FCHL}$ probands and $17 \%(95 \% \mathrm{Cl} 12-22 \%)$ of the spouses $(P=0.98)$. No homozygotes for either variant allele were detected in the case-control panel.

Subsequently, the potential effects of the intron $2 \mathrm{~A}$ allele and intron $7 \mathrm{C}$ allele on plasma TC, TG, HDL-C, FFA, apoAl, apoB, and apoClll concentrations, and LDLsize were evaluated. In FCHL patients and spouses both the intron $2 \mathrm{~A}$ allele and intron $7 \mathrm{C}$ allele carriers showed no significant associations with any of the traits tested compared to wild type individuals (data not shown). In summary, the intragenic PPARA genotyping yielded no evidence of association with FCHL.

\section{PPARA locus genotyping}

In order to confirm or reject the suggestive linkage between the PPARA locus and $\mathrm{FCHL}$ in Dutch FCHL families ${ }^{5}$, we examined the association between linkage marker D22S275 and FCHL in the case-control panell. The allele distribution of D22S275 in the case-control panel was fully consistent with the distribution predicted by Hardy-Weinberg equilibrium. The overall allele frequency distribution of $D 22 S 275$ did not differ between FCHL probands and spouses $(P=0.74)$.

The complete sequencing of chromosome 22 has resulted in the availability of more reliable marker and gene position data in public databases. These novel data showed that D22S275 is situated $20 \mathrm{Mb}$ from the PPARA gene, whereas D22S928, located within $1 \mathrm{Mb}$, is the nearest informative marker (Figure 4.1). Therefore association of this marker with FCHL was examined in the case-controll panel. The allele distribution of $\mathrm{D} 22 \mathrm{~S} 928$ in the case-control panel was fully consistent with the distribution predicted by Hardy-Weinberg equilibrium. The overall allele frequency of D22S928 in FCHL probands did not differ significantly ( $P=0.34)$ from that in spouses.

To study whether the PPARA locus is a madifier locus in FCHL, instead of a causal locus, we evaluated whether genetic variation at the PPARA locus associated 
with certain subphenotypes from the overall complex FCHL phenotype: Notably, the allele frequency distribution of D22S928 differed significantly $(P=0.038)$ in FCHL probands with a combined hyperlipidemic phenotype compared to isolated hyperlipidemic probands, i.e. hypercholesterolemia or hypertriglyceridemia alone (Table 4.3A). Analyses of individual alleles revealed that allele CA157 was significantly enriched in combined hyperlipidemic FCHL probands ( $56.5 \%$ vs $37.9 \%$ in isolated hyperlipidemic probands: $P<0.010$ ).

PPARA gene expression has been shown to affect APOCIII and APOAl gene transcription ${ }^{20}$ and, moreover, the APOAI-CIII-AIV gene cluster has been shown to affect the $\mathrm{FCHL}$ phenotype ${ }^{21}$ Therefore, associations between D22S928 alleles and plasma apoCIII and apoAl concentrations were tested. In FCHL probands with a plasma apoCIII concentration greater than the $75^{\text {th }}$ percentile (apoCIII $\geq 5.9$ $\mathrm{mg} / 100 \mathrm{ml})$, a significantly different distribution of $D 22 S 928$ alleles $(P=0.011)$ was found compared to probands with a plasma apoCIII concentration under the $75^{\text {th }}$ percentile (apoCIII $<5.9 \mathrm{mg} / 100 \mathrm{ml}$ : Table 4.3B). It was observed that D22S928 allele CA149 was significantly less frequent in $\mathrm{FCHL}$ probands with a high plasma apoCIII concentration $(10.2 \%$ vs $33.3 \%$ in probands with plasma apoClll $<5.9 \mathrm{mg} / 100 \mathrm{ml}$ : $P<0.0001)$. Notably, the distribution of aliele CA157 was similar to that found with the combined hyperlipidemia phenotype (Table 4.3A), but this was not statistically significant. In spouses no associations with plasma apoCIII concentrations were found, and no associations were found with plasma apoAl concentrations in both FCHL probands and spouses.

\section{Genotype-phenotype relations}

Based on the observed association in FCHL probands of D22S928 allele CA149 with plasma apoCIII concentrations and allele CA157 with combined hyperlipidemia, we studied the effect of these alleles on quantitative lipid traits (Table 4.4). FCHL probands carrying allele CA149 had significantly decreased plasma apoCIII concentrations (unadjusted $P=0.035$, adjusted $P=0.082$ : Table 4.4A), and elevated plasma FFA concentrations (unadjusted $P=0.007$, adjusted $P=0.014$ ). In spouses, allele CA149 carriers showed no significant associations with plasma lipid traits compared to non-carriers (Table 4.4A). When the effect of the CA157 allele was studied in FCHL probands no significant associations were found (Table 4.4B). In 
contrast, spouses carrying allele CA157 had significantly higher plasma HDL-C levels compared to non-carriers (unadjusted $P=0.004$, adjusted $P=0.011$; Table 4.4B).

Table 4.3 D22S275 and D22S928 allele frequency differences.

\begin{tabular}{lll}
\hline D22S928 & $\begin{array}{l}\text { Combined } \\
\text { hyperlipidemic FCHL }\end{array}$ & $\begin{array}{l}\text { lsolated } \\
\text { hyperlipidemic FCHL } \\
\text { probands } \mathrm{n}(\%)\end{array}$ \\
& probands $\mathrm{n}(\%)$ \\
\hline
\end{tabular}

(A) 0223928 allele frequencies in combined hyperlipidemic $\mathrm{FCHL}$ probands vs isolated hyperlipidemic FCHL probands

$\begin{array}{llll}\text { CA149 } & 11(17.7) & 23(24.2) & \text { NS } \\ \text { CA157 } & 35(56.5) & 36(37.9) & <0.010 \\ \text { CA173 } & 0(0.0) & 7(7.4) & \text { NS } \\ \text { CA175 } & 16(25.8) & 29(30.5) & \text { NS }\end{array}$

Overall frequency

0.038

difference

Number of

$62(100)$

$95(100)$

chromosomes $(\%)$

D225928

FCHL probands with FCHL probands with $P^{*}$

apocill $>75^{\text {th }} \quad$ apoCIII $<75^{\text {th }}$

percentile in (\%) percentile $\mathrm{n}(\%)$

(B) D22S928 allele frequencies in FCHL probands with apoC\|ll $75^{\text {th }}$ percentile vs FCHL probands with apocill< $<5^{\text {th }}$ percentile

$\begin{array}{llll}\text { CA149 } & 5(10.2) & 18(33.3) & <0.0001 \\ \text { CA157 } & 32(65.3) & 20(37) & \text { NS } \\ \text { CA173 } & 2(4.1) & 1(1.9) & \text { NS } \\ \text { CA.175 } & 10(20.4) & 15(27.8) & \text { NS }\end{array}$

Overall frequency

difference

Number of

$49(100)$

$54(100)$

chromosomes $(\%)$

$P$ "represents Bonferroni corrected values 
Table 4.4 Effects of D22S928 CA149 and CA157 alleles on FCHL quantitative traits in FCHL probands and spouses.

\begin{tabular}{|c|c|c|c|c|c|c|c|c|}
\hline \multirow{2}{*}{$\begin{array}{l}\text { Traits } \\
\text { (mmolut. }\end{array}$} & \multicolumn{4}{|c|}{ FCHL probands $(n=10 i 2)$} & \multicolumn{4}{|c|}{ Spoteses (n } \\
\hline & $x / x(n=69)$ & $\begin{array}{l}x / 449 \text { and } 1494449 \\
(n=33)\end{array}$ & P & $p^{3}$ & $x / x(n=61)$ & 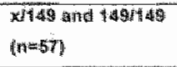 & ${ }^{2}$ & $F^{3}$ \\
\hline \multicolumn{9}{|c|}{ 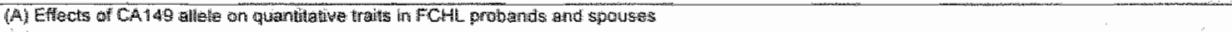 } \\
\hline 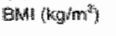 & $27.4 \div 2.90$ & $27.3 \pm 3.05$ & N:S & MNS & $25.3+4.0$ & $25.5 \times 5$ & $\mathbb{N}$ & NS \\
\hline TC & $0.8 \div 1.5$ & $7.2+3.6$ & MS & Nis & 5 焉 it: 1 & $5 . \pm 0.9$ & $\operatorname{sis}$ & NS \\
\hline$H D D_{-C}$ & $0.93+0.29$ & $0.92 \pm 0.18$ & Ws & $\mathbb{N}$ & $4.21+0.38$ & $1.23 \pm 0.43$ & NS & $\mathbb{N}$ \\
\hline TG & $28+1.7$ & $3.2+2.4$ & AHS & NE & $4.2 \times 1.6$ & 1.284 & NES & $\mathrm{NS}$ \\
\hline Fin & $0.42 \pm 0.48$ & $0.57+0.24$ & 0,007 & 0.014 & $9.49 \div 0.21$ & $0,47 \pm 0.19$ & 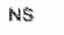 & ins \\
\hline ApOAll (gril) & $1.33+0.30$ & $1.33 \div 0.23$ & NAS & NS & 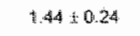 & $1.43+0.25$ & $\mathrm{NSB}$ & Ner \\
\hline ApoB $(g / \mathrm{L})$ & $1.38 \div 0.34$ & $1.39 \pm 0.34$ & NSS & NSE & 1. 000 : 0.26 & $0.97+0.22$ & $\mathbb{N S}$ & $\mathrm{NS}$ \\
\hline $\begin{array}{l}\text { Apoctll } \\
\text { (Ang/liaOna) }\end{array}$ & $6.23 \pm 1.73$ & $5.23 \pm 1.91$ & 0.035 & $0.0,8:$ & $4.22 \times 1.04$ & $4.79 \pm 1.413$ & NS & NiS \\
\hline $\begin{array}{l}\text { Lot - size } \\
\left(1.10^{16} \mathrm{~m}\right)\end{array}$ & 260.4105 & $258.3 \pm 9.06$ & NS & NS & $2706 \div 804$ & $270.6 \times 7.30$ & NS & 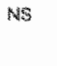 \\
\hline \multirow{2}{*}{$\begin{array}{l}\text { Traits } \\
\text { (mmolfit) }\end{array}$} & \multicolumn{4}{|c|}{ FCHL probartds (n=102) } & \multicolumn{4}{|c|}{ Spolusess $\{n=1247$} \\
\hline & $x / x(n=4 i 5)$ & $\begin{array}{l}\text { xilts7 and } 457 / 157 \\
(11 \div 57)\end{array}$ & $P^{\prime}$ & $P^{p l}$ & $n / x(n)=54)$ & $\begin{array}{l}\text { Nit157 alnd } 1577457 \\
(n=73)\end{array}$ & $p^{x}$ & $p^{p}$ \\
\hline \multicolumn{9}{|c|}{ 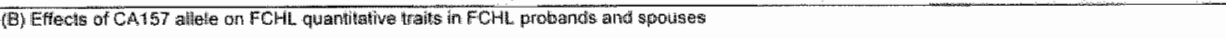 } \\
\hline BMI $\left(\mathrm{kg}_{\mathrm{g}} \mathrm{m} \mathrm{m}^{2}\right)$ & $27.8+3.47$ & 26.93 .02 & N\$ & NS & $25.4+3.3$ & $253: 43$ & NS & $\mathrm{NS}$ \\
\hline TC: & $0.7 \pm 1.7$ & $7.1 \pm 2.9$ & MS & $\mathbb{N S}$ & 5.6.1: 11 & $5.5+1.0$ & Nos & NS \\
\hline HDE $-\mathrm{C}$ & $0.92 \div 0.22$ & $0.93 \div 3.28$ & Nis & NSS & $1.11 \pm 0.26$ & $1.30 \div 0.44$ & $0: 004$ & MDI \\
\hline$T G$ & $2.7 \div 1.7$ & 32221 & MS & NS & $4.2 \pm 15$ & $1.21 \pm 1.6$ & NS & Nis \\
\hline FFA & $0.49=0.25$ & $0,46 \pm: 0,18$ & As & NS & $0.46 \pm 0.19$ & $0.50 \pm 0.22$ & NS & $N B$ \\
\hline ApoAl $(g / g)$ & $1.31 \pm 0.23$ & $1.35+0.31$ & \#S & $\mathrm{NSS}$ & $1.41 \pm 0.22$ & $1.46 \pm 0.25$ & NS & WE \\
\hline Apot 604 & $1.37 \pm 0.29$ & $1.41=0.38$ & $\mathbb{N S}$ & MIS & $1.02 \div 0.22$ & 0.9920 .27 & $M S$ & Ns \\
\hline $\begin{array}{l}\text { ApoCill } \\
\text { (mg//oprins) }\end{array}$ & $5,47 \leq 1,83$ & $6.94 \pm 1.84$ & MS & $\mathrm{N}$ & $4.22 \pm 1.31$ & $4.45: 1.07$ & NS & NSS \\
\hline $\begin{array}{l}\text { LDL-5äze } \\
\left(1.10^{\circ} \mathrm{m}\right)\end{array}$ & $257, \forall \pm 9.15$ & $261.7 \pm 10.8$ & WS & NS & $2698+7.66$ & $272.2+7.96$ & $\mathrm{NS}$ & NAS \\
\hline
\end{tabular}

Data represent mean $\pm \mathrm{SD}$.

P-values are provided for 2 separate analyses. "Unadjusted using Student's t-test. "Adjusted for agle and BMI using logistic regression.

\section{Discussion}

The objective of the present study was to establish the involvement of the PPARA locus (chromosome 22q13.3) in FCHL. A previous linkage study detected at best suggestive linkage between the PPARA locus and FCHL when multiple genes were tested, and a limited number of FCHL families were used. The present data show that the PPARA locus influences plasma apoCIII concentrations and the 
combined hyperlipidemic phenotype in FCHL subjects, but not in spouses, indicating that this gene modifies the expression instead of contributing to the FCHL phenotype in a direct manner.

Mutation detection experiments of the coding region of the PPARA gene, led to the identification of four novel mutations and the previously reported $L 162 \mathrm{~V}$ variant in FCHL probands. No exceptional lipid phenotypes were observed except that the three FCHL probands each carrying one of the novel variants had remarkably low plasma HDL-C levels. The prevalence of the $L 162 \mathrm{~V}$ variant in the spouse group was similar to previously reported general population frequencies ${ }^{15 ; 17}$, but unfortunately, in FCHL probands there were not enough carriers to enable an association study. Therefore, two recently identified non-coding PPARA polymorphisms in intron 2 and 7 were studied, but these did not associate with FCHL. Our results do not exclude PPARA as a modifier gene in FCHL since the biologicall role of these polymorphisms remains to be established. Ideally, a polymorphism should represent a functional change in physiology, but at present no coding polymorphisms with a frequency greater than $10 \%$ are available for the PPARA gene. ${ }^{19}$ The lack of association with these noncoding SNPS could, in theory, also be due to the limited number of subjects tested. However, in populations of similar size significant associations with the intron 2 polymorphism have been reported. ${ }^{17}$

The absence of association between markers D22S275 and D22S928 and FCHL, indicates that DNA variation in the PPARA locus does not primarily contribute to $\mathrm{FCHL}$, but is more likely a modifier locus. The strategy of sub-phenotyping has previously been shown to be very effective in other disorders ${ }^{22}$, and therefore this strategy was applied using D22S928, the nearest informative marker to the PPARA locus. D22S928 showed significant association with plasma apoCIII levels and, remarkably, also with the combined hyperlipidemic phenotype in FCHL probands, showing that the PPARA locus modifies the combined lipoprotein phenotype.

Marker D22S928 is situated within $1 \mathrm{Mb}$ upstream of the PPARA promoter, and given its modifying effect on characteristic. FCHL traits that are under transcriptional control of the PPARA gene. PPARA is most likely responsible for this effect. Specifically, CA157 was shown to increase the likelihood of FCHL subjects to present with combined hyperlipidemia, while all other D22S928 alleles were underrepresented, suggesting that they protect against the expression of the combined hyperlipidemic phenotype of FCHL. The data also suggest that the CA157 
allele is a marker for decreased PPAR activity. The frequency of allele CA149 was significantly higher in FCHL probands with low apoClll $\left(<75^{\text {th }}\right.$ percentile) which suggests, given the role of PPARo in the inhibition of apocill expression ${ }^{23,24}$ "that CA149 is in allelic association with variants which are associated with increased PPAR $\alpha$ activity. Intragenic screening of PPARA could not confirm nor exclude this. In our view, the fact that D22S928 is situated II Mb from PPARA implies that one or more functional polymorphism(s) that are in linkage disequilibrium with 0225928 alleles CA149 and CA157 may be present in the PPARA promoter or other regulatory sequences. Promoter polymorphisms can affect transcription of the PPARA gene and result in either increased or decreased expression.

ApoCIII is an apolipoprotein that, when present in high concentrations, limits the clearance of triglycerides from the circulation. Under normal circumstances, PPAR $\alpha$ activation increases lipolysis through increased lipoprotein lipase gene expression ${ }^{25}$ and promotes hepatic clearance of triglycerides through a decrease in apoclll expression. PPAR $\alpha$ also enhances transcription of the HDL apolipoproteins $\mathrm{Al}$ and All, thereby increasing HDL-C production. The observed modifying effect of the PPARA locus on plasma apoCIll concentrations in combination with the positive effects of fibrate treatment on lipid traits in FCHL patients, such as HDL-C, apoCIII and $\mathrm{TG}^{14}$, imply a role of PPARA in the pathophysiology of the FCHL phenotype. ${ }^{20}$ Elevated plasma apoCIII concentrations, and low plasma HDL-C concentrations, both well-known FCHL characteristics ${ }^{26}$ which have been shown to be associated with PPARA alleles in this study, imply decreased PPAR $\alpha$ function. Decreased PPAR function can result in decreased hepatic FFA uptake secondary to lowered fatty acid binding protein (FABP) and fatty acid transport protein (FATP) expression. ${ }^{3327}$ Moreover, those FFAs taken up will be preferably used for TG synthesis because of decreased FFA $\beta$-oxidation. Increased hepatic triglyceride synthesis will contribute to increased VLDL production, more apoClll containing remnant lipoproteins, and a decrease in $\mathrm{HDL}$-cholesterol through decreased apoAl and apoAll gene expression. ${ }^{11}$ Thus, reduced PPARa activity can contribute to the FCHL atherogenic lipoprotein phenotype in multiple ways. In addition, other genes have been identified recently that are directly or indirectly under transcriptional control of PPAR $\alpha$, such as sterol regulatory element-binding protein (SERBP)regulated genes, involved in cholesterol synthesis ${ }^{27}$, phospholipid transfer protein 
(PLTP), involved in HDL particle size and lipid composition modulation ${ }^{28,29}$, and cholesterol 7 $\alpha$-hydroxylase (CYP7A1), involved in the conversion of cholesterol in bile-acids ${ }^{30}$ It is possible that one PPARa metabolic pathway will contribute to the complex phenotype of FCHL. To unequivocally include PPARA as a modifier gene in FCHL, its biological function in human FCHL hepatic tissue should be studied, for instance by gene-expression studies, but at this time human FCHL liver samples are very hard to obtain. Until such data are available, another gene responsible for the observed effects cannot be excluded.

In conclusion, the present data showed that PPARA has a modifying effect on plasma apoCIII concentrations and the combined hyperlipidemic phenotype in $\mathrm{FCHL}$ subjects but not in spouses. In spouses, a modifying effect on HDL-C concentrations was found. These results clearly demonstrate the genetically complex nature of FCHL and identify the PPARA locus as a modifier locus of the FCHL lipid-phenotype. 


\section{References}

1. Goldstein JL, Schrott HG, Hazzard WR, Bierman EL, Motulsky AG. Hypertipidemi in coronary heart disease. II. Genetic analysis of lipid levels in 176 families and delineation of a new inherited disorder, combined hyperlipidemia. J.Clin Invest. 1973;52:1544-1568.

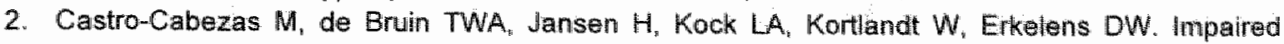
chylomicron remnant clearance in familial combined hyperlipidemia. Arterioscler. Thromb. Vasc.Biol. 1993:13:804-814.

3. Bredie SJ, Kiemeney LA, de Haan A.F, Demacker PN, Stalenhoef AF. Inhenited susceptibility determines the distribution of dense low-density lipoprotein subfraction profiles in familial combined hyperlipidemia. Am.J.Hum. Genet. 1996;58:812-822.

4. Pihlajamaki J, Karjalainen L. Karhapaa P. Vauhkonen I, Laakso M. Impaired free fatty acid suppression during hyperinsulinemia is a characteristic finding in familial cambined hyperlipidemia, but insulin resistance is observed only in hypertriglyceridemic patients. Arterioscler. Thromb. Vasc. Biol. 2000;20:164-170.

5. Aouizerat BE, Allayee H, Cantor RM, Dallinga-Thie GM, Lanning CD, de Bruin TWA Lusis Ad, Rotter Jll. Linkage of a candidate gene locus to familial combined hyperlipidenia - Lecithin cholesterol acyltransferase on 16q. Arterioscler. Thromb. Vasc.Biol. 1999;19:2730-2736.

6. Eurlings PMH, van der Kallen CJH, Geurts JMW, van Greevenbroek MMU, de Bruin TWA. Genetic dissection of familial combined hyperlipidemia. Mol Genet Metab. 2001;74:98-104.

7. Pajukanta P, Nuotio I, Terwilliger JD, Porkka KV, Ylitalo K, Pihlajamakì J; Suomalainen AJ, Syvanen AC, Lehtimaki T, Viikari JS, Laakso M. Taskinen MR, Ehnholm C. Peltonen L. Linkage of familial combined hyperlipidaemia to chromosome 1q21-q23. Nat. Genet. 1998;18:369-373.

8. Aouizerat $B E$, Allayee $H$, Cantor RM, Davis $R C$, Lanning $C D$, Wen $P Z$, Dallinga-Thie $G M$, de Bruin TWA, Rotter $J$, Lusis AJ. A genome scan for familial combined hyperlipidemia reveals evidence of linkage with a locus on chromosome 11. Am.J.Hum. Genet. 1999;65:397-412.

9. van der Kallen CJH, Cantor RM, van Greevenbroek MMJ, Geurts JMW, Bouwman FG, Aouizerat $B E$, Allayee $H_{1}$ Buurman WA, Lusis AJ, Rotter Jl, de Bruin TWA. Genome scan for adiposity in Dutch dyslipidemic families reveals novel quantitive trait laci for leptin, body mass index and soluble tumor necrosis factor receptor superfamily 1A. Int.J.Obes.Relat.Metab. Disord. 2000;24:1381-1391.

10. Allayee $H$, de Bruin TWA, Dominguiez KM, Cheng LS-C, Ipp E, Cantor RM, Krass KL, Keulen ETP, Aouizerat BE, Lusis AJ, Rotter Jl. Genome-scan for blood pressure in Ductch dyslipidemic families reveals linkage to a locus on chromosome 4p. Hypertension. 2001;38:773-778.

11. Schoonjans $K$, Staels $B$, Auwerx $J$. The peroxisome proliferator activated receptors (PPARS) and their effects on lipid metabolism and adipocyte differentiation. Blachim.Biophys.Actu. 1996:1302:93-109.

12. Schoonjans $K$, Staels $B$, Auwerx J. Role of the peroxisome proliferator-activated receptor (PPAR) in mediating the effects of fibrates and fatty acids on gene expression. J.Lipid Res. 1996;37:907= 925 .

13. Staels B, Dallongeville J, Auwerx J, Schoonjans K, Leitersdorf $E_{8}$ Fruchart JC. Mechanism of action of fibrates on lipid and lipoprotein metabolism. Circulation. 1998;98:2088-2093.

14. Bredie SJ, Westerveld HT, Knipscheer HC, de Bruin TWA, Kastelein JJ, Stalenhoef AF. Effects of gemfibrozil or simvastatin on apolipoprotein-B-containing lipoproteins, apolipoprotein-Cill and lipoprotein(a) in familial combined hyperlipidaemia. Noth. J.Med. 1996;49;59-67.

15. Vohl MC, Lepage P, Gaudet $D$, Brewer $C G$, Betard $C$, Perron $P$, Houde $G$, Cellier C, Faith JM, Despres JP. Morgan K, Hudson TJ. Molecular scanning of the human PPARa gene: association of the L162v mutation with hyperapobetalipoproteinemia. J.Lipid Res. 2000;41:945-952.

16. Geurts JMW. Janssen RGJH, wan Greevenbroek MMJ, van der Kalien C.JH. Cantor RM, Bu X. Aquizerat BE, Allayee H, Rotter $\mathrm{J}$, de Bruin TWA. identification of TNFRSF $1 B$ as a novel modifier gene in familial combined hyperlipidemia. Hum. Mol. Genet. 2000;9:2067-2074.

17. Flavell DM, Pineda-Torra I, Jamshidi $Y$, Evans D, Diamond JR, Elkeles RS, Bujac SR, Miller G, Talmud PJ, Staels B. Humphries SE. Variation in the PPARalpha gene is associated with altered 
function in witro and plasma lipid concentrations in Type II diabetic subjects. Diabetologia. $2000,43: 673-680$.

18. hitp: fwww gdb org.

19. hittp: /www nobi. nim nith gow/SNP

20. Pineda-Torra $I$, Gervois $P$, Staels $B$. Peroxisome proliferator-activated receptor alpha in metabolic disease, inflammation, atherosclerosis and aging. Cum Opin Lipidol 1999;10:151-159.

21. Dallinga-Thie GM, van Linde-Sibenius TM, Rotter Jl, Cantor RM, Bu X Lusis AJ, de Bruin TWA. Complex genetic contribution of the Apo Al-CIII-AIV gene cluster to familial combined hyperlipidemia. Identification of different susceptibility haplotypes. J.Clin./nvest. 1997:99:953964.

22. Jarvik GP, Rozek LS, Brophy VH, Hatsukami TS, Richter RJ, Schellenberg GD, Furlong CE. Paraoxonase (PON1) phenotype is a better predictor of vascular disease than is PON1(192) or PON1 155) genotype. Arterioscler. Thromb. Vasc. Biol. 2000;20:2441-2447.

23. Hertz R, Bishara SJ, Bar TJ. Mode of action of peroxisome proliferators as hypolipidemic drugs. Suppression of apolipoprotein C-III. J Eiol.Chem. 1995;270:13470-13475.

24. Staels $\mathbb{B}_{x} V_{U} \mathbb{D N}$, Kosykh $V A_{\text {, Saladin }} R$, Fruchart JC, Dallongeville J, Auwerx J. Fibrates downregulate apolipoprotein C-lll expression independent of induction of peroxisomal acyl coenzyme A oxidase. A potential mechanism for the hypolipidemic action of fibrates. J. Clin.linvest. 1995;95:705-712.

25. Schoonjans $K$, Peinado OJ, Lefebvre AM, Heyman RA, Briggs $M$, Deeb $S$, Staels B, Auwerx $J$. PPARalpha and PPARgamma activators direct a distinct tissue-specific transcriptional response via a PPRE in the lipoprotein lipase gene. EMBO J. 1996;15:5336-5348.

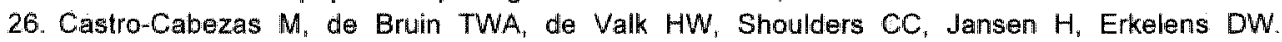
Impaired fatty acid metabolism in familial combined hyperlipidemia. A mechanism associating hepatic apolipoprotein B overproduction and insulin resistance. J.Clin. Invest. 1993;92:160-168.

27. Patel DD, Knight BL. Wiggins D. Humphreys SM, Gibbons GF. Disturbances in the normal regulation of SREBP-sensitive genes in PPAR alpha-deficient mice. J.Lipid Res. 2001;42:328337.

28. Tu AY, Albers Jل. Gilucose regulates the transcription of human genes relevant to HDL metabolism: responsive elements for peroxisome proliferator-activated receptor are involved in the regulation of phospholipid transfer protein. Diabetes. 2001;50:1851-1856.

29. Tu AY, Albers JJ. DNA sequences responsible for reduced promoter activity of human phospholipid transfer protein by fibrate. Biochem. Biophys. Res. Commun. 1999;264:802-807.

30. Marrapodi M, Chiang JY. Peroxisome proliferator-activated receptor alpha (PPARalpha) and agonist inhibit cholesterol 7alpha-hydroxylase gene (CYP7A1) transcription. J.Lipid Res. $2000 ; 41: 514-520$. 
Chapter 6

General Discussion 
Familial Combined Hyperlipidemia (FCHL) is the most common genetic hyperlipidemia in man. The principal features are hypercholesterolemia, hypertriglyceridemia, elevated apolipoprotein $\mathrm{B}$ (apoB) and apoClll concentrations, all related to a combination of excess hepatic secretion and impaired catabolism of lipoproteins, and elevated postprandial free fatty acids (FFA). ${ }^{1.2}$ In addition to abnormalities in hepatic lipid metabolism, insulin resistance (IR) of adipose tissue and muscle has been documented in FCHL as well. ${ }^{3.4}$ Adipose tissue is one of the major contributors of FFA in the circulation. Postprandially high levels of FFA in the circulation can contribute to both a decrease in insulin-stimulated glucose uptake in skeletal muscle and an increase in hepatic lipoprotein synthesis, both characteristics of $\mathrm{FCHL} .5,6$ All these abnormalities in organ function may be genetic. Therefore, liver, adipose tissue and muscle are interesting target tissues, for functional and differential gene expression studies in FCHL, to assess their role in the genetic background of FCHL. In the first part of the present thesis we have focused on adipose tissue function in FCHL, and in the second part we have implemented candidate gene analysis. Both studies will be discussed in more detail.

\section{Adipose tissue in FCHL}

\section{Adipose tissue: an endocrine organ}

In the last few years the role of adipose tissue as an endocrine organ, with paraand autocrine protein signaling, has been recognized. In addition, adipose tissue has a role in triglyceride (TG) storage, i.e. free fatty acid (FFA) storage, during periods of excess caloric intake and mobilization of its reserves when energy demand increases. At the same time, the role of adipose tissue in diseases such as type 2 diabetes mellitus (DM2) and obesity has been a focus of attention. ${ }^{7.8}$ The same holds true in FCHL. As described in chapter 1, visceral obesity, i.e. adipose tissue mass, has been linked to increased risk of non-fatal coronary artery disease (CAD) in $\mathrm{FCHL}^{9}$, and has been shown to be an important determinant of $\mathbb{R}$ in FCHL subjects. ${ }^{5,10}$ Moreover, expression of the $\mathrm{FCHL}$ phenotype has been shown to depend, in part, on body mass index (BMI). ${ }^{11,12}$ 


\section{Adipose tissue FFA buffering capacity}

Adipose tissue has been suggested to play a crucial rolle in the buffering of the post-prandial FFA flux. ${ }^{13}$ After a meal the plasma FFA concentration could potentially increase tenfold, but this does not occur. Typically, there is an increase of two-fold ${ }^{14}$ thus there has to be a buffering capacity or entity in the body. The buffering of the FFA flux in the postprandial state is most likely the result of three more or less related mechanisms; i) suppression of FFA release, most likely from adipose tissue, ii) increased clearance of circulating lipoprotein-associated TG, probably through lipoprotein lipase (LPL), and iii) suppression of endogenous very low-density lipoprotein (VLDL)-TG secretion by the liver. Insulin is an important factor in all these mechanisms because insulin has been shown to suppress hormone sensitive lipase (HSL) activity ${ }^{15}$, and to up-regulate LPL expression, which liberates FFA from TG ${ }^{1 / 5}$. As a result insulin favors FFA (re)esterification and, in addition, suppresses hepatic VLDL-TG secretion. ${ }^{17}$ Adipose tissue acts as a buffer for a $30 \mathrm{~min}$ to 5 hour period postprandially, after which adipose tissue starts to release FFA again. ${ }^{14}$

Interestingly, FCHL adipocytes have been shown to have impaired FFA reesterification $^{4}$, and FCHL adipocytes have been suggested to exhibit impaired acylation of $T G$, from $F F A$ and glycerol, by $A S P^{18,19}$. It is also possible that FFA trapping or transport is impaired, adding to the impaired adipose tissue FFA buffering. Moreover, FCHL subjects are characterized by inadequate clearance of post-prandial FFA. ${ }^{20}$ These observations are evidence of a role of adipose tissue in the pathophysiology of $\mathrm{FCHL}$.

\section{Adipose tissue differential gene expression: evidence for altered function}

By differential gene expression studies, in which gene expression in subcutaneous adipose tissue from FCHL subjects was compared to that in age, gender and $\mathrm{BMI}$ matched controls, we were able to show that consistent differences in expression exist between FCHL and control adipose tissue (chapter 2 and 3). In general, genes involved in cell cycle progression were found to be up-regulated in $\mathrm{FCHL}$, whereas genes promoting apoptosis were down-regulated. In addition, we 


\section{Control}

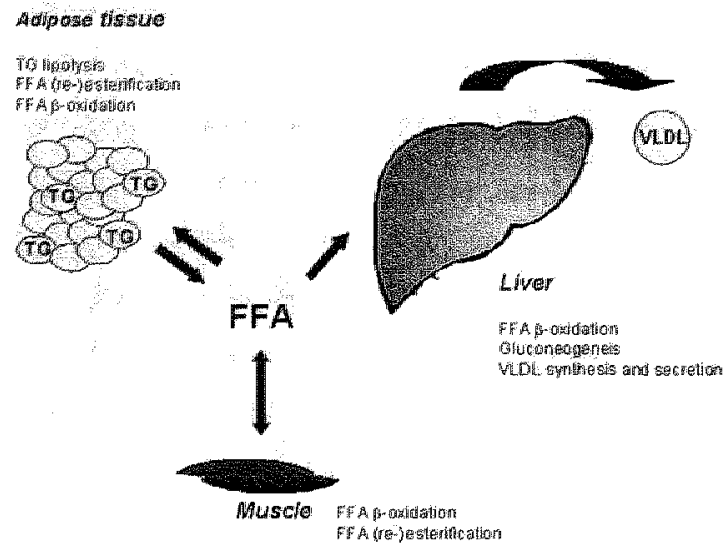

FCHL

\section{Aolipose tissue}

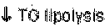

U. FFA Ge-jestentication

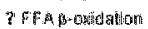
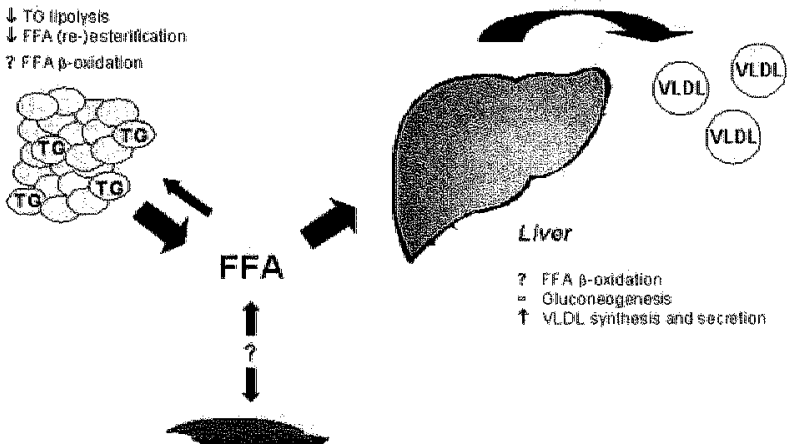

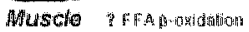

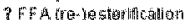

Figure 6.1 Postwlated mechanism of impaired adipose tissue FFA metabolism in FCHL.

Reduced FFA incorporation by adipose tissue results in an increased FFA flux towards the liver. This subsequently triggers thepatic VLDL production adding to the increases lipoprotein flux in FCHL. 
showed that several genes involved in FFA metabolism and insulin signaling are differentially expressed in FCHL adipose tissue:

The differential expression of genes involved in FFA metabolism and insulin signaling support an important role, and perhaps even a primary role, of adipose tissue in the pathogenesis of $\mathrm{FCHL}$. For instance, the down-regulation of hydroxyacyl-Coenzyme A dehydrogenase/3-ketoacyl-Coenzyme A thiolase/enoylCoenzyme A hydratase (HADHA), an enzyme involved in mitochondrial fatty acid beta-oxidation ${ }^{21}$, up-regulation of fatty-acid-Coenzyme A ligase 2 (FACL2), an enzyme involved in the conversion of free long-chain fatty acids into fatty acyl-CoA esters, reflect alterations in intracellular FFA metabolism (chapter 3). On the other hand, the increase in expression of the adipose tissue cytokines tumor necrosis factor alpha (TNF $\alpha$ ) and interleukin 6 (IL-6) further illustrate changes in insulin signaling (chapter 2). FFA and TG play an important role as physiological inducers of $T N F \alpha^{22}$, and indeed, TNF $\alpha$ gene expression has been shown to be associated with plasma TG concentrations. ${ }^{23}$ Moreover. TNF $\alpha$ signaling through its receptors has been recognized as a mechanism in TNF $\alpha$ induced insulin resistance. ${ }^{22}$ Interestingly, a link between $T N F \alpha$ signaling and $F C H L$ has recently reported by our laboratory. ${ }^{24,25} \mathrm{IL}-6$ has been shown to increase hepatic TG secretion ${ }^{22.25}$, thus adding to the FCHL hyperlipidemic phenotype. Both TNF $\alpha$ and IL-6 affect $L P L$ expression negatively ${ }^{22}$, and this may contribute to the delayed elimination of circulating TG containing lipoproteins in $\mathrm{FCHL}$.

Based on these observations, combined with previous data ${ }^{4.18,20}$, it can be hypothesized that impaired adipose tissue FFA buffering in FCHL results in an increased FFA flux towards liver (Figure 6.1). In time, this may result in TG accumulation in liver and muscle, reducing their insulin sensitivity. Indeed, in subjects with FCHL fatty liver is frequently present (unpublished observation), and $\mathrm{FCHL}$ subjects are as insulin resistant in muscle as subjects with DM2. ${ }^{4}$ Moreover, FFA activate hepatic gluconeogenesis, but plasma glucose levels are not increased in FCHL. The cause of the increased postprandial FFA flux in FCHL is most likely a combination of genetic predisposition and environmental factors.

Large adipocytes, in a non-disease situation, are generally found to be less sensitive to insulin. ${ }^{27}$ In DM2 the presence of larger adipocytes in subcutaneous adipose tissue is a risk marker. ${ }^{28,29}$ There is no evidence for increased adipocyte 
size in FCHL (unpublished observations), suggesting that decreased insulin sensitivity due to increased adipocyte size is not at the basis of impaired FFA buffering in FCHL. However, FCHL adipocytes are less sensitive to insulin, either due to genetic predisposition or as a consequence of physiological changes due to FCHL expression. Therefore, the subset of cell cycle regulators differentially expressed in FCHL adipose tissue may reflect hyperplasia of adipocytes, in order to accommodate the persistent lipid supply. This proposed mechanism does not imply that the compensatory hyperplasia of adipose tissue is sufficient to maintain normal lipid or FFA metabolism in FCHL.

The current data cannot distinguish between genes differentially expressed as a result of an adaptive response to hyperlipidemia or a genetic predisposition to FCHL. Therefore, FCHL adipose tissue gene expression should be compared with that of subjects with a different hyperlipidemia, i.e. familial hypercholesterolemia (FH) and subjects with DM2. The comparison between FCHL and $\mathrm{FH}$ will provide information about adaptive changes in gene expression involved in lipid metabolism. Further insight in adipose tissue insulin signaling will be obtained when comparing adipose tissue from FCHL to that of DM2. FCHL subjects have insulin resistant adipose tissue whereas subjects with DM2 are not characterized by adipose tissue $\mathbb{R}$ in terms of lipid metabolism. ${ }^{4}$ Therefore, the differences identified in FCHL will probably reflect genetic abnormalities in insulin signaling, most likely combined with adaptational changes. It should be mentioned once more that this general limitation of gene expression studies in heritable disease, i.e. primary genetic versus adaptational changes, can be overcome by combining the results with those obtained by linkage studies. ${ }^{30}$

\section{Future perspectives: FCHL adipose tissue studies}

Although most biological evidence has been obtained from in vitro studies, many studies have reported that accumulation of intra-abdominal adipose tissue is associated with insulin resistance and increased CAD risk. ${ }^{31-33}$ it would be interesting to determine the amount of intra-abdominal adipose tissue and its relation to the amount of subcutaneous adipose tissue in FCHL subjects. Subsequently, these data 
can be used to assess the risk between the amount of various adipose tissue depots and CAD in FCHL in more detail.

In the present thesis only a proportion of human gene products, 1.e. \pm 800 . has been studied in FCHL subcutaneous adipose tissue. However, the suppression subtractive hybridization (SSH) technique generated FCHL adipose tissue specific CDNA libraries enriched for (potential) differentially expressed gene in FCHL. The results have confirmed the value of the SSH technique because of the 235 different SSH sequences studied, 114 were differentially expressed. However, there are still many potentially interesting genes that have not been studied yet. First of all, the SSH libraries contain many more cDNAs. Second, large-scale microarray analysis would be useful to study numerous genes simultaneously although many will be less obvious candidate genes for FCHL adipose tissue dysfunction. When applying this second approach it is essential that adequiate bioinformatics tools, such as cluster analyses, will be used for data analysis. In addition, focusing on common denominators of affected pathways will also help to filter useful information from the raw expression data.

At present, a limited number of adipose tissue secreted proteins have been studied in FCHL. A more detailed study of adipose tissue secreted proteins is therefore warranted. A wide range of signals originate form adipose tissue such as TNF $\alpha$, IL-6, leptin, and their soluble receptors (reviewed in ${ }^{8,22}$ ). In addition,

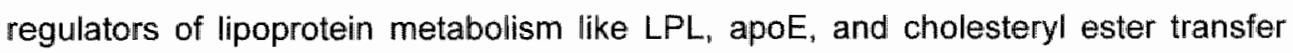
protein (CETP) are secreted. The increasing list of proteins known to be secreted also includes angjotensin, plasminogen activator inhibitor-1 (PAl1), tissue factor, and transforming growth factor beta (TGF $\beta$ ), resistin, adiponectin, prostaglandins, and insulin-like growth factor $1(\mid \mathrm{GF} 1)^{8,22}$ Based on the fact that for a large proportion of these proteins evidence has been obtained of a role in cardiovascular related diseases such as DM2 and obesity ${ }^{8,22,34}$, it is of great interest to study these proteins in more detail in FCHL. An integrated functional genomics approach, in which genetic association studies are combined with targeted gene expression analyses, and, when optional, assessment of protein plasma concentrations "will be a suitable way to study the contribution of these adipose tissue secreted proteins to the pathophysiology of FCHL. 
It is our strong opinion that differential gene expression studies will help to unravel the molecular basis of FCHL; especially in combination with genetic linkage data. Large-scale microarray experiments in which a large proportion of human gene products are studied, could be used as a trait in linkage analyses, and such a combined approach yields information on the pathways involved in the pathophysiology of FCHE. Interestingly, some of the genes identified as being differentially expressed in FCHL adipose tissue in the present thesis, are situated at chromosomal loci implicated in FCHL. For instance, in Finnish FCHL families signifficanl linkage was found with chromosome 1q21-23 (log of odds (LOD) score 5.94 ). ${ }^{35}$ Proteasome prosome macropain subunit beta type 4 (PSMB4) and S100 calcium binding protein A13 (S100A13), both found to be down-regulated, are situated at this chromosomal location. In Dutch families, linkage with chromosome $1 p 31$ was obtained for apoB, leptin, and $\left.B M\right|^{11,36}$, and, interestingly, the prostaglandin E receptor 3 (PTGER3) gene corresponds to this region. Although they are not directly related to lipoprotein and lipid synthesis, secretion or metabolism, these novel candidate genes are interesting targets for further analyses.

\section{FCHL genetic association studies}

At present, many of the monogenetic diseases have been mapped and the causal genes have been identified. A major challenge remaining is to reveal the genetic determinants of complex diseases, such as FCHL. Unraveling the complex genetics of these disorders will provide insight at the molecular level of their pathogenesis. Linkage and/or association studies are generally used for the identification of genes causing complex disorders. In the present thesis, a casecontrol association study design was chosen to assess the involvement of candidate genes in $\mathrm{FCHL}$. A candidate gene is generally chosen based on knowledge of the biological function, e.g. in FCHL genes involved in lipid or lipoprotein metabolism. Moreover, transcription factors are potentially good candidates because they can modulate multiple metabolic or functional pathways simultaneously, thus contributing to a disease phenotype in multiple ways. In this thesis, the ligand-activated transcription factors peroxisome proliferator-activated receptors alpha (PPAR $\alpha$ ) and 
gamma (PPARy), belonging to the nuclear receptor superfamily, were studied (chapter 4 and 5).

\section{PPARa in FCHL}

The peroxisome proliferator-activated receptor alpha (PPARA) gene is both an interesting positional candidate gene in $\mathrm{FCHL}$, based on suggestive linkage to chromosome $22 q 13.3^{37}$, as well as a strong conceptual candidate gene. PPAR regulates genes controlling fatty acid catabolism " by increasing lipolysis (by increasing LPL and reducing apoClll gene transcription) and $\beta$-oxidation ${ }^{36.39}$, and is predominantly expressed in liver, heart, and skeletal muscle. PPAR $\alpha$ is activated by natural ligands derived from fatty acids ${ }^{40}$, and hypolipidemic drugs such as fibrates. ${ }^{41}$ Fibrate treatment has been shown to be effective in the management of $F C H L$, with a predominant effect on the correction of hypertriglyceridemia and low high-density lipoprotein cholesterol (HDL-C) levels. ${ }^{42}$ In addition, PPAR $\alpha$ has also been implicated in changes in plasma apoB concentrations. ${ }^{43}$

Reduced PPAR $\alpha$ activity can contribute to the FCHL atherogenic lipoprotein phenotype in multiple ways. Genetic variation at the PPARA locus was shown to influence plasma apocill concentrations and the combined hyperlipidemic phenotype in FCHL subjects, but not in spouses (chapter 4). Apart from the association of PPARA with elevated plasma apoCIII concentrations, PPARA was also found to be associated with low plasma HDL-C concentrations. Both are well known FCHL characteristics ${ }^{20}$, and the observed associations imply decreased PPAR $\alpha$ function. Decreased PPAR $\alpha$ function can result in decreased hepatic FFA uptake, adding to the postprandial plasma FFA flux further challenging adipose tissue and liver FFA buffering (Figure 6.1). Moreover, those FFA taken up will be preferably used for TG synthesis because of altered FFA B-oxidation capacity. In turn, this will lead to increased VLDL-TG production, more apoCIII containing remnant proteins, and a decrease in HDL-C through decreased apoAI and apoAll gene expression. ${ }^{39}$ 


\section{PPARY IN FCHL}

PPARy is highly expressed in adipose tissue and the intestine where it regulates genes such as LPL, fatty acid transport protein (FATP), CD36 and adipophilin ${ }^{44}$, involved in control of uptake, transport, storage, and disposal of lipids. ${ }^{45}$ Naturall ligiands for PPARy are fatty acids but synthetic ligands such as antidiabetic thiazolidinediones bind PPAR $\gamma$ with high affinity. ${ }^{46}$ The insulin sensitizing action of thiazolidinediones has been attributed to PPAR $y$ activation. ${ }^{47,48}$ Therefore, the PPARG gene, situated on chromosome 3p25, is an interesting conceptual candidate gene with regard to both hyperlipidemia and insulin resistance in FCHL.

The findings in chapter 5 identify PPARG as a modifier gene in FCHL with an insulin sensitizing action supporting the observations in FCHL adipose tissue differential gene expression studies, that provided independent evidence for altered FFA metabolism and insulin signaling in FCHL adipose tissue (chapter 2 and 3). More specifically, we showed that genetic variation in the PPARG gene was associated with lower plasma FFA, glycerol and apoAl concentrations in FCHL subjects, but not in spouses. Interestingly, in Finnish FCHL subjects, variation in the PPARG gene was found to be associated with lower plasma insulin concentrations ${ }^{49}$, whereas FFA and glycerol were not studied. FFA and glycerol released from adipose tissue TG via LPL-mediated lipolysis are key mediators of impaired insulin sensitivity. ${ }^{13}$ As previously mentioned, increased adipose tissue FFA flux, may, in part, contribute to reduced insulin sensitivity and hyperlipidemia in FCHL (Figure 6.1), in addition to genetic predisposition to adipose tissue insullin resistance.

\section{General conclusions and future perspectives: PPARA and PPARG association studies}

The finding that genetic variation in both the PPARA and PPARG gene affects lipid traits specifically in FCHL subjects, but not in controls, implies that the genetic background, and, possibly, environmental factors, determines whether a gene acits as a modifier locus. Interestingly, recent studies determining genetic predisposition to DM2, showed that variations with a weak functional effect in the PPARG gene 
could have a significant effect on overall population disease risk. ${ }^{50}$ This might also be the case for PPARA and PPARG in FCHL and is an interesting concept for further study.

The main focus of the PPARA and PPARG gene association studies was to assess their modifying effect on plasma lipid levels. However, it could be possible that other, at present still unknown, traits are more directly related to their function, and will more clearly illustrate their role in FCHL. For instance, atherosclerotic lesion progression could be a phenotype of altered PPAR function, based on the fact that over the past few years a role of PPARs, specifically PPAR $\alpha$ and PPAR $\gamma$, has been recognized in the development and progression of atherosclerosis. ${ }^{38,51.53}$ Intima media thickness (IMT), a marker of atherosclerosis, has been previously shown to be increased in subjects with FCHL compared to age and gender matched controls ${ }^{54}$. It would therefore be of interest to study the relationship between PPARs and IMT in $\mathrm{FCHL}$, in order to assess the role of PPARs in progression of atherosclerosis in FCHL.

The genetic effects of PPARA variation on the FCHL phenotype will be primarily exerted through liver lipoprotein metabolism. In order to obtain the full picture of PPARa dysfunction in FCHL, hepatic gene expression studies focusing on PPARA target genes would be of great value. In this way the pathways that are significantly affected due to altered PPAR $\alpha$-mediated gene transcription will be dissected and could be studied in further detail using in vitro studies. However, human hepatic FCHL tissue is hard to obtain. In the meantime, FCHL animal models would provide an elegant alternative for these gene expressions studies in FCHL.

The data obtained using the genetic association study design, have indicated that transcription factors are indeed good candidates for the genetic pathophysiology of FCHL. The PPAR family includes another member, namely the peroxisome proliferator-activator receptor delta (PPARס). Interestingly, PPAR $\delta$ was found to be down-regulated in FCHL adipose tissue (chapter 3). At present little is known about the function of PPARS, but recent evidence suggests a role for this receptor in the control of adipogenesis ${ }^{55}$. Besides, PPAR8 has also been suggested to be a tissue and developmental specific regulator of PPAR $\alpha$ and PPAR $\gamma$ target genes. ${ }^{56}$ This makes PPARס an interesting target for further study in FCHL, both for genetic association as well as for in vitro studies assessing its role in FCHL adipose tissue. 
Since PPARs regulate gene expression through heterodimerization with the retinoid $X$ receptor $(\mathbb{R X R})^{38}$, PPAR mediated responses on lipid and lipoprotein gene transcription can also be elicited through $R \times R$ ligands. Interestingly, the $R X R$ gene resides within the Finnish FCHL locus on chromosome $1 \mathrm{q} 21-\mathrm{q} 23^{35}$, and is therefore also an interesting candidate gene for FCHL.

\section{Concluding remarks}

Clinical evidence as well as independent experimental evidence implies a role for adipose tissue in the pathophysiology of FCHL. $4,18,20,57$ The changes in FCHL adipose tissue function could either be adaptation, or be due to a primary genetic defect in adipose tissue. Which scenario applies in FCHL remains an important question because our data cannot distinguish between the two. In case of the first scenario, the alterations in FFA metabolism and perhaps insulin sensitivity are the result of the persisting hyperlipidemia in FCHL. This option has to be kept in mind unless comparative experiments in DM2 and FH prove otherwise. On the other hand, the presence of a primary genetic defect in adipose tissue is very likely based on the fact that alterations in FFA metabolism and insulin signaling have been found in FCHL. In addition, linkage with markers of adiposity on chromosome $1 \mathrm{p}$ and $1 \mathrm{q}$ in $\mathrm{FCHL}{ }^{11}$ further support a primary role of adipose tissue in $\mathrm{FCHL}$.

The genetic association studies on the PPARA and PPARG gene demonstrated a modifying role of PPARs in the genetic pathophysiology of FCHL. PPARG was shown to have an insulin sensitizing action on the adipose tissue related lipid traits FFA and glycerol ${ }_{1}$ supporting a role for adipose tissue in FCHL. On the other hand, genetic variation in the PPARA gene was associated with plasma apoCIII concentrations and the expression of combined hyperlipidemia in FCHL.

In conclusion, this thesis shows that both gene expression studies and genetic association studies can be successfully implemented in the genetic dissection of FCHL. It reveals potential genes and pathways involved in adipose tissue dysfunction in FCHL at least at the level of FFA metabolism and insulin signaling. Moreover, the association study concerning PPARA showed that genetic factors 
related to hepatic lipid and lipoprotein metabolism are also involved in the genetic pathophysiology of FCHL. 


\section{Referencens}

1. de Graaf J, Stalenhoef AF. Defects of lipoprotein metabolism in familial combined hyperlipidaemia. Curr. Opin Lipidol. 1998:9:189-196.

2. Taskinen MR, Casiake MJ. Packard CJ. Lipoprotein metabolism in FCHL. Eur.J.CIin.Invest. 2001:31 Suppl 1:4-4.

3. Aitman TJ, Godsland IF, Farren B, Crook D, Wong HJ, Scott J. Defects of insulin action on fatty acid and carbohydrate metabolism in familial combined hyperlipidemia. Arterioscler. Thromb. Vasc. Biol. 1997:17:748-754.

4. van der Kallen C.JH, Voors-Pette $C$, Bouwman FG, Keizer HA, LU JY, van de Hulst RRWJ, Bianchi R, Janssen M-J, Keulen ETP. Boeckx WD, Rotter $\mathrm{JI}$, de Bruin TWA. Evidence of insulin Resistant Lipid Metabolism of Adipose Tissue in Familial Combined Hyperlipidemia, but not in type 2 Diabetes. Atheroscterosis. 2002;164:337-346.

5. Purnell JQ, Kahn SE, Schwartz RS, Brunzell JD. Relationship of Insulin Sensitivity and ApaB levels to Intra-abdominal Fat in Subjects with Familial Combined Hyperlipidemia. Arterioscler. Thromb Vasc Biol. 2001;21:567-572.

6. Lewis $G F$, Steiner $G$. Acute effects of insulin in the controll of VLDL production in humans. Implications for the insulin-resistant state. Diabetes Care. 1996:19:390-393.

7. Camp $H$, Ren $D$, Leff $T$. Adipogenesis and fat-cell function in abesity and diabeles. Trends.Mol.Med. 2002;8:442-

8. Steppan CM, Lazar MA. Resistin and obesity-associated insulin resistance. Trends. Endocrinol. Metab. 2002;13:18-23.

9. Voors-Pette $\mathrm{C}$, de Bruin TWA. Excess coronary heart disease in Familial Combined Hyperlipidemia, in relation to genetic factors and central obesity. Atherosclerosis. 2001;157:481489.

10. Keulen ETP, Voors-Pette $C$, de Bruin TWA. Familial dyslipidemic hypertension syndrome: familial combined hyperlipidemia, and the role of abdominal fat mass. Am.J Hypertens. 2001;14:357-363.

11. van der Kallen CJH, Cantor RM, van Greevenbroek MMJ, Geurts JMW, Bouwman FG, Acuizerat BE, Allayee H, Buurman WA, Lusis AJ, Rotter Jl, de Bruin TWA. Genome scan for adiposity in Dutch dyslipidemic families reveals novel quantitive trait loci for leptin, body mass index and soluble tumor necrosis factor receptor superfamily 1A. Int.J.Obes.Relat.Metab. Disord. $2000 ; 24: 1381-1391$.

12. Ascaso JF, Sales J, Merchante A, Real J, Lorente R, Martinez-Valls J, Carmena R. Influence of obesity on plasma lipoproteins, glycaemia and insulinaemia in patients with familial combined hyperlipidaemia. Int.J.Obes. Relat. Metab. Disord. 1997:21:360-366.

13. Frayn KN. Adipose tissue as a buffer for dally lipid flux. Diabetologia. 2002;45:1201-1210.

14. Coppack SW, Fisher RM, Gibbons GF, Humphreys SM, McDonough MJ, Potts JL, Frayn KN. Postprandial substrate deposition in human forearm and adipose tissues in vivo. Clin Sci. (Lond.). 1990;79:339-348.

15. Frayn KN, Shadid S, Hamlani R, Humphreys SM, Clark ML, Fielding BA, Boland O, Coppack SW. Regulation of fatty acid movement in human adipose tissue in the postabsorptive-to-postprandial transition. Am.J.Physiol. 1994;266:E308-E317.

16. Eckel $\mathbb{R H}$. Lipoprotein lipase. A multifunctional enzyme relevant to common metabolic diseases. N.Engl.J. Med. 1989;320:1060-1068.

17. Lewis GF, Uiffelman KD, Szeto LW, Weller B, Steiner $G$. Interaction between free fatty acids and insulin in the acute control of very low density lipoprotein production in humans. J Clin.Invest. $1995 ; 95: 158-166$.

18. Kwiterovich-PO J, Motevalli M, Miller $M$. The effect of three serum basic proteins on the mass of lipids in normal and hyperapoB fibroblasts. Anterioscler. Thromb. Vasc. Biol 1994;14:1-7.

19. Sniderman $A D$, Cianflone $K$, Summers $L$, Fielding $B$, Frayn $K$. The acylation-stimulating protein pathway and regulation of postprandial metabolism. Proc.Nutr. Soc. 1997;56:703-712. 
20. Castro-Cabezas M., de Bruin TWA de Valk HW. Shoulders CC, Jansen H, Enketenis DW. Impaired fatty acid metabolism in familial combined hyperlipidemia. A mechanism associating hepatic apolipoprotein $B$ overproduction and insulin resistance. J.Clim. Imvest 1993;92:160-168.

21. Aoyama $T$, Wakui $K$, Orii KE, Hashimoto $T$, Fukushima $Y$. Fluorescence in situ hybridization mapping of the alpha and beta subunits (HADHA and $\mathrm{HADHB}$ ) of human mitochondrial fatty acid beta-oxidation multienzyme complex to $2 \mathrm{p} 23$ and their evolution. Cylogenot. Cell Genst. $1997 ; 79: 221-224$.

22. Fruhbeck G, Gomez-Ambrosi J, Muruzabal FJ, Burrell MA. The adipocyte: a model for integration of endocrine and metabolic signaling in energy metabolism regulation. Am.J.Physiol Endocrinol Metab. 2001;280:E827-E847.

23. Hotamisligil GS, Arner $P$, Caro JF, Atkinson RL, Spiegelman BM. Increased adipose tissue expression of tumor necrosis factor-alpha in human obesity and insulin resistance. $4 . \mathrm{Clim}$. Mmest: $1995 ; 95: 2409-2415$

24. van Greevenbroek MMJ, van der Kallen CJH, Geurts JMW, Janssen RG, Buurman WA, de Bruin TWA. Soluble receptors for tumor necrosis factor-alpha (TNF-R $p 55$ and TNF-R p 75) in familial combined hyperlipidemia. Atherosclerosis. 2000;153:1-8.

25. Geurts JMW, Janssen RGJH, van Greevenbroek MMJ, van der Kallen CJH, Cantor RM, Bu X, Aouizerat BE, Allayee $\mathrm{H}$, Rotter Jl, de Bruin TWA. Identification of TNFRSF1B as a novel modifier gene in familial combined hyperlipidemia. Hum.Mol Genet. 2000:9:2067-2074.

26. Nonogaki K, Fuller GM, Fuentes NL, Moser AlH, Staprans I, Grunfeld C, Feingold KR. Interleukin6 stimulates hepatic triglyceride secretion in rats. Endocrinology. 1995:136:2143-2149.

27. Karnieli $E$, Barzilai $A$, Rafaeloff $R$, Armoni M. Distribution of glucose transporters in membrane fractions isolated from human adipose cells. Relation to cell size. J.Clin.lnvest. 1986;78:10511055.

28. Weyer C, Foley JE, Bogardus $C_{*}$ Tataranni PA, Pratley RE. Enlarged subcutaneous abdominal adipocyte size, but not obesity itself, predicts type II diabetes independent of insulin resistance. Diabetologia. 2000;43:1498-1506.

29. Paolisso G, Tataranni PA, Foley JE, Bogardus C, Howard BV, Ravussin E. A high concentration of fasting plasma non-esterified fatty acids is a risk factor for the development of NIDDM. Diabetologia. 1995;38:1213-1217.

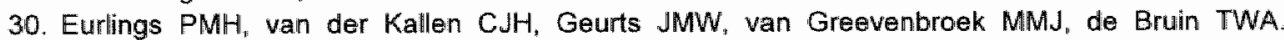
Genetic dissection of familial combined hyperlipidemia. Mol. Genet.Metab. 2001;74:98-104.

31. Richelsen $B_{*}$ Pedersen SB, Moller-Pedersen T, Bak IF. Regional differences in triglyceride breakdown in human adipose tissue: effects of catecholamines, insulin, and prostaglandin E2. Metabolism. 1991;40:990-996.

32. Engfeldt $P$. Arner $P$. Lipolysis in human adipocytes, effects of cell size, age and of regionall differences. Horm Metab Res Suppl. 1988;19:26-29.

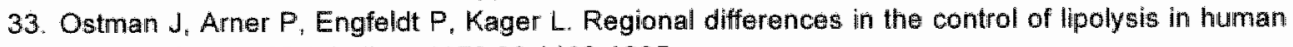
adipose tissue. Metabolism. 1979;28:1198-1205.

34. Mohamed-Ali V. Pinkney JH, Coppack SW. Adlipose tissue as an endocrine and paracrine organ. int.J.Obes. Relat Metab. Disord. 1998;22:1145-1158.

35. Pajukanta $P$, Nuotio I, Terwilliger JD, Porkka KV "Ylitalo K, Pihlajamaki s, Suomalainen AJ. Sywamen AC, Lehtimaki T, Viikari JS, Laakso M. Taskinen MR, Ehnholm C, Peltonen L. Linkage of familial combined hyperlipidaemia to chromosome 1q21-q23. Nat. Genet. 1998;18:360-373.

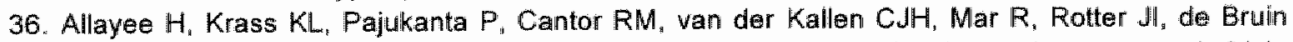
TWA, Peltonen L, Lusis AJ. Locus for elevated apolipopratein B levells on chromasome $1 \mathrm{p} 31 \mathrm{in}$ families with familial combined hyperlipidemia. Circ Res. 2002;90:926-931.

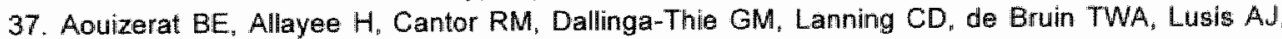
Rotter JI. Linkage of a candidate gene locus to familial combined hyperlipidemia Lecithin cholesterol acyltransferase on 16q. Anterioscler. Thromb. Vasc. Biol. 1999;19:2730-2736.

38. Pineda-Torra I, Chinetti G, Duval C, Fruchart JC, Staels B. Peroxisome proliferator-activated Ireceptors: from transcriptional control to clinical practice. Curr. Opin. Lipidol. 2001;12:245-254. 
39. Schoonjans $K$, Staels $B$, Auwerx $J$. The peroxisome proliferator activated receptors (PPARS) and their fffects on hipid metabolism and adipocyte differentiation. Biochim.Biophys.Acta. $1990 ; 1302: 83-109$

40. Schoonjans $K$, Staels $B_{i}$ Auwer $d$. Role of the peroxisome proliferator-activated receptor (PPAR) in mediating the effects of fibrates and fatty acilds on gene expression. J.Lipid Res. 1996;37:907925.

41. Staels B, Dallongewille J, Auwerx J, Schoonjanis $K$, Leitersdorf $E_{0}$ Fruchart JC. Mechanism of action of fibrates on lipid and lipoprotein metabolism. Circulation. 1998;98:2088-2093.

42. Bredie SJ, Westerveld $H T$, Knipscheer HC, de Bruin TWA, Kastelein JJ, Stalenhoef AF. Effects of gemfibrozil or simvastatin on apolipoprotein-B-containing lipoproteins, apolipoprotein-Clll and lipoprotein(a) in famillal combined hyperlipidaemia. Neth. J.Med 1996;49:59-67.

43. Vothl MC, Lepage $P$, Gaudet $D$, Brewer $C G$, Betard $C$, Perron $P$, Houde $G$, Cellier $C$. Faith JM, Despres JP, Morgan $K$, Hudson TJ. Molecular scanning of the human PPARa gene: association of the L162v mutation with hyperapobetalipoproteinemia. J.Lipid Res. 2000;41:945-952.

44. Rosen ED, Walkey CJ, Puigserver P, Spiegelman BM. Transcriptional regulation of adipagenesis. Genes Dev. 2000;14:1293-1307.

45. Walczak $R_{8}$ Tontonoz P. PPARadigms and PPARadioxes: expanding roles for PPARgamma in the control of lipid metabolism. J.Lipid Res. 2002;43:177-186.

46. Hihi AK, Michalik $L$, Wahli W. PPARs:" transcriptional effectors of fatty acids and their derivatives. Cell Mol Life Sci. 2002;59:790-798.

47. Lehmann JM, Moore LB, Smith-Oliver TA, Wilkison WO, Willson TM, Kliewer SA. An antidiabetic thiazolidinedione is a high affinity ligand for peroxisome proliferator-activated receptor gamma (PPAR gamma). J Eiol.Chem. 1995;270:12953-12956.

48. Zhang B, Berger J, Zhou G, Elbrecht $A$, Biswas $S$, White-Carrington $S$, Szalkowski D, Moller DE. Insulin- and imitogen-activated protein kinase-mediated phosphorylation and activation of peroxisome proliferator-activated receptor gamma. J.Biol.Chem. 1996;271:31771-31774.

49. Ylitaio K, Nuotio I, Viikari J, Auwerx J, Vidal H, Taskinen MR. C3, hormone-sensitive lipase, and peroxisome proliferator-activated receptor gamma expression in adipose tissue of familial combined hyperlipidemia patients. Metabolism. 2002;51:664-670.

50. McIntyre EA, Walker M. Genetics of type 2 diabetes and insulin resistance: knowledge from human studies. Clin Endocrinol.(Oxf). 2002;57:303-311.

51. Kersten S, Desvergne $B_{1}$ Wahli W. Roles of PPARs in health and disease. Nature. 2000;405:421. 424.

52. Fruchart JC, Duriez P, Staels B. Peroxisome proliferator-activated receptor-alpha activators regulate genes gowerning lipoprotein metabolism, vascular inflammation and atherosclerosis. Curr Opin Lipidol. 1999:10:245-257.

53. Barbier $O$, Torra IF, Duguay $Y$, Blanquart $C$, Fruchart JC, Glineur $C$, Staels $B$. Pleiotropic actions of peroxisome proliferator-activated receptors in lipid metabolism and atherosclerosis. Anterioscler. Thromb. Vasc Biol. 2002;22:717-726.

54. Koulen ETP, Kruijshoop M, Schaper NC. Hoeks APG, de Bruin TWA. Increased intima-media thickness in Familial Combined Hyperlipidemia associated with apolipoprotein $B$. Arterioscler. Thromb. Vasc. Biol. 2002:22:283-288.

55. Hansen JB, Zhang $H$, Rasmussen TH, Petersen RK, Flindt EN, Kristiansen K. Peroxisome proliferator-activated receptor delta (PPARditta)-mediated regulation of preadipocyte proliferation and gene expression is dependent on CAMP signaling. J.Biol.Chem. 2001;276:31753182.

57. Shi $Y$. Hon $M$, Evans RM. The peroxisome proliferator-activated receptor delta, an integrator of transcriptional repression and nuclear receptor signaling. Proc.Natl.Acad.Sci.U.S.A. 2002:99:2613-2618.

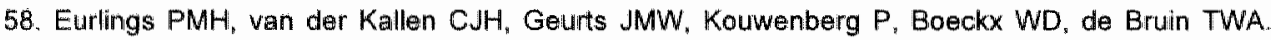
Identification of differentially expressed genes in subcutaneous adipose tissue from subjects with familiall combined hyperlipidemia. J.Lipid Res. 2002;43:930-935. 
Chapter 7

\section{Summary/Samenvatting}




\section{Summary}

Familial Combined Hyperlipidemia (FCHL) is the most common genetic hyperlipidemia in man. FCHL is characterized by familial clustering of hyperlipidemia and clinical manifestations of premature coronary heart disease (CAD), i.e. before the age of 60 years. FCHL may present itself in a family with elevated very low. density lipoprotein cholesterol, elevated low-density cholesterol, or both. In addition, subjects affected with FCHL are characterized by elevated triglycerides (TG) and insulin resistance. The seriously increased risk of fatal and non-fatal CAD in relatives of Dutch FCHL probands is 5.1 .

Defects in adipose tissue function are believed to contribute to the FCHL phenotype, but the exact mechanisms are poorly understood. FCHL patients have an abnormal free fatty acid (FFA) metabolism resulting in reduced clearance of FFA from the circulation in the postprandial state. Moreover, it has been suggested that adipocytes as well as fibroblasts from FCHL patients exhibit an impaired response to the acylation stimulating activity of the acylation-stimulatory protein (ASP) that stimulates the peripheral synthesis of TG, and thus clearance of FFA from the circulation. In addition, FCHL patients are characterized by impaired insulinmediated glucose uptake in peripheral tissues, and impaired insulin-mediated suppression of FFA. High levels of FFA in the circulation may in turn lead to a decrease in insulin-stimulated glucose uptake in skeletal muscle, as well as an increase in hepatic lipoprotein synthesis. Moreover, more FFA will be incorporated into non-adipose tissues such as liver and muscle.

Although FCHL was delineated about 30 years ago, the FCHL phenotype and its complex genetics are not fully understood yet. Initially, the familial aggregation of high plasma total cholesterol (TC) and $T_{\text {" }}$ and bimodal distribution of plasma $T G$ concentrations, was taken as evidence of a dominant mode of inheritance. However iit is now clear that that the genetics of FCHL is more complex and it has been suggested that FCHL is heterogeneous.

Chapter 1 gives an introduction into the (patho)physiology of FCHL and an overview of the genetic approaches that can be used to identify and determine the role of (candidate) genes in the (patho)physiology. In particular, genetic linkage studies, association studies, and differential gene expression studies are discussed. 
Moreover, a summary is given of the results from genetic linkage and association studies in FCHL until now.

In chapters 2 and 3 we have characterized genes that showed a significant difference in the level of expression between subcutaneous adipose tissue from FCHL subjects and unrelated, age, gender and BMI matched controls.

Chapter 2 reports on the identification of differentially expressed genes in FCHL subcutaneous tissue using commercially available macro-arrays. Human cDNA expression array analyses, in which adipose tissue from five $\mathrm{FCHL}$ patients was compared to that from four unrelated, age, gender and BMI matched controls, resulted in the identification of 22 up-regulated and 3 down-regulated genes. The upregulation of cell-cycle genes such as c-Myc, c-Jun, and G1/S-specific cyclin D1 (CCDN1), and down-regulation of cyclin-dependent kinase inhibitor 1A (CDKN1A; p21) implies activation of the adipocyte cell cycle genes. Furthermore, the differential expression of the genes coding for tumor necrosis factor alpha (TNF $\alpha$ ), interleukin 6 (IL-6) and intracellular adhesion molecule 1 (ICAM1), support a role for adipose tissue in insulin resistance and inflammation in FCHL subjects. Whether the observed changes represent a primary genetic defect or an adaptive response remains the question, but either way support a role for adipose tissue in FCHL.

The search towards new candidate genes responsible for, or related to, adipose tissue dysfunction by a combination of suppression subtractive hybridization ( $\mathrm{SSH}$ ) and macroarray technology is described in chapter 3. Comparison of subcutaneous adipose tissue from five unrelated hyperlipidemic FCHL subjects with adipose tissue form five unrelated normolipidemic, age and BMI matched control subjects resulted in the identification of 129 differentially expressed genes and gene products. These 129 genes represent: 57 unique genes, of which 1 was up-regulated and 56 were down-regulated. In addition, 35 unique ESTs were found, of which 3 were upregulated and 32 down-regulated, and 37 sequences of unknown identity, of which 2 were up-regulated and 35 down-regulated. The genes differentially expressed implied inactivation of pro-apoptotic genes, thus favoring the balance towards an active cell cycle. Moreover, differential gene expression of genes involved in insulin signaling and fatty acid beta-oxidation, support the theory that FFA metabolism in FCHL adipose tissue is altered. 
Chapter 4 reports on the association between genetic variants in the PPARG gene and FCHL traits related to adipocyte lipid metabolism, dyslipidemia and insulin resistance. In a case-control panel consisting of $79 \mathrm{FCHL}$ probands and 124 spouse controls, polymorphic marker D3S1259 and 3 intragenic PPARG variants, î. C.161T, Pro12Ala, and Pro115GIn, were studied. The Pro115GIn variant was not found in any of the subjects. Allele frequencies of the C161T, Pro12Ala variants and D3S1259 did not differ significantly between FCHL probands and spouses. In FCHL probands, carriers of the 12Ala allele had lower concentrations of plasma apoAl $(P<0.05)$ and glycerol $(P<0.05)$ compared to non-carriers, and $161 \mathrm{~T}$ allele carriers had lower plasma concentrations of FFA $(P<0.05)$ and glycerol $(P<0.01)$. No significant associations were found in spouses. These data suggest an insulin sensitizing action of PPARG variants specifically in FCHL cases, but not in controls. Moreover, these findings illustrate that in FCHL genetic predisposition, such as variants in PPARG, can significantly affect adipose tissue related insulin resistance.

Chapter 5 reports on the genetic contribution of the PPARA locus to the pathophysiology of FCHL. Mutation detection analyses of the six coding PPARA exons resulted in the identification of four novel variants, [C/T] intron $3,5234 \mathrm{G},[\mathrm{G} / \mathrm{A}]$ intron 5, and [C/A] 3' UTR in three FCHL probands, whereas no novel variants were identified in spouses. In a case-control study, markers D22S275 and D22S928 were shown not to be associated with FCHL. However, D22S928, mapped within $1 \mathrm{Mb}$ of the PPARA gene, was shown to have a modifying effect on plasma apocill concentrations $(P=0.011)$ and the combined hyperlipidemic FCHL phenotype $(P=0.038)$. Analyses of two intragenic PPARA polymorphisms, in intron 2 and 7 , revealed no association of these variants with FCHL. The $V 162$ allele, from the L162V variant, was present in $1.98 \%(95 \% \mathrm{Cl} 0.042-3.88)$ of the probands and in $4.84 \%(95 \% \mathrm{Cl} 2.15-7.55 \%)$ of the spouses $(P=0.10)$. These data show that the PPARA locus influences plasma apoCllI concentrations and the combined hyperlipidemic phenotype in FCHL subjects, but not in spouses $_{i}$ indicating that this gene modifies the expression instead of contributing to the FCHL phenotype in a direct manner.

In the final chapter of this thesis, chapter 6 , the major findings have been discussed and suggestions for further research are given. The first part discusses the role of adipose tissue in the (genetic) pathophysiology of FCHL. The second part 
discusses the role of the peroxisome proliferator-activated receptors (PPARs) in FCHL. 


\section{Samenvatting}

Genetische dissectie van Familiair Gecombineerde Hyperlipidemie Gen expressie in vetweefsel en kandidaat gen analyse

Familiair Gecombineerde Hyperlipidemie ( $F G H)$ is een familiaire aandoening die gekenmerkt wordt door wisselend verhoogde cholesterol en triglyceride waarden in het bloed. Daarnaast worden mensen met deze aandoening gekenmerkt door de aanwezigheid van insuline resistentie en een abnormaal vetzuur metabolisme na een maaltijd. Aangedane personen uit een FGH familie hebben een sterk verhoogd risico op het ontwikkelen van cardiovasculaire aandoeningen voor het $60^{\circ}$ levensjaar. In vergelijking met de algemene Nederlandse bevolking hebben aangedane personen binnen een FGH familie een $5 \times$ verhoogd risico op een fataal of niet fatale cardiovasculaire ziekte.

Op dit moment wordt aangenomen dat vetweefsel bijdraagt aan de expressie van

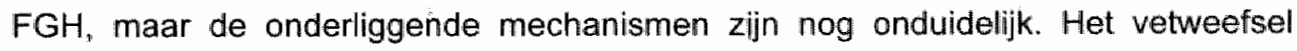
functioneert afwijkend in FGH. Mensen met FGH worden gekenmerkt door een verstoord vetzuur metabolisme na de maaltijd wat leidt tot een langere circulatietijd van deze vetzuren in de bloedbaan. Tevens zijn er aanwijzingen dat de activiteit van het acylation stimulatory protein (ASP), dat ervoor zorgt dat vetzuren in de vorm van triglyceriden in de perifere weefsels worden opgeslagen, verstoord is in fibroblasten en adipocyten (vetcellen) van FGH patiënten. FGH patiënten worden ook gekenmerkt door een verstoorde insuline gemedieerde glucose opname in de perifere weefsels, mede als gevolg van een verstoorde insuline gemedieerde suppressie van vetzuren. Hierdoor is de concentratie circulerende vetzuren hoog wat tot gevolg kan hebben dat de insuline gemedieerde glucose opname in de skeletspieren daalt, maar ook de productie van lipoproteïnen door de lever toeneemt. Tevens is er meer vetzuur inbouw en opslag in andere organen zoals spier en lever.

Alhoewel FGH voor het eerst werd beschreven in 1975, is het tot op heden nog niet volledig duidelijk hoe de aandoening genetisch in elkaar steekt en hoe het fenotype het best omschreven moet worden. In eerste instantie werd gedacht, op grond van een familiaire clustering van verhoogde plasma cholesterol en triglyceride 
waarden en een bimodale distributie van plasma triglyceride concentraties, dat het een dominant overervende aandoening was. Echter, tegenwoordig is thet duidelijk dat de genetica van FGH veel complexer is dan in het begin werd aangenomen. Tevens word nu gedacht dat het waarschijnlijk ook een heterogene aandoening betreft.

In hoofdstuk 1 wordt een introductie gegeven in de (patho)fysiologie van FGH. Verder wordt er een overzicht gegeven van de verschillende genetische strategieën die kunnen worden toegepast om meer inzicht te kunnen krijgen in de genetica en (patho)fysiologie van FGH. Zo worden genetisch koppelingsonderzoek, associatie studies en differentiële gen expressie studies besproken en worden de reeds geboekte resultaten met de eerste twee strategieën in relatie tot $F G H$ besproken.

De hoofdstukken 2 en 3 handelen over gen expressie studies in subcutaan vetweefsel van patiënten met FGH in vergelijking met dat van controle personen. FGH patiënten werden vergeleken met ongerelateerde controle personen met hetzelfde geslacht, dezelfde leeftijd en body mass index (BMI).

De identificatie van differentieel tot expressie komende genen in subcutaan vetweefsel van $\mathrm{FGH}$ patiënten met behulp van commerciële macroarrays wordt beschreven in hoofdstuk 2 . Vetweefsel van vijf FGH patiënten werd vergeleken met dat van 4 ongerelateerde controle personen met hetzelfde geslacht, dezelfde leeftijd en BMI. Een vijftal macroarray analyses resulteerde in de identificatie van 22 opgereguleerde en 3 down-gereguleerde genen. Opregulatie van de cel cyclus genen c-Myc, c-Jun en G1/S-specific cyclin D1 (CCDN1) en de down-regulatie van cyclin-dependent kinase inhibitor $1 \mathrm{~A}$ (CDKN1A; $\mathrm{p} 21)$ wijzen in de richting van activatie van de cell cyclus. Dit betekent overigens niet dat de adipocyten daadwerkelijk tot celdeling komen. De differentiële expressie van het tumor necrosis factor alpha (TNF $\alpha$ ), interleukine $6(\mathbb{I L}-6)$ en intracellulair adhesie molecuul 1 (ICAM1) gen, duiden op een rol van het subcutane vetweefsel in insuline resistentie en ontsteking in patiënten met FGH.

Hoofdstuk 3 beschrijt de zoektocht naar nieuwe kandidaat genen voor verstoorde vetweefsel functie met behulp van een combinatie van suppression subtractive hybridization (SSH) en macroarray technologie. In totaal werd het gen expressie profiel van vijf $\mathrm{FGH}$ patiënten vergeleken met dat van vijf ongerelateerde controle personen met hetzelfde geslacht, dezelfde leeftijd en BMI, waarbij 129 
differentieel tot expressie komende genen enlof genproducten werden geïdentificeerd. Onder deze 129 differentiële sequenties bevonden zich: 1) 57 bekende gen producten, waarvan er 1 was opgereguleerd en 56 downgereguleerd; 2) 35 expressed sequence tags (ESTs), waarvan er 3 opgereguleerd en 32 downgereguleerd waren, en 3) 37 onbekende gen prodwcten, waarvan er 2 waren opgeregulleerd en 35 downgereguleerd. Met name genen die betrokken zijn bij de inductie van geprogrammeerde celdood bleken verlaagd tot expressie te komen. Dit duidt op een balans in de cel die progressie door de cel cyclus bevordert. Daarnaast kwamen genen betrokken bij insuline signalering en vetzuur beta-oxidatie differentieel tot expressie. Deze laatste bevinding steunt de hypothese dat vetzuur metabolisme verstoord is in vetweefsel van personen met $\mathrm{FGH}$.

De associatie tussen genetische variatie in het PPARG gen en FGH kenmerken gerelateerd aan vetcel lipid-metabolisme, dyslipidemie en insuline resistentie wordt beschreven in hoofdstuk 4. In een case-control panel bestaande uit $79 \mathrm{FGH}$ probands en 124 controle personen, werden de polymorfe marker D3S1259 en drie intragene PPARG polymorfismen C161T, Pro12Ala en Pro115GIn bestudeerd. The Pro115GIn variant was in geen van de individuen aamwezig. In de FGH proband groep hadden dragers van het $12 \mathrm{Ala}$ allel een lagere plasma apoAll $(P<0.05)$ en glycerol $(P<0.05)$ concentratie dan probands met alleen het $12 \mathrm{Pro}$ allel. $\mathrm{FGH}$ probands met een $161 \mathrm{~T}$ allel hadden lagere plasma vetzuur $(P<0.05)$ en glycerol $(P<0.05)$ concentraties ten opzichte van probands die dit allel niet hadden. In de controle groep werden geen significante associaties gevonden. De gevonden associaties suggereren een rol voor genetische variatie in het PPARG gen in insuline resistentie met name in FGH probands, maar niet in controles. Daarnaast illustreren de data dat in FGH genetische aanleg, zoals de beschreven varianten in het PPARG gen, een significant effect kan hebben op vetweefsel gerelateerde insuline resistentie.

Hoofdstuk 5 handelt over de genetische bijdrage van het PPARA locus aan FGH. Mutatie analyse van de zes coderende exonen van het PPARA gen resulteerde in de identificatie van vier nieuwe varianten in het gen, te weten. [C/T] intron 3, S234G, [G/A] intron 5, and [C/A] $3^{\prime}$ UTR. Deze waren aanwezig in drie FGH probands, terwijl in de controles geen nieuwe varianten werden gevonden. In een case-control studie werd er geen associatie gevonden tussen de markers D22S275 en D22S928 en FGH. Daarentegen werd met marker D22S928, gelegen op $1 \mathrm{Mb}$ van 
het PPARA gen, wel een associatie werd gevonden met plasma apoCIII concentrations $(P=0.011)$ en gecombineerde hyperlipidemie $(P=0.038)$. Analyse van twee varianten gelegen in intron 2 en 7 leverde geen associaties op met FGH of gerelateerde lipiden waarden. De $L 162 \mathrm{~V}$ variant was aanwezig in het case-control panel met een frequentie van het $162 \mathrm{~V}$ allel van $1.98 \%(95 \% \mathrm{Cl} 0.042-3.88)$ in de probarids en $4.84 \%(95 \% \mathrm{Cl} 2.15-7.55)$ in de controles $(P=0.10)$. Op grond van deze bevindingen is geconcludeerd dat het PPARA locus in FCHL probands plasma apoCIII concentraties en het hebben van gecombineerde hyperlipidemie beïnloedt. Tevens laten deze bevindingen zien dat PPARA niet het primaire genetische defect van $\mathrm{FGH}$ is, maar de expressie van $\mathrm{FGH}$ modificeert.

Hoofdstuk 6 plaatst bovenstaande bevindingen verder in perspectief en draagt mogelijkheden aan voor verder onderzoek. In het eerste deel wordt de rol van vetweefsel in het ontstaan van FGH bediscussieerd. Het tweede deel gaat dieper in op de rol van de peroxisome proliferator-activated receptors (PPARs) in FGH. 
Curriculum vitae 


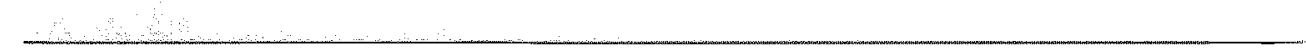




\section{Curriculum Vitae}

Petra Eurlings was born on February 25, 1975, and grew up in Puth. She completed her secondary education at the Albert Schweitzer Scholengemeenschap (currently Graaf Huyn College) in 1994. In the same year she started the study Biology at the Catholic University Nijmegen, with as specialisation Medical Biology. She did two internships at the department of Cell Biology at the Catholic University Nijmegen, under supervision of prof.dr. EJ van Zoelen, and at the department of Pathology at the Maastricht University, under supervision of prof.dr. MJAP Daemen. She obtained her MSc degree on December 15, 1998. In January 1999 she started, under supervision of prof.dr. TWA de Bruin, as a PhD student at the department of Internal Medicine, Laboratory of Molecular Metabolism and Endocrinology at the Maastricht University. The experimental work carried out until January 2003 is presented in this thesis.

Petra Eurlings werd op 25 februari 1975 geboren te Schinnen en groeide op in Puth. In 1994 behaalde ze haar diploma voor het Voortgezet Wetenschappelijk Onderwijs aan de Albert Schweitzer Scholengemeenschap (thans Graaf Huyn College) te Geleen. In datzelfde jaar begon ze met de studie Biologie aan de Katholieke Universiteit Nijmegen met als afstudeerrichting medische biologie. Tijdens deze studie werden twee hoofdvakstages afgerond bij de afdeling Celbiologie aan de Katholieke Universiteit Nijmegen onderleiding van prof.dr. EJ van Zoelen en bij de capaciteitsgroep Pathologie aan de Universiteit Maastricht onderleiding van prof.dr. MJAP Daemen. Op 15 december 1998 haalde zij het doctoraal examen. In januari 1999 startte zij, o.l.v. prof.dr. TWA de Bruin, als assistent in opleiding bij de afdeling Interne Geneeskunde in het laboratorium voor Moleculair Metabolisme en Endocrinologie aan de Universiteit Maastricht. Het onderzoek dat aldaar tot januari 2003 werd verricht heeft geleid tot de bewerking van dit proefschrift. 
List of publications 


\section{List of publications}

\section{Articles}

Eurlings PMH, van der Kallen CJH, Geurts JMW, van Greevenbroek MMJ, de Bruin TWA. Genetic dissection of familial combined hyperlipidemia. Molecular Genetics and Metabolism 2001; 74(1-2):98-104.

Eurlings PMH, van der Kallen CJH, Geurts JMW, Kouwenberg P, Boeckx WD, de Bruin TWA. Identification of differentially expressed genes in subcutaneous adipose tissue from subjects with familial combined hyperlipidemia. Journal of Lipid Research 2002; 43:930-935.

Eurlings $\mathrm{PMH}$, van der Kallen C.JH, Geurts JMW, Flavell DM, de Bruin TWA. Identification of the PPARA locus on chromosome 22q13.3 as a modifier gene in familial combined hyperlipidemia. Molecular Genetics and Metabolism 2002; 77(4): 274-281.

Eurlings PMH, van der Kallen C.JH, Geurts JMW, Kuijs R, Evelo CTA, Nanhekhan L, Boeckx WD, de Bruin TWA. New Candidate Genes for Adipose Tissue Dysfunction in Familial Combined Hyperlipidemia. Submitted.

Eurlings $P M H$, van der Kallen $C J H$, Vermeulen VMM-J, de Bruin TWA. Variants in the PPARG Gene affect Fatty Acid and Glycerol Metabolism in Familial Combined Hyperlipidemia. Submitted.

\section{Abstracts}

Eurlings PMH, Geurts JMW, de Bruin TWA. Identification of PPARa as a novel gene contributing to Familial Combined Hyperlipidemia. Second International Meeting on the Genetic Epidemiology of Complex Traits

Churchill College, April 2000, Cambridge, United Kingdom. 
Geurts JMW, Eurlings PMH, van der Kallen CJH, van Greevenbroek MMJ, Janssen RJGH, Smeets HJM, Hotker M, Vietink R, Rotter Jl, Lusis AJ, de Bruin TWA. Genetic dissection of famillal combined hyperlipidemia. International symposium on the state-of the-art in genetic analysis. June 2000, Boston. USA.

Eurlings PMH, Geurts JMW, Janssen RGJH, Bouwman FG, de Bruin TWA. Genetic Dissection of Familial Combined Hyperlipidemia. The American journal of Human Genetics, 2000; 67 (4) suppl 2: 343 .

Eurlings PMH, Geurts JMW, van der Kallen CJH, Van der Kuijl K, de Bruin TWA. Peroxisome Proliferator-Activated Receptor Alpha: Genetic Variation Contributes to Familial Combined Hyperlipidemia. PPARS: From Basic Science To Clinical Implications, April 2001, Florence Italy.

Eurlings PMH, Geurts JMW, van der Kallen $\mathrm{CJH}$, de Bruin TWA. Genetic Dissection of familial combined hyperlipidemia. European Journal of Clinical Investigation; 3 suppl $1 ; 20-21$.

Eurlings $\mathrm{PMH}_{4}$ van der Kallen $\mathrm{CJH}$, de Bruin TWA. Identification of Differentially Expressed Genes in Subcutaneous Adipose Tissue in Familial Combined Hyperlipidemia. Molecular control of adipogenesis and obesity \& Diabetes Mellitus: Molecular mechanisms, genetics and new therapies. January 2002. Keystone, USA.

Eurlings PMH, van der Kallen CJH, de Bruin TWA. The C161T and Pro12Ala variants in the PPARG gene affect fatty acid and glycerol metabolism of subjects with familial combined hyperlipidemia. PPARs. February 2003. Keystone, USA. 
Dankwoord 
Na vier jaar is het dan toch zover, de promotie. Het bekende twee stappen vooruit en drie stappen terug fenomeen is ook mij overkomen, maar uiteindelijk zijn er meer stappen vooruit dan achteruit gedaan en mag het eindresultaat er zijn! Echter, tot het afronden van een proefschrift ben ik niet alleen gekomen en is het op zijn plaats om een aantal mensen te bedanken.

Tjerk, jou wil ik als eerste bedanken. Als promotor heb jiij wel de grootste rol gespeeld in de totstandkoming van dit boekje. Je eindeloze enthousiasme en optimisme hebben altijd als een stimulans gewerkt en je hebt me veel vrijheid geboden op zoek naar een weg naar het einddoel (promotie). Af en toe verschilden we nogal van mening wat betreft aanpak en interpretatie, maar de daaruit volgende discussies hebben het eindresultaat alleen maar beter gemaakt.

Carla ik wil je bedanken voor je advies en suggesties met betrekking tot de inhoudelijke kanten van het onderzoek doen die je als begeleider gegeven hebt. Maar ook wil ik je bedanken voor het plezier dat we samen hadden met de mannen in Keystone, waar naast hoogstaand wetenschappelijk symposium bezoek ook de skipistes ontdekt dienden te worden. Als skiër ben ik voorgoed verwend! Florence waar we dankzij volledige inzet in het wel en wee van PPARs, alle historische bezienswaardigheden niet van binnen hebben kunnen bekijken en we onszelf moesten troosten met een klein ijsje.

Jan, als begeleider gedurende met name de eerste twee jaar van mijn promotie heb je me kennis laten maken met het wetenschappelijk onderzoek. lets opbouwen vanaf de grond valt niet mee maar is toch gelukt mede jou inzet.

Joséphine, voor jou (geheel) onverwacht, voor mij een logische keuze, dank je wel dat je mijn paranimf wilt zijn. Zonder jou had ik moeten leren bloedprikken, iets waar ik zelf absoluut niet tegen kan en bij kennis blijven altijd een grote uitdaging is. Dank je wel voor je hulp bij het uitnodigen van, ontvangen van, bloedprikken bij en koffiedrinken met alle vrijwilligers uit het $\mathrm{FGH}$ cohort die meededen aan het vetweefsel onderzoek. 
Vicky iij was altijd diegene die op momenten van blinde paniek mij tot kalmeren bracht. Ook het bijspringen met praktische werkzaamheden en het "buurten" waardeer ik zeer. Bedankt dat ook jij mijn paranimf wilt zijn. Deze promotie is een hele meiden aangeleglenheid!

De assistenten (sommige ondertussen al specialist) plastische chirurgie, Roel Fresow, René van de Hulst, Paul Kouwenberg, Marleen Meesters, en Lloyd Nanhekhan wil ik bedanken voor het afnemen van de vetbiopten/mini-liposucties. Prof.dr. WD Boeckx will ik bedanken voor het leiden van deze vruchtbare samenwerking.

Mede-AIO's, Steven, Martijn, Cyriel en Margriet. Ik wil jullie veel succes wensen bij het afronden van jullie promotie-onderzoek. Margriet en Cyriel, jullie zijn de eerst volgenden misschien doen jullie al wat inspiratie op. Steven en Martijn, veel idealen, een nobel streven richting Stockholm, hou dat maar goed vast! Jullie komen er wel!

Verder wil ik alle medewerkers " oud-medewerkers en studenten van het Laboratorium Moleculair Metabolisme en Endocrinologie en Laboratorium Endocrinologie noemen waar ik de afgelopen vier jaar mee samen heb gewerkt: Marleen, Margee, Anna, Riny, Ellen, Eric, Freek, Rob, Christine, Geertje, Gabriëlle, Paul, Wim, Mireille, Jeroen, Angèle, Kirsten, Martijn, Judith, Paola, Esther, Marsha, Kim en Isabelle. Samen gezellig karten, uiteten en dineren met kerst. Jullie hulp in gevallen van nood in de vorm van koffie drinken met proefpersonen of bloedafnemen zall ik niet vergeten. De hulp bij het minipreppen trouwens ook niet.

Alle mensen uit het FGH onderzoek die deelgenomen hebben aan het vetweefsel onderzoek wil ik speciaal bedanken. Het is heel waardevol voor het FGH onderzoek dat we menselijk weefsel kunnen gebruiken om op die manier het snelst bij de kern van FGH uit te komen. Misschien zijn de eerste resultaten voor sommige deelnemers een "ver van mijn bed show', maar ik ben er van overtuigd dat het onderzoek in vetweefsel uiteindelijk zal bijdragen in het gemakkelijker diagnostiseren van FGH. 
Dr. CTA Evelo, beste Chris, bedankt voor je input met betrekking tot de analyse van gen-expressie data en het identificeren van de SSH clonen. Jammer genoeg hebben we jouw kennis van bio-informatica en array-design pas in de tweede helft van mijn promotie onderzoek kunnen toepassen. In de toekomst hoop ik jouw kennis en adviezen meteen in het begin van het onderzoek toe te passen.

Dr. DM Flavell, dear Dave, thanks for your contribution to the PPARA paper.

Lieve Pap en Mam, mede dankzij jullie stimulans het maximale uit mezelf te halen heb ik dit bereikt. Pap, het volgende wat jij ooit tegen me zei illustreert dit goed: 'Petra zou je er niet eens over na willen denken om naar het atheneum te gaan als je de HAVO af hebt?'. Als jij dit toen niet had gezegd had ik hier niet gestaan.

Allerliefste Maurice, toen ik aan mijn AlO bestaan begon was je nog mijn vriend, nu inmiddels mijn man, en het belangrijkste in mijn leven. Echter promoveren was ook belangrijk en de reden waarom jij, alleen, voor negen maanden in China bent geweest. Een mooie ervaring rijker maar we zijn het eens: dat doen we nooit meer. We gaan samen naar het buitenland of niet. Je hebt je verheugd op een gepromoveerde vrouw in huis die (het liefst binnen een paar jaar) in de toekomst professor zal worden zodat jij op je lauweren kunt rusten. Helaas, de Universiteit Maastricht is en zal waarschijnlijk geen Philips worden. 